\title{
Avaliação de algoritmos de controle de congestionamento como controle de admissão em um modelo de servidores Web distribuído
}

Ricardo Nogueira de Figueiredo 
Data de Depósito:

Assinatura:

\section{Avaliação de algoritmos de controle de congestionamento como controle de admissão em um modelo de servidores Web com diferenciação de serviço}

\section{Ricardo Nogueira de Figueiredo}

Orientador: Prof. Dr. Marcos José Santana

Dissertação apresentada ao Instituto de Ciências Matemáticas e de Computação - ICMC-USP, como parte dos requisitos para obtenção do título de Mestre em Ciências - Ciências de Computação e Matemática Computacional. VERSÃO REVISADA.

USP - São Carlos

Maio/2011 
Ficha catalográfica elaborada pela Biblioteca Prof. Achille Bassi e Seção Técnica de Informática, ICMC/USP, com os dados fornecidos pelo(a) autor(a)

\begin{tabular}{|c|c|}
\hline \multirow[t]{3}{*}{ F475a } & $\begin{array}{l}\text { Figueiredo, Ricardo Nogueira } \\
\text { Avaliação de algoritmos de controle de } \\
\text { congestionamento como controle de admissão em um } \\
\text { modelo de servidores Web com diferenciação de serviço } \\
\text { / Ricardo Nogueira Figueiredo; orientador Marcos } \\
\text { José Santana -- São Carlos, } 2011 \text {. } \\
\quad 91 \text { p. }\end{array}$ \\
\hline & $\begin{array}{l}\text { Dissertação (Mestrado - Programa de Pós-Graduação em } \\
\text { Ciências de Computação e Matemática Computacional) -- } \\
\text { Instituto de Ciências Matemáticas e de Computação, } \\
\text { Universidade de São Paulo, } 2011 \text {. }\end{array}$ \\
\hline & $\begin{array}{l}\text { 1. Qualidade de Serviço. 2. Servidor Web. } 3 \text {. } \\
\text { Algoritmos de controle de congestionamento. I. } \\
\text { Santana, Marcos José, orient. II. Título. }\end{array}$ \\
\hline
\end{tabular}




\section{Agradecimentos}

Agradeço a Deus por ter conseguido chegar ate aqui, aos meus pais, Sebastião e Creusa que alem do apoio ainda me supriram com incentivo durante o tempo de desenvolvimento deste trabalho.

Agradeço também aos meus amigos e colegas de laboratório Paulo Eustáquio, Júlio Estrella, Bruno Tardiole, Maycon, Pedro e Edwin tanto na ajuda técnica que foi imprescindível para o desenvolvimento do trabalho quanto nos momentos de lazer que passamos juntos durante esse período de desenvolvimento do mestrado.

O desenvolvimento deste trabalho não foi uma tarefa trivial e nem mesmo com méritos exclusivos do autor. Por isso agradeço pela contribuição para o desenvolvimento ao orientador Orientador Professor Doutor Marcos José Santana, que me ajudou sempre no que precisei, a Professora Doutora Regina Helena Carlucci Santana, que me ajudou com os experimentos, e ao aluno de mestrado Paulo Eustáquio, que me ajudou muito desde o desenvolvimento do modelo ate a escrita de artigos e correções desta dissertação. Gostaria também de agradecer a todos os membros do grupo de Sistemas Distribuídos e Programação Concorrente que sempre deram ótimas sugestões para o desenvolvimento do trabalho.

Agradeço as agencias de fomento FAPESP e CAPES pelo financiamento deste projeto. 


\section{Sumário}

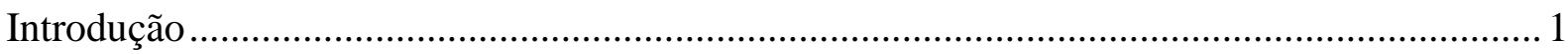

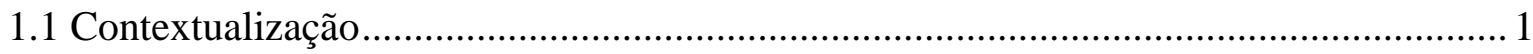

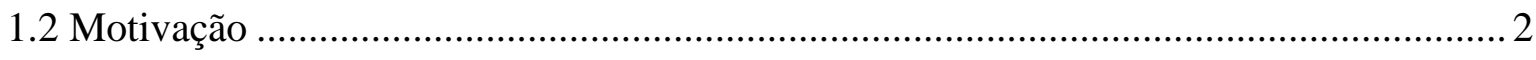

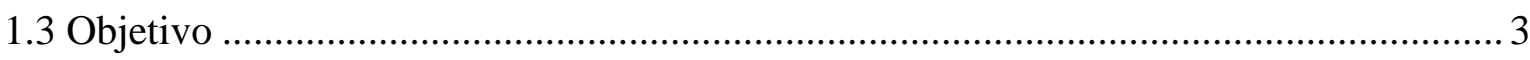

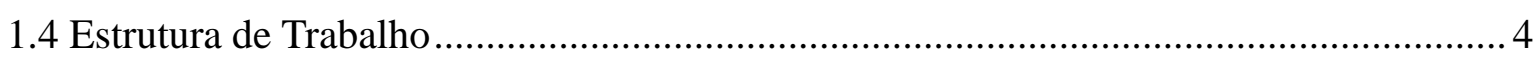

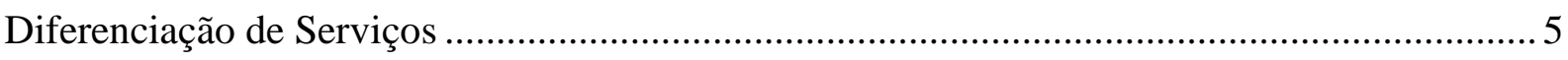

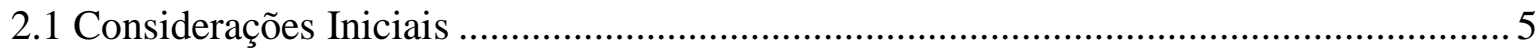

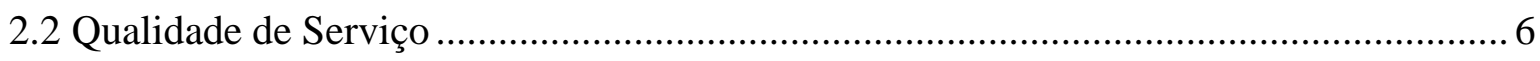

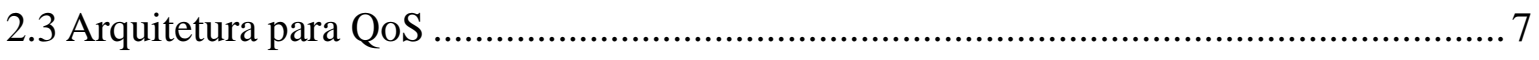

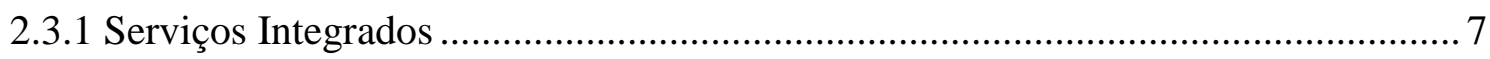

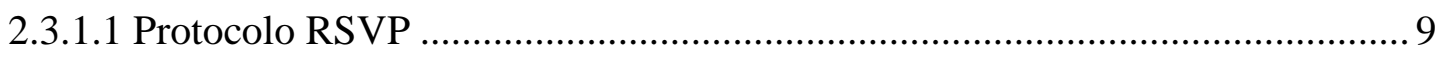

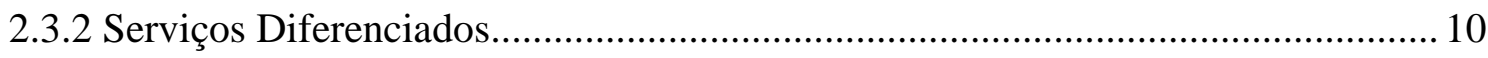

2.3.2.1 Encaminhamento Acelerado .................................................................... 12

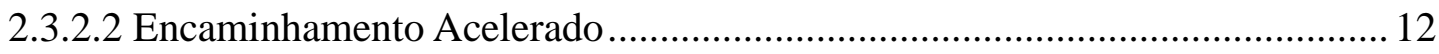

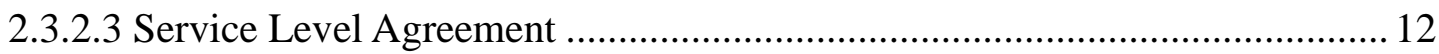

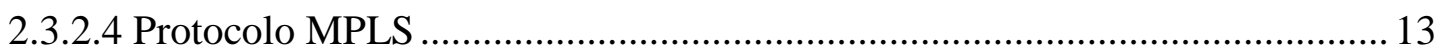

2.4 Comparação entre Serviços Integrados e Serviços Diferenciados................................. 14

2.5 Serviços diferenciados no nível de aplicação ........................................................... 15

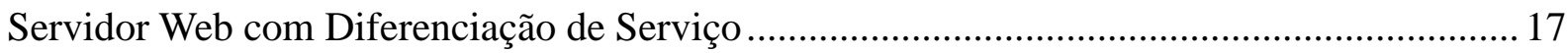

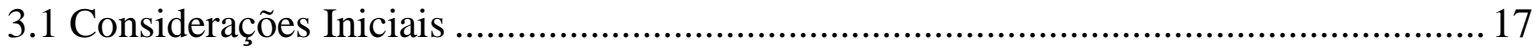

3.2 Modelo de servidor Web com diferenciação de serviço ............................................... 17

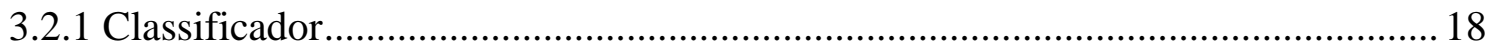

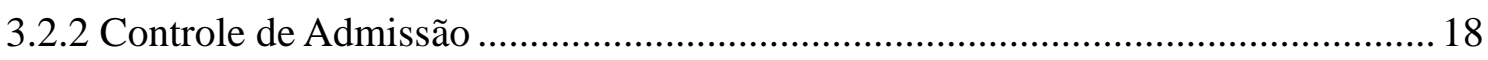

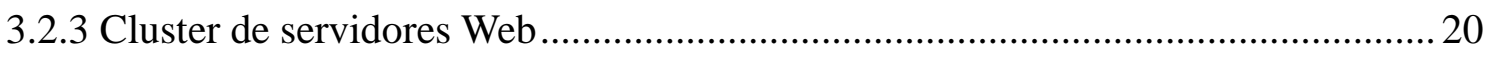

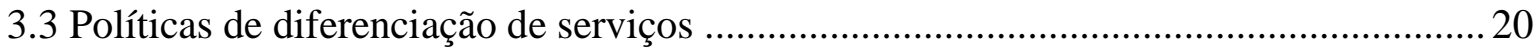

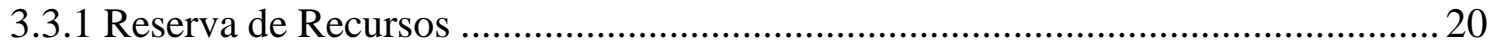

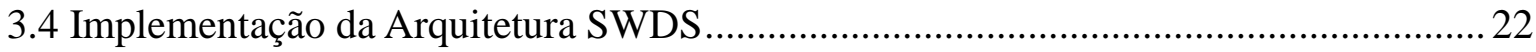

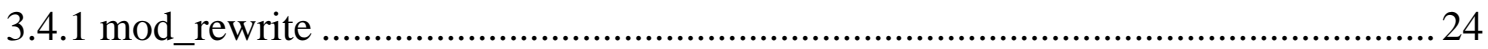




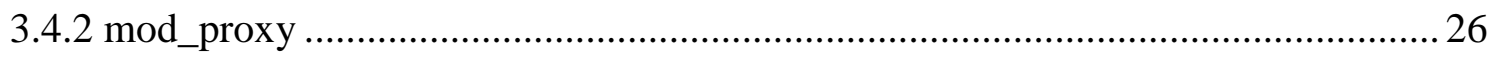

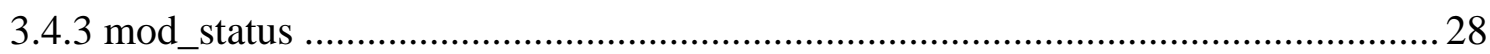

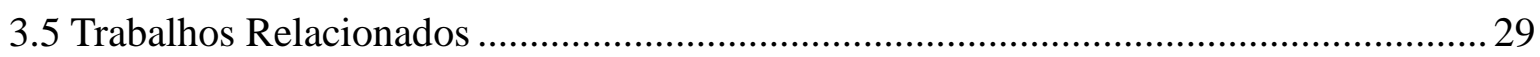

Algoritmo de Controle de Congestionamento ........................................................................... 31

4.1 Considerações Iniciais ......................................................................................... 31

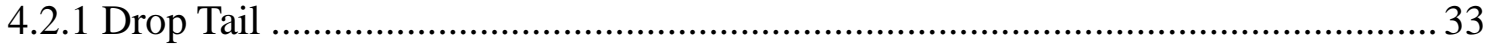

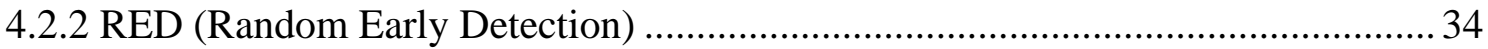

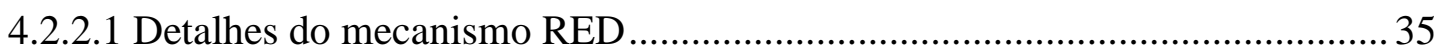

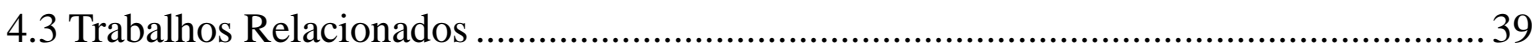

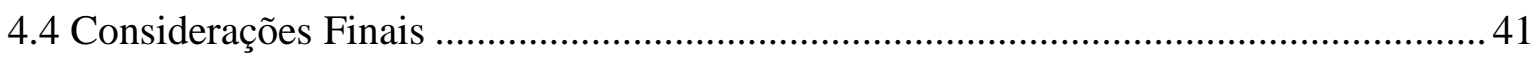

Planejamento dos Testes e Resultados Experimentais........................................................... 43

5.1 Considerações iniciais .......................................................................................... 43

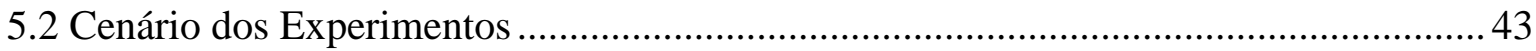

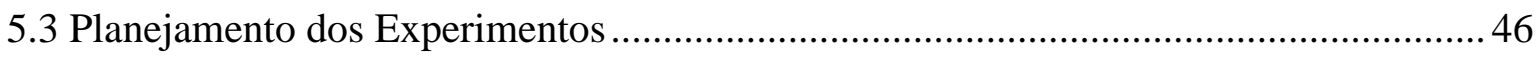

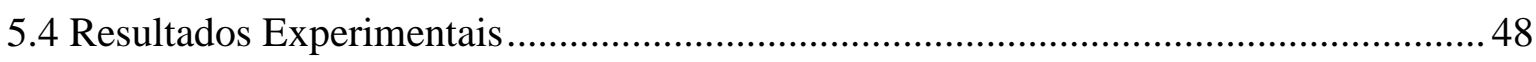

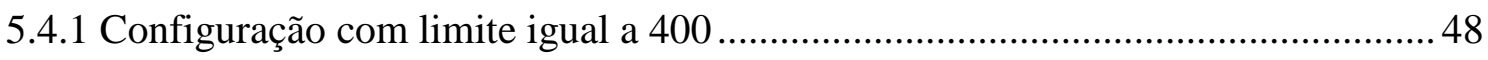

5.4.1.1 Carga com 300 requisições por segundo …………………………………..... 48

5.4.1.2 Carga com 600 requisições por segundo …………………………………..... 50

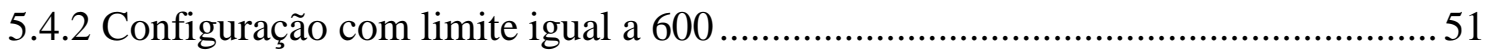

5.4.2.1 Carga com 300 requisições por segundo …………………………………...... 51

5.4.2.2 Carga com 600 requisições por segundo …………………………………..... 53

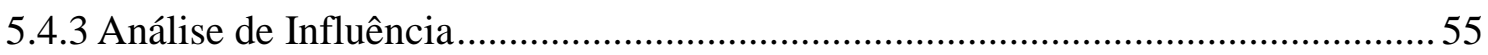

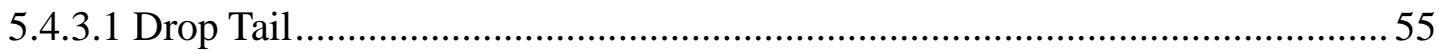

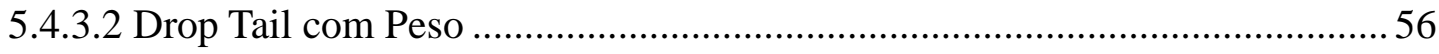

5.4.4 Comportamento do Algoritmo.............................................................................. 58

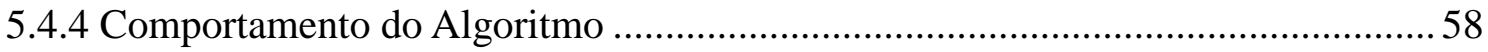

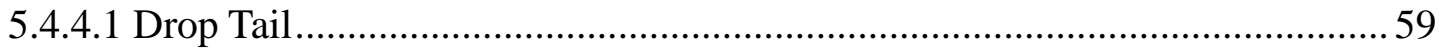

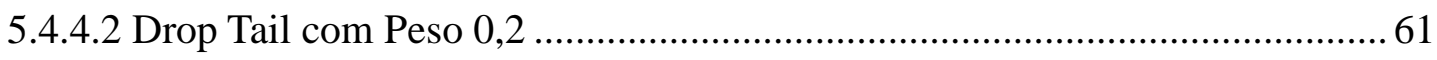

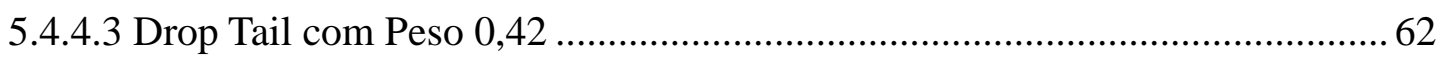

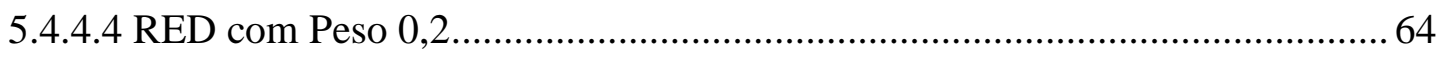

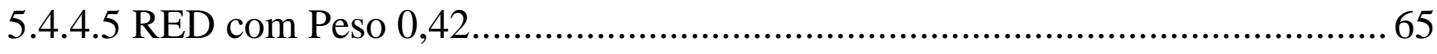

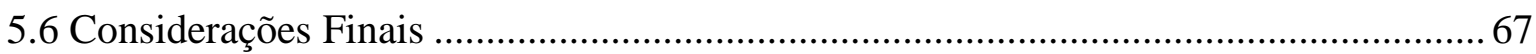




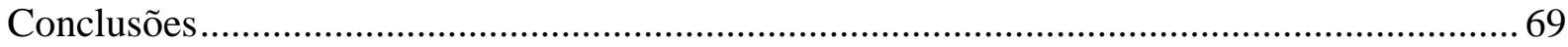

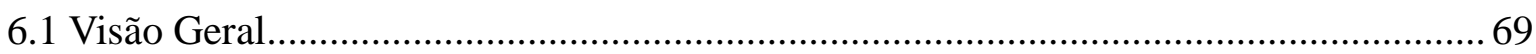

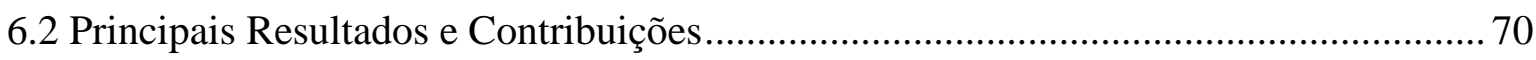

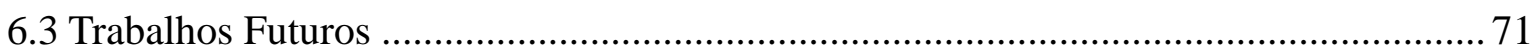




\section{Lista de Figuras}

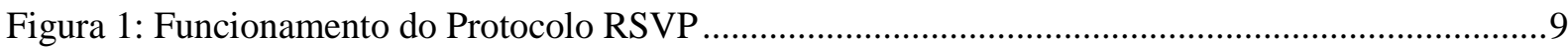

Figura 2: Cabeçalhos dos datagramas IP versão 4 e 6 (Cisco, 2011) ...................................................11

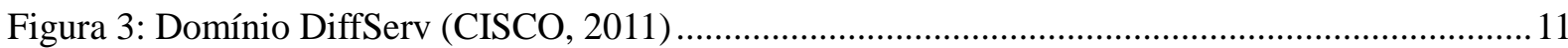

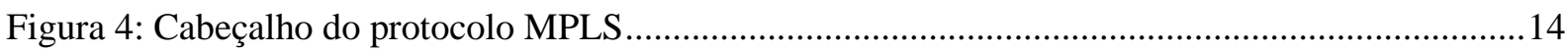

Figura 5: Servidor Web com Diferenciação de Serviço (SWDS) (Teixeira, 2004)................................18

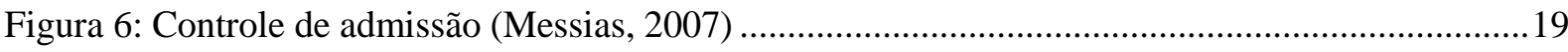

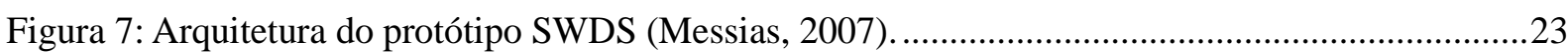

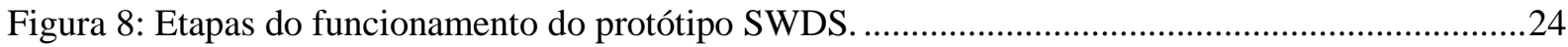

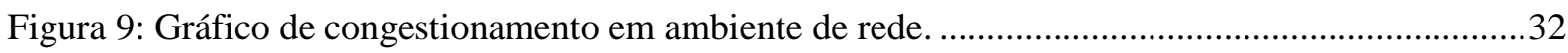

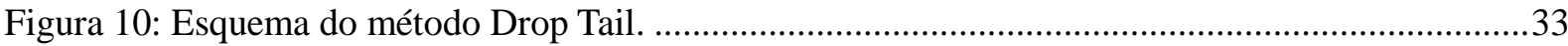

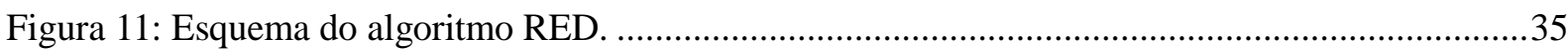

Figura 12: Comportamento real e utilizando média móvel exponencial com peso diferente. ................36

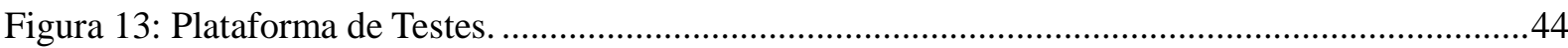

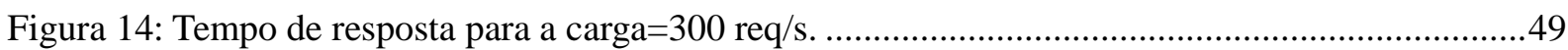

Figura 15: Porcentagem de requisições descartadas para a carga=600 req/s. ......................................49

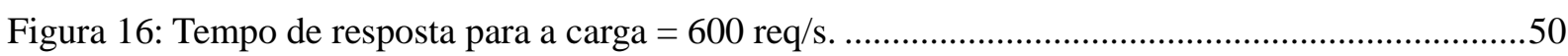

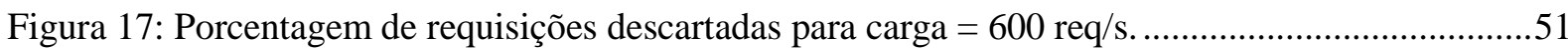

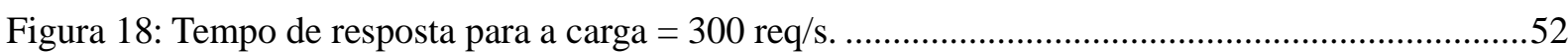

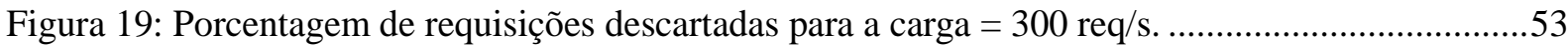

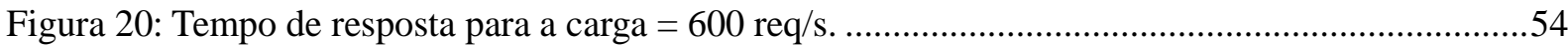

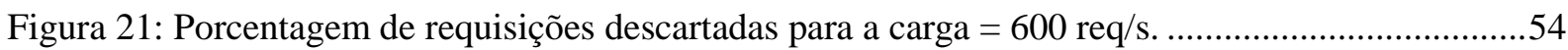

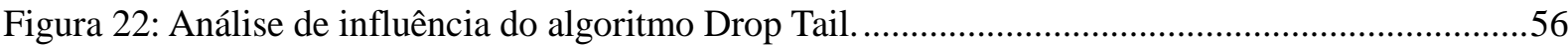

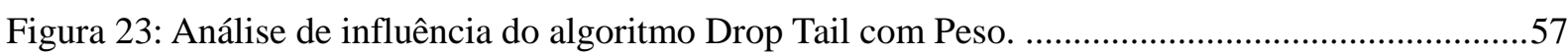

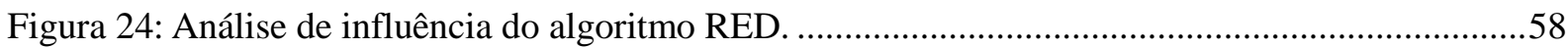

Figura 25: Comportamento do mecanismo Drop Tail com carga de 450 req/s. .....................................60

Figura 26: Comportamento do mecanismo Drop Tail carga de 800 req/s.............................................60

Figura 27: Comportamento do mecanismo Drop Tail com Peso com carga de 450 req/s......................61

Figura 28: Comportamento do mecanismo Drop Tail com Peso com carga de 800 req/s.....................62

Figura 29: Comportamento do mecanismo Drop Tail com Peso com carga de 450 req/s.....................63

Figura 30: Comportamento do mecanismo Drop Tail com Peso com carga de 800 req/s......................63

Figura 31: Comportamento do mecanismo RED com carga de 450 req/s. ..........................................64

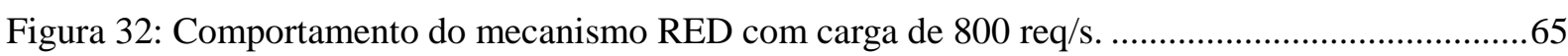

Figura 33: Comportamento do mecanismo RED com carga de 450 req/s. ............................................66

Figura 34: Comportamento do mecanismo RED com carga de 800 req/s. .........................................66 


\section{Lista de Tabelas}

Tabela 1: Comparação entre arquitetura DiffServ e IntServ (Dovrolis e Ramanathan, 1999). ..14

Tabela 2: Configuração das máquinas utilizadas nos experimentos......................................................45

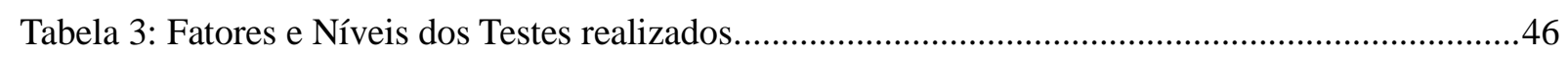




\section{Lista de Códigos}

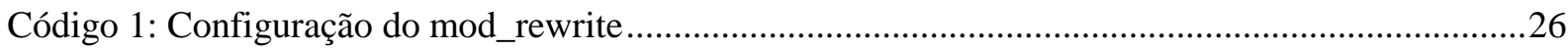

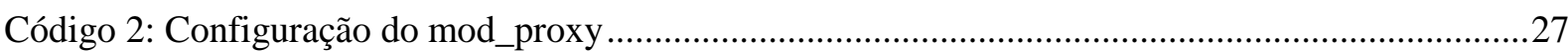

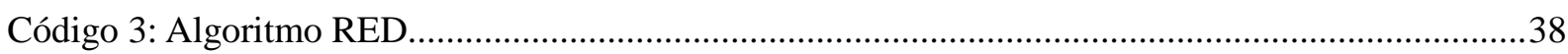




\section{Lista de Símbolos}

\begin{tabular}{|c|c|}
\hline$C B Q$ & Class Based Queuing \\
\hline$C P U$ & Central Processing Unit \\
\hline DNS & Domain Name Server \\
\hline DSCP & Differentiated Service Code Point \\
\hline FIFO & First In, First Out \\
\hline GSDPC & Grupo Sistemas Distribuídos e Programação Concorrente \\
\hline HTTP & HyperText Transfer Protocol \\
\hline IETF & Internet Engineering Task Force \\
\hline IP & Internet Protocol \\
\hline MPLS & MultiProtocol Label Switching \\
\hline$P H B$ & Per-Hop Behavior \\
\hline$Q o S$ & Quality of Service \\
\hline$R E D$ & Random Early Detection \\
\hline$R F C$ & Request For Comment \\
\hline$R S V P$ & Resource Reservation Protocol \\
\hline$S L A$ & Service Level Agreement \\
\hline$S W D S$ & Servidor Web com Diferenciação de Serviço \\
\hline$U R L$ & Universal Resource Locator \\
\hline$W F Q$ & Weighted Fair Queuing \\
\hline$W W W$ & World Wide Web \\
\hline
\end{tabular}




\section{Resumo}

Esta dissertação apresenta a construção de um protótipo de servidor Web distribuído, baseado no modelo de servidor Web com diferenciação de serviços (SWDS) e a implementação e avaliação de algoritmos de seleção, utilizando o conceito de controle de congestionamento para requisições HTTP. Com isso, além de implementar uma plataforma de testes, este trabalho também avalia o comportamento de dois algoritmos de controle de congestionamento. Os dois algoritmos estudados são chamados de Drop Tail e RED (Random Early Detection), no qual são bastante difundidos na literatura científica e aplicados em redes de computadores. Os resultados obtidos demostram que, apesar das particularidades de cada algoritmo, existe uma grande relação entre tempo de resposta e a quantidade de requisições aceitas. 


\begin{abstract}
This MSc dissertation presents the implementation of a prototype for a distributed web server based on the SWDS, a model for a web server with service differentiation, and the implementation and evaluation of selection algorithms adopting the concept of congestion control for HTTP requests. Thus, besides implementing a test platform this work also evaluates the behavior of two congestion control algorithms. The two algorithms studied are the Drop Tail and the RED (Random Early Detection), which are frequently discussed in the scientific literature and widely applied in computer networks. The results obtained show that, although the particularities of each algorithm, there is a strong relation between the response times and the amount of requests accepted in the server.
\end{abstract}




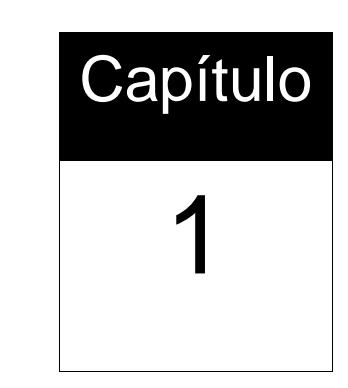

\section{Introdução}

\subsection{Contextualização}

A popularização da Internet e o surgimento de novas aplicações fizeram com que a WWW (World Wide Web) se estabelecesse como o meio preferido pelos usuários convencionais para acesso a informações (ANDREOLINI, 2004). Mais recentemente, um outro modo de utilização da Internet se estabeleceu, definindo-se uma interface orientada a negócios. Entretanto, na década de 80, a Internet era utilizada quase que exclusivamente em âmbito acadêmico, estando ainda por vir o uso proliferado em aplicações diversificadas de negócios, entretenimento e de relacionamento pessoal. Assim, nos anos 80 o que se tinha era a possibilidade de realização de operações de comunicação e compartilhamento de arquivos entre centros de pesquisa e pessoas. Naquela época, os conteúdos trafegados na Internet eram compostos, majoritariamente, por textos. Posteriormente, passou-se a utilizar diversos outros recursos, além de textos, incluindo imagens, animações e vídeos (STANKOVIC et al, 2001), e isso vem, continuamente evoluindo desde então.

Com isso, muitas empresas estão seriamente motivadas a migrarem, ou desenvolverem partes dos seus serviços críticos, para interfaces Web (SHAN et al., 2005). A proposta é tornar a aplicação acessível aos usuários na Web, independentemente das plataformas de hardware e software adotadas. A única necessidade é o uso de um navegador.

No entanto, o resultado obtido nesta migração de sistemas pode implicar no aparecimento de alguns pontos negativos, tais como o processamento em larga escala e o consumo expressivo de recursos de rede para a transmissão de dados (GUO et al., 2004). A implementação de uma arquitetura simples de servidores, pode se tornar insuficiente em ambientes com grande número de atendimentos. Um exemplo dessa situação são sites populares que recebem, diariamente, uma quantidade considerável de requisições. À medida que os acessos aumentam, as máquinas têm como consequência a degradação do seu 
desempenho, provocando o aumento indesejável de uma métrica básica e relevante para o usuário final: o tempo de resposta. O tempo de resposta é o tempo gasto desde o instante em que se faz a solicitação de um conteúdo a um servidor, até o instante do recebimento do seu primeiro byte de resposta. Caso esse intervalo de tempo seja muito grande, pode ocasionar a insatisfação por parte dos usuários e consequentemente a diminuição da popularidade do site.

Outro fator a ser considerado dentro desse contexto é com relação aos diversos perfis de usuários da Internet. Com isso, as requisições devem ser tratadas com um determinado grau de preferência, pelo menos sob a visão do usuário (DOVROLIS e RAMANATHAN, 1999). O motivo deste ponto é o modelo atual da Internet (modelo de atendimento conhecido como best-effort), que não permite priorizar o atendimento de certas requisições oriundas de um dado cliente.

Uma solução, aparentemente trivial, seria aumentar a largura de banda, porém, essa solução não proporciona o efeito almejado visto que o crescimento do número de usuários da Internet é muito maior, absorvendo rapidamente as vantagens que poderiam ser introduzidas. Uma alternativa a fim de minimizar esse problema, em nível de rede, é aplicar o conceito de qualidade de serviço (QoS) por meio de fornecimento de diferenciação de acordo com a prioridade do usuário. Entretanto, segundo MESSIAS (2007), todo o esforço empregado na garantia de serviço em elementos de rede será totalmente completo se tal abordagem abranger também os servidores Web. Isto é, não basta garantir QoS em nível de rede, se na aplicação no servidor essa garantia for perdida.

Portanto, atualmente ainda existe muito interesse por parte dos pesquisadores desta área em contribuir com soluções voltadas a oferecer diferenciação de serviços em nível de aplicação, pois os elementos finais responsáveis pelo atendimento ao usuário estão localizados nos servidores Web.

Entre os trabalhos que propõem o uso de serviços diferenciados em nível de aplicação pode ser citado o trabalho de TEIXEIRA (2004), onde é proposto um modelo de servidores Web com diferenciação de serviços, denominado SWDS, o qual serve de base para este trabalho.

\subsection{Motivação}

A Internet foi criada tendo como base um modelo denominado "melhor esforço" (besteffort) o qual trata todo o tráfego sem prioridades ou distinção de pacotes, oferecendo 
tratamento de maneira uniforme, sendo processados da melhor forma e no menor tempo possível (CLARK \& FANG, 1998). Com isso, tal característica não ficou restrita somente em nível de rede e atingiu também a camada de aplicação, pois a maioria dos servidores Web desenvolvidos atendem as requisições sem nenhum critério de seleção, uma vez que utilizam a política de atendimento denominada FIFO (First-In, First-Out) (BHATTI \& FRIEDRICH, 1999). No entanto, dentro do contexto Web, há requisições que devem ser tratadas com certo grau de preferência, pelo menos sob a visão do usuário (DOVROLIS \& RAMANATHAN, 1999).

Observando-se o fato de que várias empresas passaram a utilizar a Web como um meio orientado a negócios, algumas propostas de serviços podem ser oferecidas aos seus usuários. Tais propostas são baseadas na criação de classes, que disponibilizariam produtos de modo diferenciado, provendo um tratamento privilegiado, por exemplo, para os pagantes e realizando certo relaxamento para as demais categorias de clientes. Vale ressaltar que este relaxamento não deve ser demasiado visto que os membros das classes inferiores podem, futuramente, tornarem-se membros da classe pagante.

A partir do reconhecimento do método inadequado oferecido pelo modelo best-effort é visto a necessidade em incluir soluções que possam fornecer qualidade de serviço para os usuários. Nessa visão de beneficiar a prioridade dos usuários, a IETF (Internet Engineering Task Force) vem procurando soluções que ofereçam qualidade de serviço na camada de rede (BHATTI e FRIEDRICH, 1999). Entretanto, como já observado por ANDREOLINI (2004) em seu trabalho, aplicar qualidade de serviço somente na camada de rede não é suficiente para dar suporte adequado à diferenciação de serviço fim-a-fim.

\subsection{Objetivo}

Trabalhos anteriores, desenvolvidos dentro do Grupo de Sistemas Distribuídos e de Programação Concorrente (GSDPC), por exemplo por TRALDI (2006) e ESTRELLA (2006), utilizaram o modelo SWDS exclusivamente com a técnica de modelagem e simulação.

Neste trabalho, têm-se como objetivo duas etapas: na primeira tem-se a construção do modelo SWDS em ambiente real de servidores Web distribuídos, aplicando-se o conceito de diferenciação de serviço proposto por TEIXEIRA (2004); na segunda o foco será no 
desenvolvimento e avaliação de algoritmos de controle de admissão a fim de observar seu comportamento dentro desse contexto de diferenciação de serviços na camada de aplicação.

Com isso, a meta de implementação de uma plataforma de testes real deve ser alcançada através do uso de um conjunto de máquinas dedicadas, sendo esta infra-estrutura física disponibilizada para este projeto através de financiamento provido pela FAPESP (Processo No. 2007/02647-0).

\subsection{Estrutura de Trabalho}

Esta dissertação está organizada em cinco capítulos, descritos resumidamente a seguir.

No capítulo 2 apresenta-se um levantamento sobre os conceitos necessários para o entendimento sobre qualidade de serviço $(\mathrm{QoS})$ e serão mostradas as arquiteturas propostas pela IETF para diferenciação, tais como, IntServ, Diffserv. Ao final desse capítulo é feita uma revisão destacando-se alguns trabalhos desenvolvidos que abordam diferenciação de serviço dentro do assunto de servidores Web.

O capítulo 3 descreve o modelo SWDS e seus componentes apresentados no trabalho de Teixeira (2004). Também serão vistos, a descrição e o funcionamento dos módulos utilizados na implementação do SWDS. Ao final, serão revisados alguns trabalhos realizados pelo GSPSC que utilizaram o modelo SWDS como plataforma de teste para desenvolvimento de novos algoritmos, componentes etc.

O capítulo 4 mostra os conceitos iniciais e também o pseudocódigo dos algoritmos de controle de congestionamento aplicados majoritariamente em contexto de rede de computadores tal como, Drop Tail e, principalmente, o método RED (Random Early Detection).

No capítulo 5 são apresentados os resultados deste trabalho, que foram obtidos por meio de experimentos executados no protótipo SWDS, juntamente com os algoritmos de controle de congestionamento utilizando-se ferramentas de submissão por carga sintética. Ao final dos testes foram feitas medições e validações dos dados através da utilização de métodos estatísticos, incluindo o uso de intervalos de confiança sobre as amostras coletadas.

Por fim, o capítulo 6 apresenta os comentários finais acerca da dissertação, as conclusões e algumas sugestões para trabalhos futuros. 


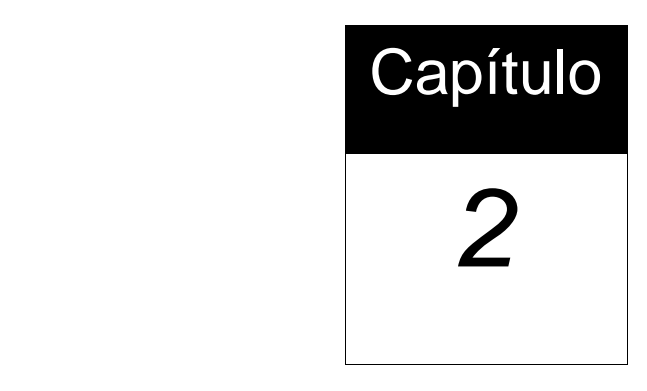

\section{Diferenciação de Serviços}

\subsection{Considerações Iniciais}

Há alguns anos, devido ao grande crescimento da utilização da Internet, o tráfego de requisições tem crescido vigorosamente, dobrando de valor a cada ano (ODLYZKO, 2003). Esse fato se atribui a dois motivos principais: (1) a popularização da Internet e (2) o surgimento de novas mídias e novas aplicações. Essas aplicações implicam em uma utilização maior de recursos computacionais, tais como processamento, memória, rede, entre outros.

A Web foi a aplicação que impulsionou a popularização da Internet, resultando no desenvolvimento de novas alternativas e opções de negócios. A maior parte dessas aplicações são irrestritas e completamente abertas aos usuários como comércio eletrônico, multimídia, VoIP, vídeos sob demanda, entre outros. Esse conjunto de aplicações juntamente com suas informações faz com que a Internet, atualmente, seja um importante meio de comunicação e interação. Mas, relacionado a isso, existem fatores implícitos que mascaram para os usuários alguns problemas relacionados a esse uso excessivo, no momento da utilização. Esses fatores são: o desempenho não satisfatório causado pela alta demanda, a falta de segurança e a confiabilidade. Contudo, outro ponto influencia na incompatibilidade entre o modelo atual da Internet (best-effort) e a implantação de Qualidade de Serviço, devido ao fato da implementação atual não oferecer, a priori, uma definição e manutenção para as aplicações (CASTRO et al., 2003). Para isso, seria necessário analisar e redesenhar o modelo atual, de modo que a maioria dos critérios de diferenciação seja satisfeita e supra a necessidade dos usuários.

Como solução para tal problema existem técnicas e níveis de qualidade de serviço, além disso, existe a elaboração de algoritmos adaptativos e definições de classes para efetuar diferenciação de serviços (KAJANCKAS et al., 2004). A qualidade de serviço é a característica pertinente para a próxima geração da Internet (STRNADL, 2002). É com esse 
foco que a proposta de TEIXEIRA (2004) foi desenvolvida, com o objetivo de prover tais técnicas na camada de aplicação, construindo um modelo flexível, composto de componentes que auxiliam na diferenciação de serviço.

Este capítulo aborda os conceitos de qualidade de serviço, definindo as técnicas existentes em nível de rede e quais podem ser aplicadas em servidores Web.

Qualidade de serviço é um conceito que possui sua base fundamentada na idéia de que nem todas as aplicações necessitam do mesmo desempenho durante suas execuções (FLUCKINGER, 1995). Uma definição de QoS seria a capacidade dos elementos de rede (Roteadores e Switchs) em fornecer uma medida para evitar atrasos e de alguma forma garantir largura de banda, mantendo os acordos de tráfego (STARDUST, 1999). Qualidade de serviço tem como critério principal a satisfação final do usuário e também está relacionada à garantia de entrega de pacotes sem atraso (delay) e com possibilidade de minimizar as perdas para determinados tipos de aplicações (ZHAO et al., 2000).

Há três princípios de QoS que precisam ser observados na construção de um serviço (AURRECOECHEA, 1998):

- Integração: Estados de qualidade de serviço podem ser configurados, preditos e mantidos fim-a-fim de forma integrada e em todas as camadas de uma arquitetura com diferenciação;

- Separação de responsabilidades: As atividades de transferência de dados, controle e gerência são distintas dentro de uma arquitetura de qualidade de serviço;

- Transparência: A complexidade existente nas subcamadas de especificação e gerência de qualidade de serviço deve ser ocultada das aplicações.

Há duas maneiras de oferecer qualidade de serviço: relativa e absoluta. A especificação de qualidade de serviço em uma abordagem absoluta visa prover algumas métricas a serem alcançadas, como por exemplo, especificar um limiar máximo de tempo de 
atraso ou a perda de pacotes. Na outra abordagem, a qualidade de serviço relativa utiliza a diferenciação de serviços baseando-se em prioridades, isto é, garantindo que uma aplicação em uma classe de maior preferência nunca receberá um serviço pior do que de qualquer classe inferior (ZHAO et al, 2000).

\subsection{Arquitetura para QoS}

O conceito de qualidade de serviço em redes de computadores tem sido um assunto bastante pesquisado e discutido em ambientes acadêmicos nos últimos anos, sendo que houve diversas propostas com várias abordagens com o intuito de aperfeiçoar tal objetivo (WEN \& LU, 2002). Com isso, a finalidade dessas pesquisas é permitir que programadores desenvolvam aplicações que solicitem uma infraestrutura apropriada fazendo com que, se possível, essas exigências sejam mantidas por toda a rede (ou seja, fim-a-fim). Entre tais abordagens, merecem destaque as arquiteturas de Serviços Integrados (IntServ) e Serviços Diferenciados (DiffServ) (STARDUST, 1999) (ZHAO et al, 2000).

\subsubsection{Serviços Integrados}

Uma das soluções propostas para fornecer suporte à qualidade de serviço na Internet foi a arquitetura de Serviços Integrados (IntServ). Esse serviço foi definido pela RFC 1633 (BRADEN et al., 1994) e tem como características o suporte na comunicação fim-a-fim e o uso de gerenciamento e tratamento de qualidade por fluxo em elementos intermediários de rede ao longo do caminho (SEMPREBOM, 2006). Esse método possui semelhança com os circuitos virtuais utilizados antigamente em telefonia, onde é estabelecida uma conexão dedicada e fim-a-fim entre emissor e receptor. KUROSE e ROSS (2006) destacam algumas características essenciais de qualidade de serviço em uma infra-estrutura onde tais características são:

- Recursos Reservados: os elementos de rede devem conhecer a quantidade de recursos (buffers, largura de banda) disponíveis para que o fluxo possa realizar a reserva necessária; 
- $\quad$ Estabelecimento da Chamada: uma sessão com qualidade de serviço deve certificar se a reserva dos recursos será suficiente em todos os elementos da rede, durante a transmissão entre a origem e o destino.

$\mathrm{Na}$ arquitetura IntServ, a idéia principal consiste em prover garantia dos serviços prestados de modo antecipado, realizando manutenções periódicas no estado dos elementos de rede. Para isso, a arquitetura conta com o auxílio de um protocolo, chamado RSVP (Resource Reservation Protocol), que possui a finalidade de lidar com as reservas feitas pelos fluxos durante o percurso (CARPENTER \& NICHOLS, 2002). Há dois componentes na arquitetura IntServ que auxiliam na garantia do serviço: o controle de admissão, responsável por verificar a disponibilidade do serviço desejado na rede, e o protocolo de reserva de recursos (RSVP) no qual é necessário para criar e manter os estados individuais dos fluxos (reserva de largura de banda, contas e filtros) nos roteadores durante o trajeto (SCHLEMBACH et al., 2001). Na arquitetura IntServ há duas classes de serviços, denominadas Serviço Garantido e Serviço de Carga Controlada, além do modelo convencional de melhor esforço (best-effort) encontrado nas redes IP (GOZDECKI et al., 2003). A seguir são descritas as duas classes de serviços:

- Serviço Garantido: Especificado na RFC 2212 (SHENKER et al, 1997), tem como proposta fornecer um limite superior rígido para atraso fim-afim, além de garantir a disponibilidade de largura de banda. Esse serviço se destina à aplicações que possuem requisitos restritos de tempo real para funcionar, atingindo um alto nível de qualidade de serviço na Internet;

- Serviço de Carga Controlada: especificado na RFC 2211 (WROCLAWSKI, 1997), possui o objetivo de fornecer um serviço equivalente ao modelo de melhor esforço em uma rede pouco utilizada, com quase nenhuma perda ou atraso. Em situações de sobrecarga, essa abordagem será capaz de compartilhar a largura de banda entre múltiplos fluxos de uma maneira controlada, garantindo um serviço melhor que o usual. Entretanto, esse modelo não oferece garantias de atraso máximo, apenas um limiar probabilístico, assim como também não pode assegurar que pacotes não serão perdidos.

\subsubsection{Protocolo RSVP}


Definido pela RFC 2205 (BRADEN et al., 1997), o RSVP é o protocolo da arquitetura IntServ que opera na camada de rede e realiza controle e sinalização de pacotes TCP/IP, sendo bastante utilizado por equipamentos de rede para reserva de recursos. A alocação é feita perguntando-se a cada elemento intermediário se existe a possibilidade de fornecer os recursos desejados à aplicação. Caso algum desses elementos esteja impossibilitado de prover algum recurso, a conexão entre os pontos não é estabelecida. A figura 1 mostra de modo esquemático o funcionamento do protocolo RSVP.

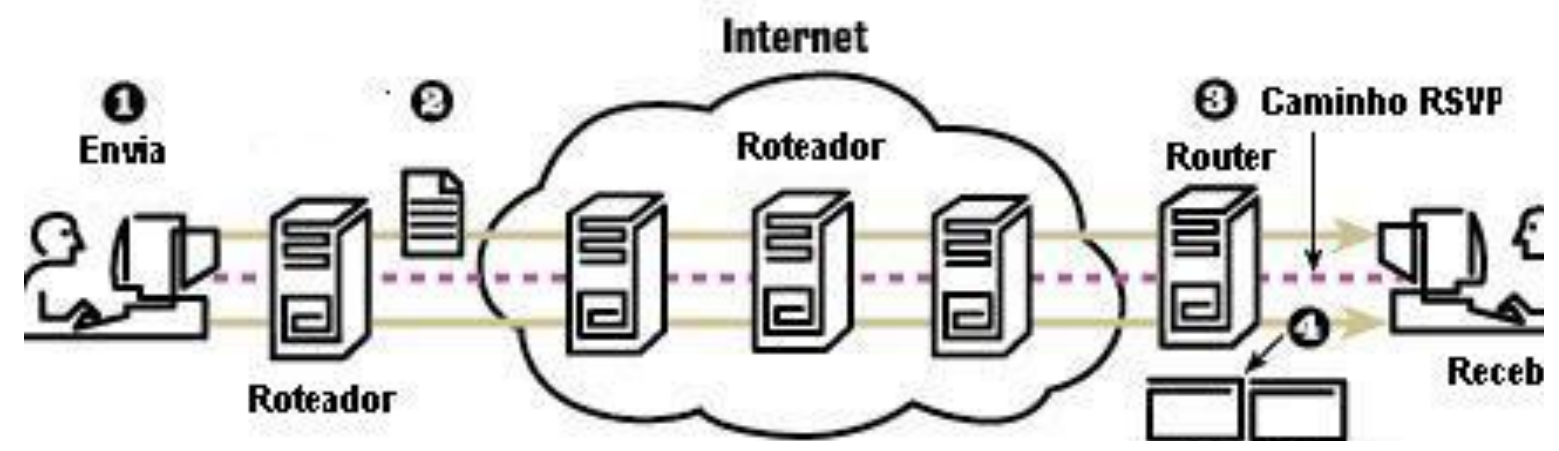

O procedimento efetuado pelo protocolo RSVP é descrito passo a passo a seguir: O usuário envia uma requisição de qualidade de serviço na rede (1). A requisição trafega pelo trajeto reservando os recursos necessários até alcançar a máquina de destino (2). Ao final, o receptor responde ao usuário no qual foi estabelecido um fluxo em cada elemento intermediário interligando o solicitante e o receptor (3). Contudo, a comunicação fim-a-fim é estabelecida, e a troca de dados é realizada. Algumas características encontradas no protocolo RSVP são:

- $\quad$ Há suporte a IPv4 e IPv6 (PADILLA et al., 2006);

- As reservas para os fluxos são iniciadas pelo receptor dos dados;

- $\quad$ O RSVP oferece vários estilos de reservas, para se adaptar a uma grande variedade de aplicações e usos;

- Toda reserva no RSVP tem um tempo máximo de validade, sendo assim, é necessário atualizar periodicamente o estado dos fluxos. 
A abordagem proposta pela arquitetura IntServ aplica-se melhor a um ambiente de rede local (CARPENTER \& NICHOLS, 2002). Para garantir o nível de qualidade de serviço desejado nesse modelo, é utilizado o conceito de reserva de recursos, efetuado pelo RSVP. KUO \& KO (2003) mostraram em seu trabalho que o protocolo RSVP não oferece um mecanismo flexível para reserva de recurso em grandes ambientes, portanto, a próxima seção aborda a arquitetura denominada serviços diferenciados, onde possui uma implantação mais adequada sob grandes cenários.

\subsubsection{Serviços Diferenciados}

Definido pela RFC 2475 (BLAKE et al., 1998), a arquitetura de Serviços Diferenciados (DiffServ) surgiu para atender as deficiências encontradas no IntServ, como escalabilidade e a dificuldade de implantação de tal arquitetura em uma rede com as dimensões da Internet (MAN et al., 2004).

A arquitetura DiffServ é um mecanismo baseado em classes de serviço e composta por funções implementadas em nós da rede. Dentre estas funções podem-se ressaltar a classificação (ou marcação) de pacotes, características de encaminhamento por nó e funções de condicionamento de tráfego como medição, formatação e vigilância (SHIODA \& MASE, 2005).

Para que haja a classificação dos pacotes é necessário que cada pacote tenha referência a sua prioridade para a realização do tratamento. A marcação de pacotes no protocolo IPv4 é feita através do campo Type-of-Service (ou o campo Traffic Class do IPv6) que passa a ser denominado como DS (Differentiated Service). Com isso, os seis primeiros bits do campo DS passam a ser chamados de campo DSCP (Diferentiated Services CodePoint) e passam a ser utilizados na especificação de como serão tratados os pacotes (MAGALHÃES \& CARDOZO, 1999). O processo pelo qual é realizado o tratamento diferenciado feito pelos roteadores para o repasse de pacotes baseado no campo DSCP é chamado de PHB (Per-Hop Behavior). A figura 2 mostra a pilha de protocolos IPv4 e Ipv6. 


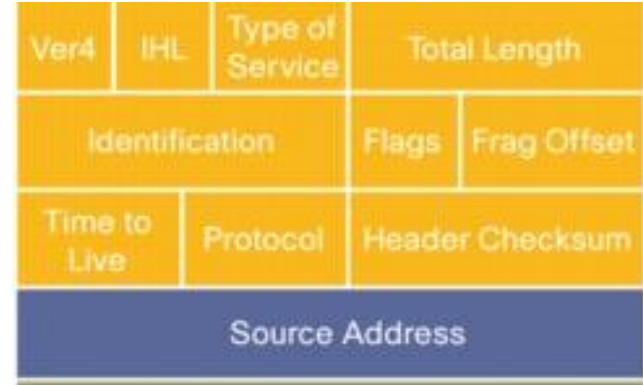

Destination Address

IP Options

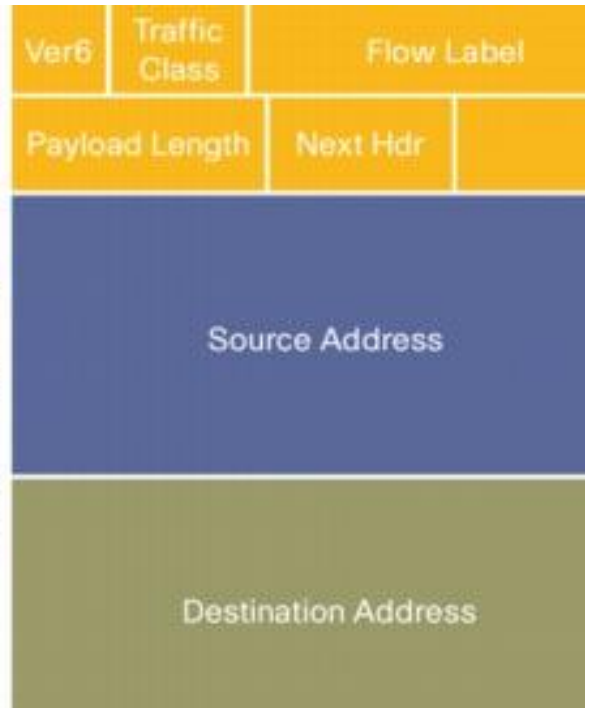

Na figura 3 pode ser visto um exemplo de domínio de Serviços Diferenciados o qual pode ser definido como um conjunto contíguo de nós que operam com uma política de disponibilização de serviços comum e com um conjunto de grupos PHB, que são implementados em cada nó (BLAKE et al., 1998). Esse domínio é formado por nós de borda e nós internos, e ambos devem ter a capacidade de aplicar um tratamento apropriado aos pacotes baseando-se no conteúdo do campo DSCP. A figura 3 mostra um domínio Diffserv.

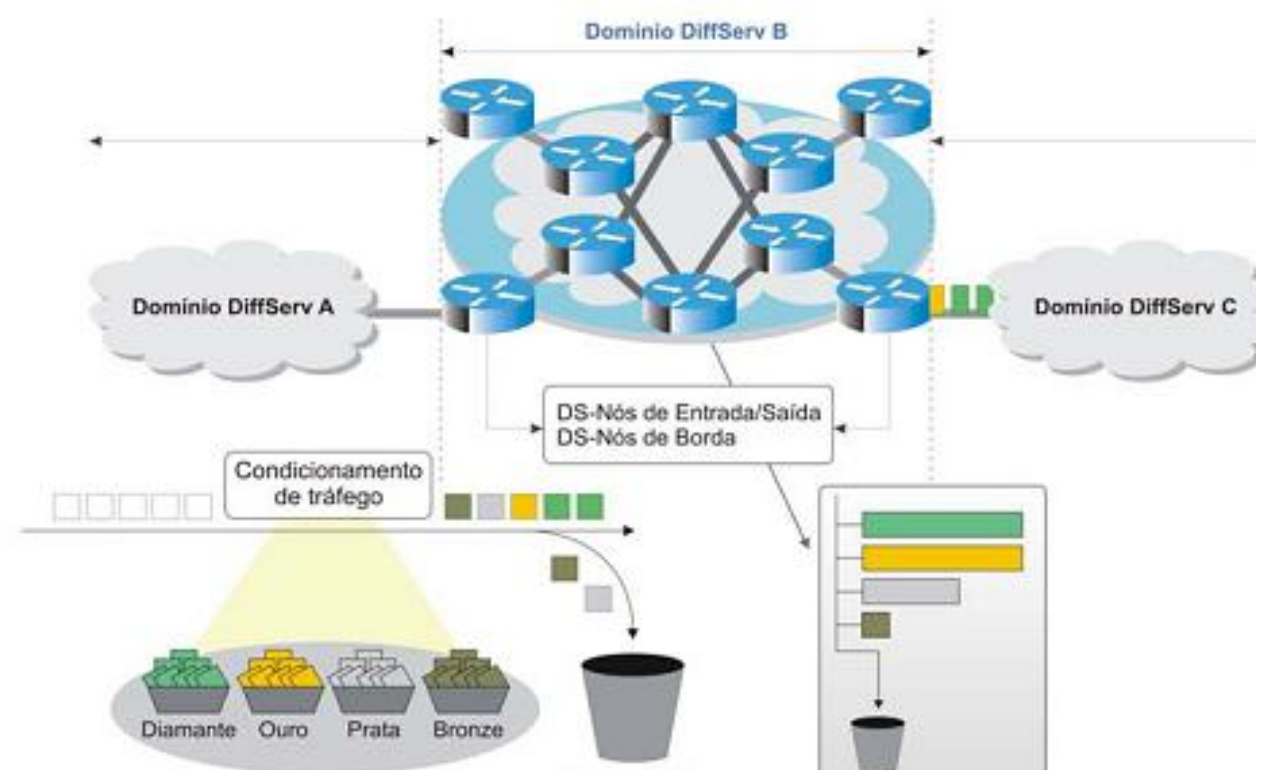

\subsubsection{Encaminhamento Acelerado}

O serviço de Encaminhamento Acelerado (Expendited Forwarding - EF) fornece 
garantias mais rígidas de qualidade de serviço, com baixos valores de perda, atraso e jitter.

Embora o encaminhamento acelerado proveja um excelente serviço, o qual é especificamente voltado para aplicações com maior sensibilidade à variação de tempo, se existir um congestionamento não é possível tratar todos os pacotes (ou a maioria) com alta prioridade. Os problemas como perda de pacotes, atrasos e variações de atraso ocorrem por causa da existência de fila nos roteadores (HARJU \& KIVIMAKI, 2000). Com isso, os pacotes pertencentes a uma classe serão encaminhados para a fila de maior prioridade, tendo o privilégio de serem repassados primeiramente e os últimos a serem excluídos sob qualquer circunstância.

\subsubsection{Encaminhamento Acelerado}

A classe de serviço denominada Encaminhamento Garantido (Assured Forwarding AF) é definida pela RFC 2597 (HEINANEN et al., 1999), e consiste em dividir o tráfego em diversas classes e fornecer para todas estas classes a quantidade mínima de recursos (buffer, largura de banda) para prover qualidade de serviço (LI \& YONG-LE, 2010). Um fator atrativo no serviço AF está relacionado à ausência do controle de admissão ou classificação por fluxo. Portanto é escalável sob ambos os aspectos: controle e caminhos dos dados. O AF somente provê diferenciação qualitativa nas classes, no sentido de que algumas classes recebem menores atrasos e menor perda do que outras, mas a diferenciação não é quantificada e nem limites absolutos são oferecidos (CHRISTIN et al, 2002).

As vantagens desse serviço estão em proporcionar um melhor trabalho que a política de melhor esforço, fazendo o controle do descarte de pacotes em momentos de congestionamento de tráfego, além de ser uma alternativa de oferta de serviço de baixo custo para implementar diferenciação de serviço em aplicações tais como áudio, vídeo, aplicações online, etc.

\subsubsection{Service Level Agreement}

A definição de SLA (Service Level Agreement) consiste em um "contrato de serviço" feito entre transmissor e receptor, no qual são estabelecidos os valores de limites para cada parâmetro (XIAO \& NI, 1999).

Um SLA pode ser negociado em bases mensais ou anuais e, dessa forma, pode ser chamado de estático; quando negociado para requisição de serviços de QoS sob demanda, 
utilizando um protocolo RSVP, é considerado como dinâmico.

A aplicação de políticas de qualidade de serviço pode ser usada em qualquer tipo de dado que possa ser extraído do conteúdo do tráfego, como data e hora, endereços de origem e destino, e outras, inclusive as informações contida nos cabeçalhos (STARDUST, 1999). O SLA também pode especificar questões como, procedimentos de tarifação e cobrança, serviços de criptografia e autenticação, procedimentos de renegociação dos parâmetros do SLA, ações a serem tomadas para o tráfego fora de perfil, dentre outros (VASILIOU, 2000).

\subsubsection{Protocolo MPLS}

O protocolo MPLS (Multi-Protocol Layer Switching), especificado pela RFC 3031 (ROSEN et al., 2001), consiste em um framework que oferece o encaminhamento e a comutação dos fluxos de tráfegos pela rede, de forma eficiente. No roteamento IP, cada roteador no caminho verifica o cabeçalho do pacote IP e encaminha de acordo com sua tabela de roteamento, o que faz aumentar o tempo de processamento. Um método para minimizar esse tempo de processamento é a utilização do protocolo MPLS.

Numa rede MPLS, somente os roteadores de borda analisam cada pacote e criam um caminho atribuindo-lhe um rótulo, assim, os demais roteadores irão somente substituir, ou seja, fazer um chaveamento de rótulos até que o pacote chegue ao seu destino (MAN et al., 2004). Dessa forma, a parte pesada do processamento dos pacotes é feita nas bordas da rede, diminuindo o processamento no núcleo. Como a taxa de pacotes no núcleo da rede é maior que a taxa de pacotes nas bordas, o processo é agilizado (AWDUCHE e JABBARI, 2002). A figura 4 mostra o campo do cabeçalho MPLS. 
Figura 4: Cabeçalho do protocolo MPLS

As arquiteturas de disponibilização de qualidade de serviço, juntamente com outras soluções (RSVP, DiffServ, MPLS), parecem ser bastante promissoras. De modo geral, é possível uma combinação dessas arquiteturas durante o percurso entre o emissor e o receptor, para que possa ser obtido o melhor de cada uma delas (STARDUST, 1999).

\subsection{Comparação entre Serviços Integrados e Serviços Diferenciados}

As diferenças entre os dois tipos de serviços mais populares com relação a qualidade de serviço são mostrado na tabela 1 .

Tabela 1: Comparação entre arquitetura DiffServ e IntServ (Dovrolis e Ramanathan, 1999).

\begin{tabular}{|c|c|c|}
\hline Itens Comparados & IntServ & DiffServ \\
\hline $\begin{array}{c}\text { Granularidade da } \\
\text { diferenciação de serviços }\end{array}$ & Fluxos Individuais & Fluxos Agregados \\
\hline Manutenção do Estado & Por Fluxo & Por Agregação \\
\hline Tipo de diferenciação de & Garantia determinística ou & $\begin{array}{c}\text { Garantia absoluta ou } \\
\text { proporcional }\end{array}$ \\
\hline serviço & Fim-atística & Local (por salto) \\
\hline Coordenação & Limitada pelo número de & $\begin{array}{c}\text { Limitada pelo número de } \\
\text { fluxos }\end{array}$ \\
\hline Escalabilidade & clase serviço \\
\hline
\end{tabular}




\begin{tabular}{|l|c|c|} 
Sinalização & $\begin{array}{c}\text { Características de fluxos ou } \\
\text { requisitos de QoS }\end{array}$ & Convenção da classe \\
\hline
\end{tabular}

Ao analisar os conceitos abordados anteriormente e verificar a tabela 1, pode-se identificar diferenças entre as arquiteturas DiffServ e IntServ. A diferença básica entre as arquiteturas é o nível de granulação do tratamento independente do fluxo na rede e a escalabilidade (GOZDECKI et al., 2003). Enquanto o IntServ oferece a alocação do recurso necessário de modo individual, o DiffServ provê a manutenção dos estados através de classes de serviço.

\subsection{Serviços diferenciados no nível de aplicação}

Nas seções anteriores foram realizadas revisões que abrangem o conceito de QoS em nível de rede. Particularmente foram abordados tópicos sobre Serviços Integrados e Serviços Diferenciados. Conforme mencionado neste trabalho, para uma melhor solução de QoS faz-se necessário que todos os elementos do sistema cooperem, até mesmo componentes como servidores Web, que não estão preparados para efetuar diferenciação de serviço. A maior parte dos servidores Web trata todas as requisições HTTP de forma igualitária, obedecendo ao escalonamento FIFO (First-In First-Out), sendo que, dessa forma, é eliminado qualquer tipo de oferecimento de QoS (BHATTI e FRIEDRICH, 1999).

Nesta seção serão descritos alguns trabalhos realizados com a finalidade de oferecer qualidade de serviço em nível de aplicação, cujo foco é oferecer diferenciação no lado do servidor (em nível de aplicação), sem alterar a ação do código no sistema operacional, devido a sua complexidade.

No trabalho de SERRA et al. (2005) foi proposta uma nova arquitetura, chamada WSDSAC (Web Servers - Differentiated Services Admission Control) para prover QoS utilizando balanceamento de carga e um mecanismo para o controle de admissão baseado no Diffserv. A plataforma é composta por elementos, como Class Switch que é responsável pela classificação e pela admissão das requisições, e o Class Gateway, que faz o repasse das requisições para o nó que possui a menor carga. A coleta de informação de carga é realizada por um processo monitor instalado em cada nó, que mede a carga baseando-se na técnica de Coeficiente de Reatividade, que informa uma idéia da tendência de carga no nó. A partir desse valor, o 
modelo opera variando entre três modos distintos: exclusivo, que atende somente uma classe, compartilhado, que atende a outras classes e saturado, que não atende novas requisições que chegam ao sistema.

Em BHOJ et al. (2000) é implementado um servidor Web denominado, Web2K, que oferece QoS utilizando um middleware entre o servidor Web e a pilha de protocolos TCP/IP. Esse middleware é uma biblioteca que pode ser adicionada dinamicamente ao programa servidor e nela são implementadas algumas funções para diferenciação de serviço, tais como priorização de requisições, controle de fila preditivo, e um controle de admissão de vários estágios. Nenhuma alteração é realizada no código do sistema operacional ou no servidor Web.

SHAN et al. (2005) realizaram algumas modificações no código fonte do APACHE sobre o sistema operacional LINUX, visando a atender as requisições com qualidade de serviço, denominando o sistema gerado de QoS Apache. A arquitetura do protótipo consiste em um módulo de classificação e outro de priorização das requisições. Sendo assim, a requisição recebe seu valor de prioridade e é encaminhada para um dos processos que estão sendo executados na máquina. Esses dois processos estão executando em uma mesma máquina e com prioridades distintas, configuradas através dos comandos "setpriority" ou "nice" do UNIX. Os testes mostraram que foi possível obter diferenciação nas duas diferentes classes em relação ao servidor APACHE que não possuía características de QoS.

\subsection{Considerações Finais}

Neste capítulo foram apresentados e discutidos os principais conceitos de QoS na Internet, mais especificamente na camada de rede, onde a qualidade de serviço está mais difundida. Foi realizada também uma revisão de alguns trabalhos relacionados, que abordam diferenciação de serviço em servidores Web. Essa revisão é de fundamental importância para o desenvolvimento desa dissertação de mestrado, estando diretamente relacionada ao desenvolvimento do projeto considerado.

No próximo capítulo será abordado o modelo SWDS desenvolvido por TEIXEIRA (2004), que servirá como base para o projeto considerado neste trabalho e que tem servido de base para diversos outros trabalhos do GSDPC, ao longo dos últimos anos. 


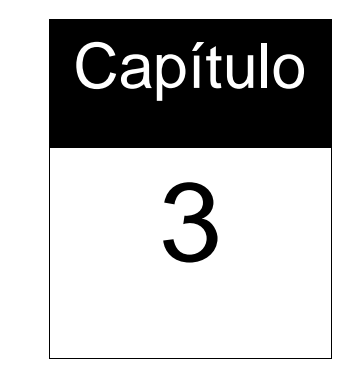

\section{Servidor Web com Diferenciação de Serviço}

\subsection{Considerações Iniciais}

Há um grande esforço por parte dos pesquisadores em inserir a característica de diferenciação de serviços na camada de aplicação, pois, com isso haveria uma redução no tratamento igualitário das requisições HTTP por servidores Web. Sendo assim, é preciso que tais servidores possuam a capacidade de analisar a demanda, tanto de usuários quanto das aplicações, de modo a estarem atentos para tratar de maneira diferenciada cada requisição de acordo com suas respectivas prioridades.

Neste capítulo é apresentado o modelo SWDS, elaborado por TEIXEIRA (2004), no qual o modelo é composto por componentes que trabalham de forma conjunta com o servidor Web e operam de modo a realizar diferenciação de serviços. Neste capítulo será apresentada uma visão geral do modelo SWDS, com a finalidade mostrar a estrutura do componente de controle de admissão para diferenciação de serviços. Por fỉm, será mostrada uma implementação real da arquitetura e alguns trabalhos realizados pelos membros do GSDPC que utilizaram o modelo SWDS.

\subsection{Modelo de servidor Web com diferenciação de serviço}

Atualmente, a maioria dos softwares de serviços Web tratam as requisições HTTP utilizando a política FCFS (First Come, First Served), no qual é constituído de uma fila na qual cada requisição, após ser aceita, espera por seu atendimento obedecendo uma ordem de chegada. Um modelo de servidores Web distribuído é apresentado nesta seção, cujo intuito é prover diferenciação de serviços aos seus usuários. O trabalho de TEIXEIRA (2004) descreve, exatamente, esse modelo que é composto por um conjunto de máquinas servidoras seguindo 
os requisitos de qualidade de serviço previamente acertados. $\mathrm{Na}$ figura 5 é mostrada a arquitetura e, posteriormente, os componentes do SWDS.

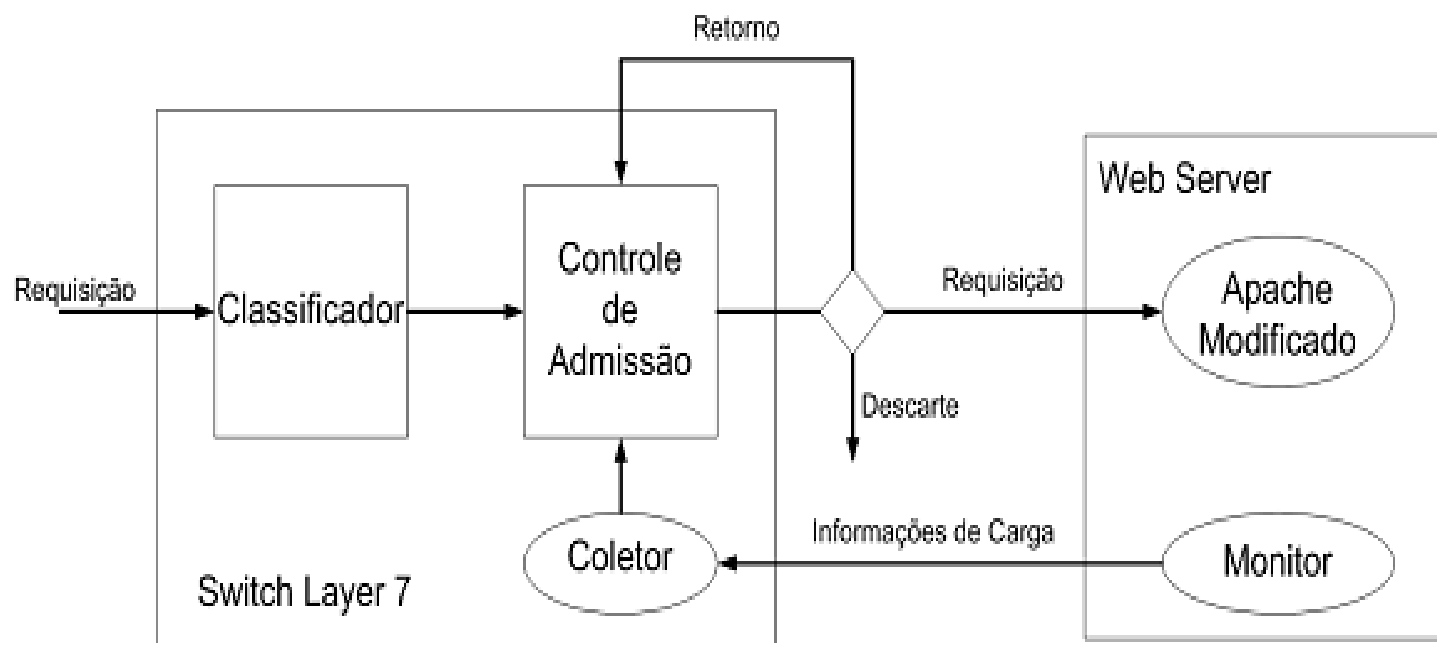

\subsubsection{Classificador}

É o primeiro componente dentro da arquitetura SWDS, sendo que a sua finalidade é de receber as requisições e classificá-las de acordo com um critério pré-estabelecido. Além do critério de classificação pela origem da requisição, outras regras podem ser consideradas nesse processo, tais como: urgência no atendimento, o conteúdo a ser requisitado, entre outros;

\subsubsection{Controle de Admissão}

Este módulo é responsável por receber as requisições classificadas e gerenciar sua aceitação pelo servidor. Nesta etapa podem ser levados em conta as políticas de atendimento implementadas e as informações de cargas apresentadas pelo sistema. Caso o sistema apresente sinais de sobrecarga, uma requisição poderá ser descartada ou, de acordo com o algoritmo, poderá ter suas exigências renegociadas, com o intuito de que possa ser aceita em uma classe de prioridade inferior.

No trabalho de MESSIAS (2007) são descritos os componentes necessários para a construção do módulo de controle de admissão. A figura 6 mostra uma visão organizacional desse módulo e logo a seguir uma descrição da funcionalidade de cada componente. 


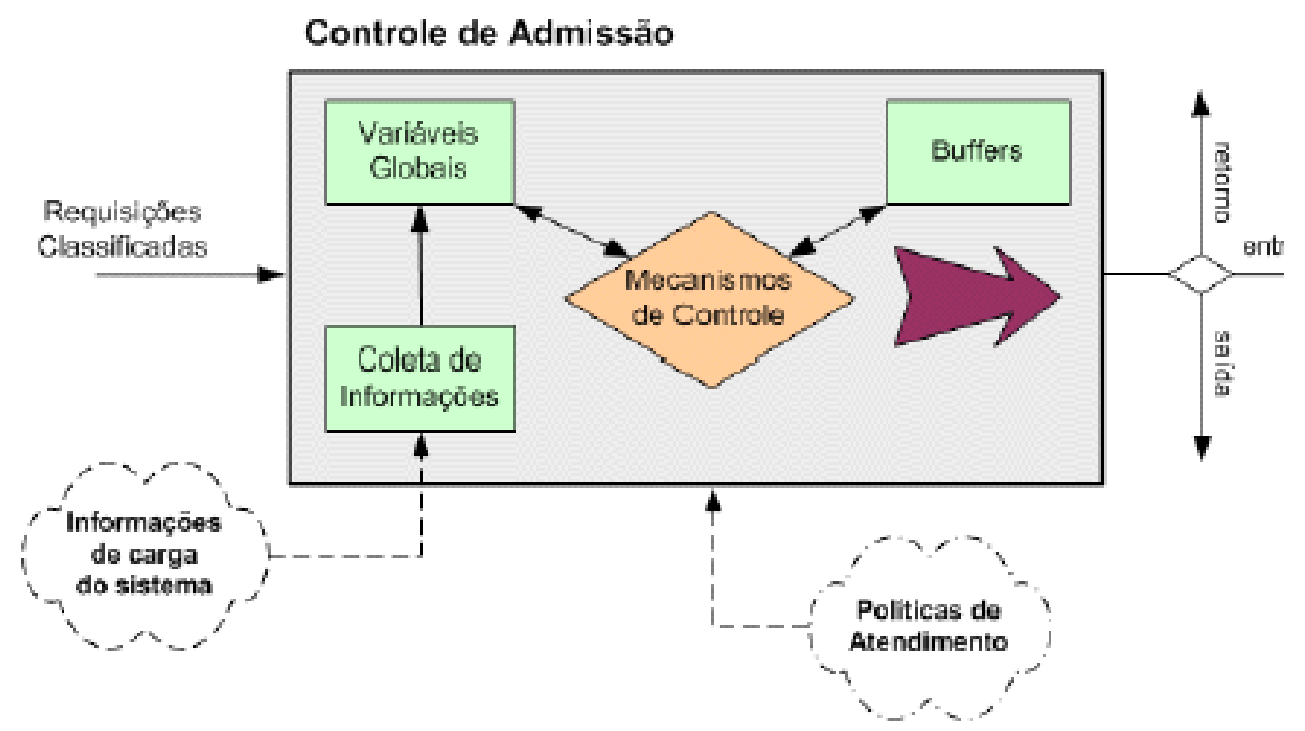

- Área de Variáveis Globais: Guarda informações referentes ao estado do sistema e às métricas relevantes para o Controle de Admissão, como o tamanho das filas do cluster, o tempo de resposta das requisições e a utilização do sistema. Essa área pode ser ampliada de acordo com a necessidade;

- Área de Buffers: Composta por buffers utilizados, por exemplo, para limitar o número total de clientes de classe presentes no servidor, número de clientes em fila, etc;

- Coleta de Informações: Responsável por coletar informações atualizadas da carga do sistema, servindo como base para a tomada de decisões;

- Mecanismos de Controle: Os mecanismos de controle de admissão implementados no SWDS podem se basear em parâmetros tais como, tamanho de fila, tempo de resposta e utilização do sistema.

3.2.3 Cluster de servidores Web 
É o conjunto de servidores organizados de modo a cooperarem entre si, para que a requisição possa ser atribuída a um nó do cluster conforme o algoritmo de distribuição de carga vigente. Após a conclusão do processamento, o resultado retorna ao cliente que originou a solicitação.

Segundo TEIXEIRA (2004), o servidor proxy e cada nó do cluster deve ser considerado como um servidor Web convencional, sendo composto de CPU, disco, e interface de rede, já que o modelo não exige uma arquitetura formada necessariamente de máquinas dispostas em um sistema distribuído. Assim, como não é definida nenhuma plataforma de hardware para o funcionamento da arquitetura e nenhuma exigência com relação ao sistema operacional é especificada.

\subsection{Políticas de diferenciação de serviços}

Nessa seção serão apresentadas algumas políticas que possuem a finalidade de oferecer qualidade de serviço determinando a priorização de uma classe de serviço e, especificando a distribuição de requisições entre as diferentes classes de serviços.

No trabalho de TEIXEIRA (2004) foram elaborados três algoritmos para diferenciação de serviços, sendo divididos em duas abordagens: reserva de recursos (adaptativo e estático) e escalonamento baseado em prioridades.

\subsubsection{Reserva de Recursos}

Nessa abordagem, os algoritmos de diferenciação de serviços são aplicados ainda na fase de despacho das requisições HTTP, determinando a forma de distribuição das mesmas entre os nós do cluster (ZHANG \& ZHAO, 2006). O módulo de controle de admissão atua como escalonador e atribui as requisições a grupos de máquinas servidoras segundo a classe a qual pertence.

No trabalho de TEIXEIRA (2004), foi desenvolvido um algoritmo de diferenciação de serviços, elaborado segundo os princípios do CBQ (Class Based Queuing). Este algoritmo de diferenciação de serviço, chamado de algoritmo de reserva de recursos (RSV), proporciona o isolamento de desempenho (ARON et al., 2000) para cada classe. Seu funcionamento consiste em realizar a subdivisão do cluster em partições, relacionando essas partições às classes de 
serviço. Com isso, uma parcela da capacidade de processamento é reservada para cada classe de requisições, isolando assim o desempenho entre as classes e, evitando a interferência no comportamento entre elas.

Embora o algoritmo seja adequado em alguns casos, existem situações em que pode não ser eficiente (TEIXEIRA et al., 2003). Devido à característica estática do particionamento, o algoritmo RSV aplica-se adequadamente em casos em que padrões de carga de trabalho são previamente conhecidos, o que não se encontra na Web.

Por ser um ambiente altamente dinâmico, a variação de carga na Web, pode fazer com que alguns recursos destinados a uma classe de serviço fiquem sobrecarregados enquanto outros sejam subtilizados. Uma possível solução para este problema seria a implementação de um algoritmo que se baseando em algumas informações do ambiente, consiga realizar o particionamento do cluster dinamicamente (ZHANG et al., 2002).

\subsubsection{Escalonamento baseado em prioridade}

A abordagem anterior estudou o uso de esquemas do tipo Class-Based Queueing para a diferenciação de serviços, mostrando algumas de suas limitações, principalmente quando se faz a alocação estática dos servidores (ou processos) às classes de usuários, o que pode não ser muito eficiente, devido ao fato da necessidade de se ter um conhecimento mais detalhado da carga que será imposta ao sistema, tornando-se inviável em um ambiente altamente dinâmico como a Web (FLOYD \& PAXSON, 2001).

Nessa abordagem, ao contrário do enfileiramento baseado em classes, o escalonamento buscando priorizar determinadas requisições é feito em cada nó do cluster, sendo escalonadas primeiro as requisições pertencentes às classes com maiores prioridades. A vantagem desta abordagem é que, havendo um balanceamento de carga eficiente, todos os recursos do sistema serão usados igualitariamente, pois não há reserva de recursos para determinadas classes. Além disso, a diferenciação de serviços é realizada de forma distribuída, ao contrário da abordagem anterior que depende de um componente central (controle de admissão) para esse fim. Desse modo, essa abordagem aumenta a confiabilidade e a escalabilidade do sistema, pois a responsabilidade associada à diferenciação de serviços é transferida para cada nó do cluster (HOLTON et al., 2009). 


\subsection{Implementação da Arquitetura SWDS}

Após a implementação do modelo para o ambiente real, a arquitetura SWDS esta sendo utilizada em uma plataforma de testes com o intuito de avaliar e testar algoritmos de controle de admissão e também algoritmos de escalonamento de requisições. O Web Cluster construído para o protótipo SWDS é baseado em uma arquitetura distribuída de servidores Web locais denominada Web Switch Layer-7 (CARDELLINI \& CASALICCHIO, 2002).

Nesse modelo foi delegada uma máquina com a responsabilidade de receber as requisições dos clientes (Frontend) e despacha-las para um servidor responsável por processa-la (Backend). O Frontend e os Backends são conectados por meio de uma rede local de alta velocidade. Após atender as requisições, o Backend envia a resposta de volta ao Frontend que, por fim, repassa-a ao cliente. O servidor que recebe as requisições (Frontend) em uma arquitetura de cluster de servidores Web é comumente chamado na literatura de Web Switch (CARDELLINI \& CASALICCHIO, 2002).

No trabalho de CARDELLINI et al (1999) são descritas e classificadas 4 arquiteturas de servidores Web.

- baseada no Cliente: nesse ambiente os documentos Web são direcionados pelo próprio cliente (através dos navegadores) para um servidor Web específico do cluster, visto que essas máquinas possuem replicação dos documentos;

- baseada no DNS: o processo de tradução do endereço para IP realizado pelos servidores DNS permitem que, a partir dessa funcionalidade sejam implementadas políticas que possibilite a distribuição de requisições de modo a selecionar o servidor Web apropriado;

- baseada em um Despachante: este cenário implementa um componente centralizado, no qual torna o cluster transparente para o usuário, sendo assim, o despachante (Web Switch) identifica cada servidor do sistema com um IP privado. Em Messias (2007) é descrito dois modos de operação do despachante, one-way e two-way;

- $\quad$ baseada em servidor: esta técnica consiste utilizar primeiramente um servidor DNS para atribuir a requisição do cliente para um nó dos servidores Web, em caso de sobrecarga o servidor pode atribuir a tarefa para outra máquina. YANG et al. (2007) utilizou essa arquitetura para o desenvolvimento de seu trabalho. 
A arquitetura SWDS implementada neste trabalho foi construída baseando-se no trabalho de ANDREOLINI (2004) e sua organização é mostrada na figura 7.

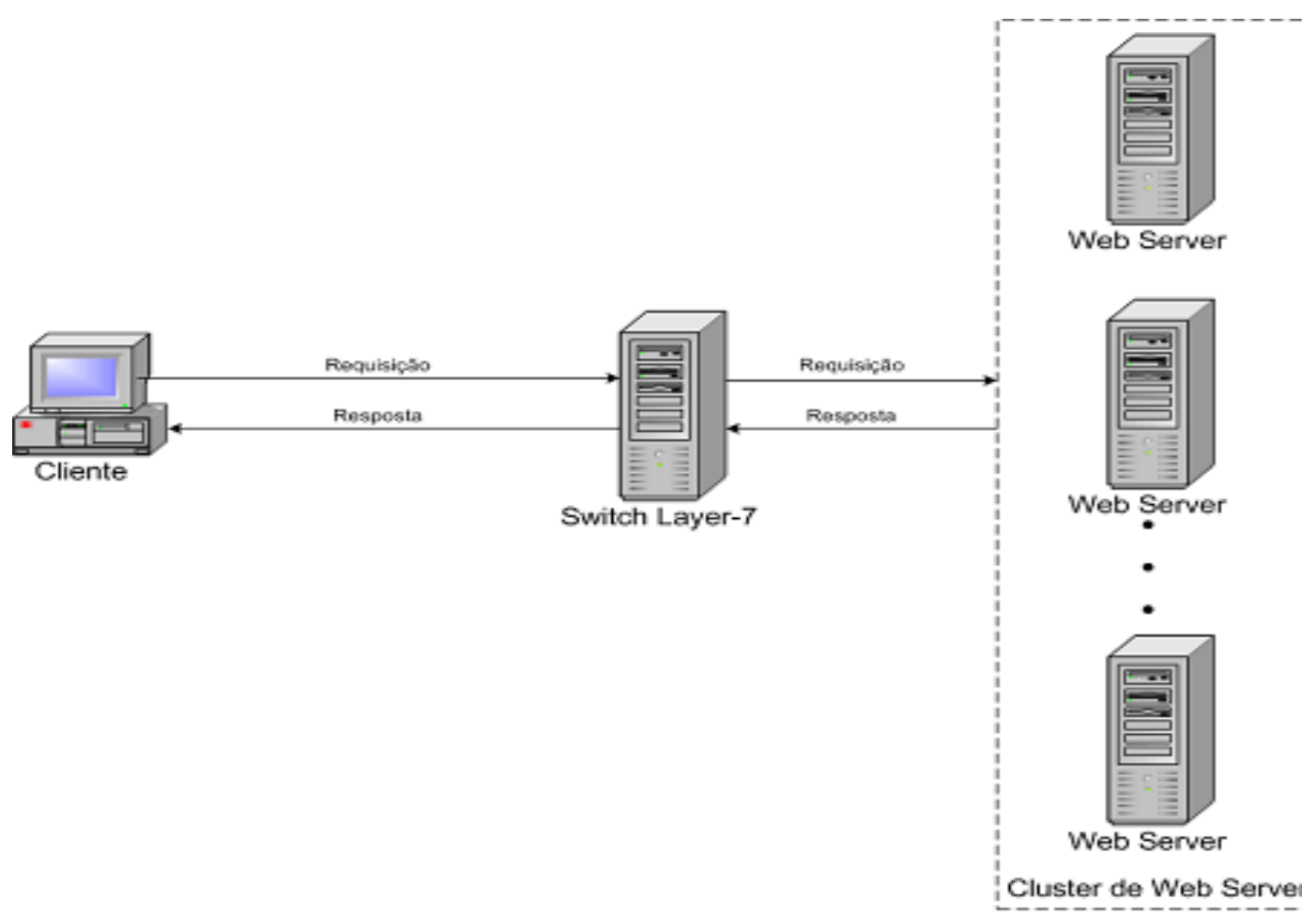

Para implementar os componentes do modelo SWDS foram utilizados o APACHE como software servidor e alguns módulos, denominados mod_rewrite, mod_proxy e mod_status (APACHE SOFTWARE FOUNDATION, 2009) juntamente com a técnica do proxy reverso (ENGESCHALL, 1998).

De acordo com a figura 8, o funcionamento do sistema consiste em: o servidor Web (Web Switch) é responsável por receber a requisição do cliente (1) e repassa ao mod_rewrite (2). Tal módulo tem o papel de classificar a requisição no sistema, sendo assim recebe a requisição e classifica-a a partir da informação da classe especificada na URI do cabeçalho HTTP. Em seguida, o mod_rewrite encaminha (3) a requisição para um programa externo ao APACHE chamado AdmControl, responsável pelo controle de admissão. O AdmControl possui três funções: a primeira é receber informações do tamanho da fila dos servidores, a segunda é realizar cálculos do algoritmo para decidir se descarta ou admite a requisição e, por fim, despachar a requisição segundo a política implementada (4). A comunicação entre o módulo mod_rewrite e o AdmControl é feita através de manipuladores de arquivos stdin/stdout. As 
informações de quantidade de requisições processadas pelo servidor Web são fornecidas com o auxilio de outro módulo do APACHE denominado mod_status. O mod_status captura a informação de carga do servidor e transmite, por arquivo, assim os monitores leêm este arquivo e utilizando sockets repassam para o Web Switch. Após a tomada de decisão, a requisição é repassada para o módulo mod_proxy $(5,6)$, que posteriormente encaminha a requisição para o servidor especificado pelo programa externo $(7,8,9)$. Por fim, a requisição é atendida pelo servidor selecionado e a resposta despachada de volta para o Web Switch, que novamente retorna para o usuário que a solicitou $(10,11,12)$.

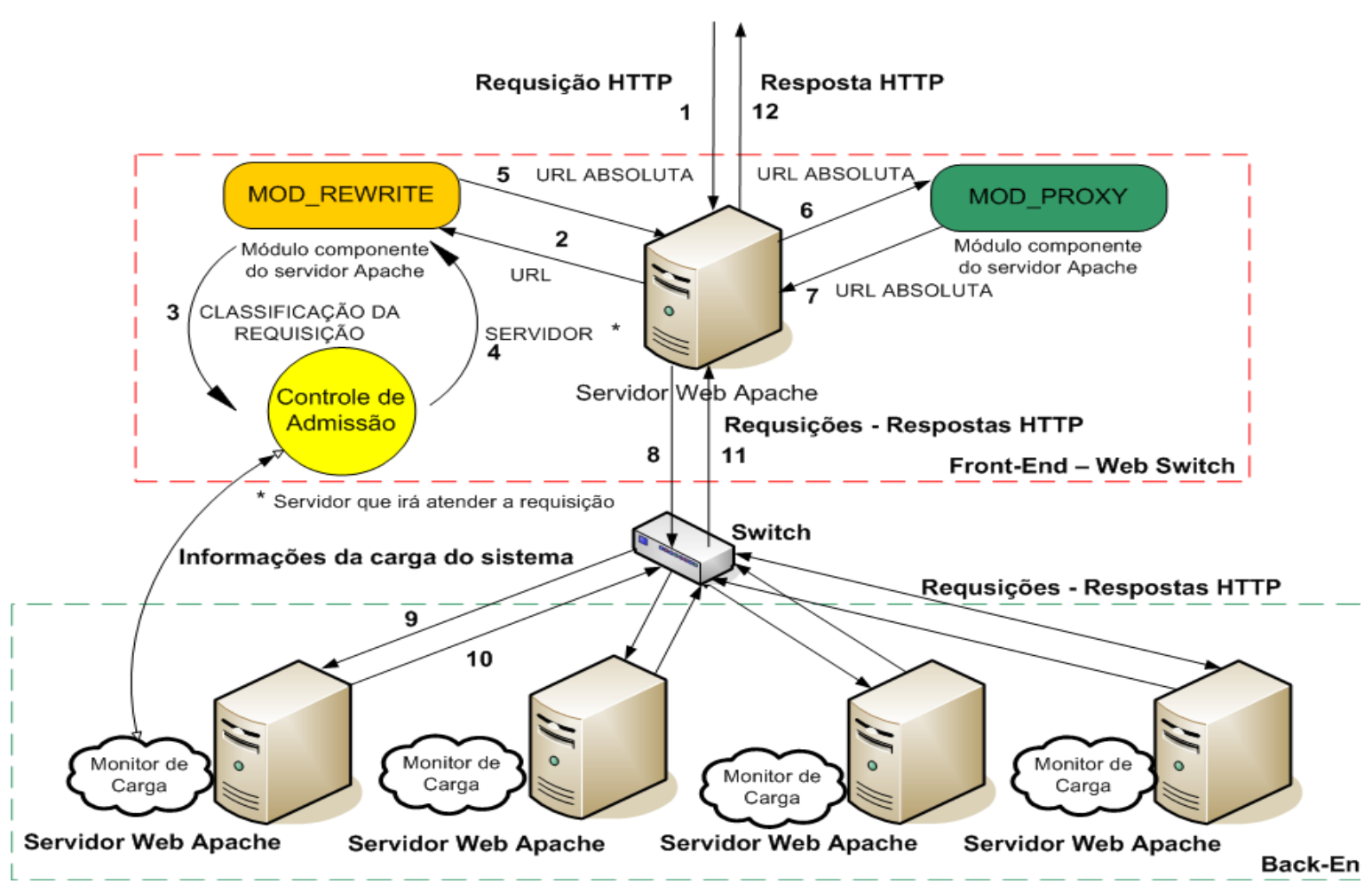

\subsection{1 mod_rewrite}

Desenvolvido por Ralf Engeschall (APACHE SOFTWARE FOUNDATION, 2009), o mod_rewrite possui a finalidade de reescrever URLs baseado-se em regras de expressão regular. Este módulo dá suporte a um número ilimitado de regras e condições, provendo assim, um mecanismo de manipulação de URL flexível e poderoso.

Para obter URLs mais flexíveis, o módulo mod_rewrite faz uso de diversos parâmetros, como por exemplo, variáveis do servidor, variáveis de ambiente e informações extraídas 
de cabeçalhos HTTP. O resultado da reescrita pode ser usado por um sub-processo interno, para redirecionamento externo ou para redirecionamento interno (na mesma rede local) através de um proxy.

Uma alternativa atrativa que o mod_rewrite oferece é a possibilidade de utilizar programas externos, em diversas linguagens, para realizar a reescrita de URLs. Para este trabalho, foram exploradas algumas dessas características do mod_rewrite para implementar o classificador e o controle de admissão no sistema. A seguir são descritas algumas diretivas no mod_rewrite utilizadas para a implementação do classificador:

- $\quad$ RewriteEngine: Habilita ou desabilita o mecanismo de reescrita;

- $\quad$ RewriteRule: Define regras para a reescrita de URLs;

- RewriteMap: Define uma função de mapeamento do tipo chave-valor que pode ser utilizada pela diretiva RewriteRule. Essa função pode ser estática (um arquivo texto contendo pares de chaves-valores, por exemplo) ou dinâmica (programas externos que lêem uma chave do RewriteRule através do manipulador de arquivo stdin e devolvem um valor correspondente a esta chave escrevendo o mesmo em stdout);

- $\quad$ RewriteLock: Define o nome de um arquivo (lockfile) para prover sincronização no RewriteMap.

O código 1 mostra as diretivas usadas para configurar o mod_rewrite no arquivo de configuração do Apache e uma explicação do funcionamento do mod_rewrite na implementação do SWDS. 
No código 1, é visto na primeira linha a habilitação do mecanismo de reescrita de URLs pelo mod_rewrite, logo abaixo é indicado o caminho do arquivo de sincronização de acesso ao programa externo (file.lock). O programa externo implementa os componentes classificador e controle de admissão da arquitetura SWDS.

Em seguida, é definido o caminho para o programa externo (admControl) que servirá como componente para reescrita de URLs, por fim o valor retornado pelo programa será atribuído a variável (prgmap) que completará URL (balancer://\$ prgmap $\} /$ ) na próxima linha do trecho. A diretiva $[\mathrm{P}]$ presente no final da regra significa que se trata de um redirecionamento interno para o mod_proxy usando a URL especificada. O restante do trecho de configuração será visto na próxima seção.

Mais informações sobre o mod_rewrite pode ser obtidas em (APACHE SOFTWARE FOUNDATION, 2009).

\subsection{2 mod_proxy}

Este módulo implementa um proxy/gateway para o Apache assim como mecanismos de proxy para AJP13 (Apache JServe Protocol versão 1.3), FTP, CONNECT (para SSL), HTTP/0.9, HTTP/1.0 e HTTP/1.1. O módulo pode ser configurado para se conectar a outros módulos de proxy, para estes e outros protocolos.

As características de proxy do Apache são divididas em vários módulos além do mod_proxy: mod_proxy_http, mod_proxy_ftp, mod_proxy_ajp, mod_proxy_balancer, e mod_proxy_connect. O Apache pode ser configurado como um proxy ou como um proxy reverso.

Um proxy é um servidor intermediário que fica entre o cliente e o servidor de origem. Para alcançar algum conteúdo no servidor de origem, o cliente envia uma requisição ao proxy, solicitando acesso ao servidor de origem e o proxy, então, faz a requisição ao servidor de origem, recebe a resposta e a repassa ao cliente. Um uso típico de um proxy é permitir acesso à internet para clientes internos à uma rede local que, caso contrário, são restringidos por um firewall. Um proxy também pode servir como cache (através do módulo mod_cache no Apache, por exemplo) para reduzir o uso da rede.

Outra forma é o proxy reverso, ao contrário do modo anterior, os clientes apenas visualizam um servidor Web comum. Nenhuma configuração especial no cliente é necessária. O cliente faz seus pedidos normalmente ao proxy reverso e este decide para onde enviar esses pedidos, repassando o conteúdo ao cliente de forma transparente, como se ele mesmo tivesse 
processado a requisição. Uma utilização prática do proxy reverso é permitir realizar o balanceamento de carga entre alguns servidores Backends em um cluster de servidores por exemplo (ENGELSCHALL, 1998), ou para prover mecanismos de cache para um servidor Backend mais lento. O mod_proxy possui alguns algoritmos já implementados, como por exemplo, Round Robin, Shortest Job First, Weighted Traffic Counting.

Como foi visto anteriormente, o Apache pode ser configurado como proxy reverso na diretiva RewriteRule, utilizando a flag $[\mathrm{P}]$. Mais detalhes sobre mecanismos de proxy do software podem ser obtidos em APACHE SOFTWARE FOUNDATION (2009).

O trecho de código abaixo mostra o arquivo de configuração do APACHE modificado para ser utilizado como proxy.

Percebe-se que, a saída do programa externo (class1 ou class2) completará a URL (balancer://\$ $\{$ prgmap $\} /)$ definida no trecho do mod_rewrite e posteriormente a requisição é enviada para um desses dois grupos de máquinas e, consequentemente, processada. Para obter um grau de diferenciação de serviço entre as classes determinadas foi configurado uma quantidade maior de máquinas para atender a classe 1 (classe de maior prioridade) do que a classe 2.

\subsection{3 mod_status}

Este módulo possibilita o administrador recuperar métricas de desempenho do seu sistema. Essas informações do servidor são facilmente extraídas através da apresentação de uma página HTML no qual o administrador pode configurar para ser atualizada periodicamente. As informações recuperadas pelo módulo são: 
- $\quad$ O número de threads (ou processo) ociosos;

- $\quad$ O status de cada thread (ou processo), o número de requisições que as threads (ou processo) tem executadas e o número total de bytes processados pela thread (ou processo);

- $\quad$ O número total de acessos e a contagem de bytes processados;

- $\quad$ O tempo total de execução do servidor;

- A média dada pelo número de requisições por segundo, o número de bytes processados por segundo e a média do número de bytes por requisição;

- $\quad$ A porcentagem atual de CPU usada por cada thread (ou processo) e o total executado pelo APACHE.

Mais detalhes sobre o funcionamento ou informações sobre esse módulo podem ser obtidos em APACHE SOFTWARE FOUNDATION (2009).

No presente trabalho, esse módulo é usado para auxiliar o sistema de monitoramento implementado no protótipo atual do SWDS. Além do módulo mod_status, o sistema consiste de outros dois programas hospedados nas máquinas Backend, sendo o primeiro programa desenvolvido em linguagem Perl e o segundo programa em C.

O programa em Perl tem a funcionalidade de conectar-se com o servidor Web local (Backend) e requisita uma página fornecida pelo módulo contendo todas as informações do servidor. Após essa operação, o programa realiza uma filtragem neste conteúdo e extraí somente as métricas necessárias, posteriormente os valores destas métricas são gravados em um arquivo texto.

O programa desenvolvido em $\mathrm{C}$ possui a lógica de coletar essa informação gravada em arquivo texto e transferir, utilizando a biblioteca de sockets, periodicamente para o processamento no Web Switch.

Vale ressaltar que, depois de alguns experimentos utilizando algumas informações fornecidas pelo sistema operacional como utilização de CPU ou, utilização de memória RAM para descarte de requisições. Com isso, foi observada a necessidade do uso de métrica representativa para essa análise. Nesse caso, o módulo mod_status passou a ser usado após uma observação realizada no trabalho de XIONG et al (2005), no qual referem-se ao uso de uma métrica representativa para um sistema de carga baseada no número de conexões ocupadas do servidor. 


\subsection{Trabalhos Relacionados}

Atualmente, o GSDPC possui uma grande base de conhecimento aplicada à diferenciação de serviço em servidores Web, construída a partir do desenvolvimento de diversos trabalhos nos últimos anos. Em todos esses trabalhos o modelo SWDS proposto por (TEIXEIRA, 2004) foi utilizado como base para o desenvolvimento.

O trabalho de MOURÃO (2006) propôs incorporar um módulo adicional ao modelo SWDS, tornando-o capaz de realizar o reconhecimento de sessões.

Em SILVA (2006) foi apresentado um software gerador de carga sintética, denominado W4Gen (World Wide Web Workload Generator), para exercitar os servidores Web do modelo SWDS. Para o programa foram consideradas algumas categorias de requisições, o que possibilitou a composição de cargas diferenciadas que representam vários cenários reais. Essa ferramenta foi desenvolvida utilizando-se a linguagem Java e também algumas bibliotecas de estatística para a distribuição de probabilidade de alguns parâmetros de carga. Através desse trabalho foi possível rever a caracterização da carga de trabalho dos servidores Web, baseando-se em quatro características: o intervalo de chegada das requisições, as classes de objetos, o código de resposta e o tamanho dos objetos.

Em ESTRELLA (2006) foram desenvolvidos dois algoritmos, cuja finalidade é realizar negociações no módulo de controle de admissão. Sendo assim, o objetivo foi reduzir o tempo de resposta das requisições com alta prioridade e também dar uma nova chance às requisições, de modo que elas não fossem descartadas.

Outro trabalho abordado é o de TRALDI et al. (2006), no qual foram desenvolvidos dois algoritmos para diferenciação de serviços, um deles denominado RSVAdap e o outro Weighted Fair Queuing (WFQ). O primeiro consiste em reservar recursos de forma dinâmica, no caso de servidores Web são alocadas máquinas de acordo com a demanda dos usuários, e o segundo é baseado no WFQ existente para a camada de rede, onde as requisições são divididas e para cada uma delas é atribuído um peso de acordo com sua classe de prioridade. Assim, o atendimento é calculado com base nesse peso e em uma previsão do término do processamento da mesma.

Em BARROS et al. (2008) foi introduzida uma nova forma de seleção e descarte das requisições ao módulo de controle de admissão do SWDS, baseando-se em lógica fuzzy. O funcionamento consiste em um controlador PI (Proportional-Integrated) que efetua cálculos, tendo como parâmetro de entrada a porcentagem de utilização do cluster. Posteriormente, o 
resultado é enviado para um componente denominado máquina de inferência, no qual possui duas matrizes associativas preenchidas com conjuntos de regras de execução baseada no conhecimento do comportamento do SWDS. Os testes desses experimentos foram realizados utilizando o controle de admissão com e sem o uso de lógica fuzzy. Os resultados mostram a redução de $50 \%$ no tempo de resposta na classe de maior prioridade e a diminuição na variabilidade da taxa de utilização do sistema.

\subsection{Considerações Finais}

Neste capítulo foi abordado o modelo do servidor Web com diferenciação de serviço (SWDS), proposto na tese de doutorado de Mário M. Teixeira (TEIXEIRA, 2004) e que serviu de ponto de partida para diversos trabalhos desenvolvidos no GSDPC nos últimos anos. Esse modelo servirá também como base para o projeto a ser desenvolvido neste trabalho de mestrado. As principais características do modelo SWDS, bem como alguns trabalhos desenvolvidos a partir do mesmo, foram apresentadas, visando a ampliar a visão geral do tema com o objetivo de facilitar o desenvolvimento do protótipo previsto neste trabalho de mestrado. 


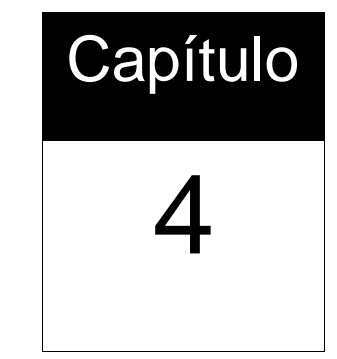

\section{Algoritmo de Controle de Congestionamento}

\subsection{Considerações Iniciais}

O controle de tráfego é a palavra-chave para a estabilidade de uma rede (ELLOUMI \& AFIFI, 1997). A fim de lidar com congestionamento, os elementos de rede (links, roteadores, etc) implementam grandes filas (buffer) para que os pacotes esperem por processamento. Com o decorrer do tempo, essas filas podem aumentar, de forma substancial, a latência e causar grandes rajadas. Por isso, os roteadores fazem uso de algoritmos de enfileiramento para controlar a sobrecarga em suas filas.

Neste capítulo serão mostrados os aspectos principais de dois algoritmos utilizados como controladores de congestionamento em redes: o Drop Tail e o RED. O método RED (Random Early Detection), desenvolvido por FLOYD \& JACOBSON (1993), é o algoritmo mais conhecido e por isso será o método mais enfatizado neste trabalho. Como dito anteriormente, o mecanismo RED é bastante empregado como gerenciador de fila em roteadores de redes, sendo que neste trabalho os dois mecanismos mencionados serão inseridos como algoritmo de controle de admissão no protótipo SWDS.

\subsection{Gerenciamento Ativo de Filas - AQM}

O crescimento da Internet gerou um aumento exponencial no tráfego de pacotes na rede, tendo como resultado problemas de sobrecarga inerentes aos equipamentos. Um exemplo desse problema é o congestionamento, onde essa situação é ocasionada devido ao excesso de carga imposta gerando uma redução do desempenho. Sendo assim, os pacotes transmitidos serão completamente entregues em cenários onde a capacidade de utilização da rede é baixa, em um cenário oposto ocorrerá a rejeição destes pacotes. Em um ambiente de 
alto tráfego nenhum pacote alcançará o destino. A figura 9 apresenta o gráfico mostrando a entrega e congestionamento de pacotes.

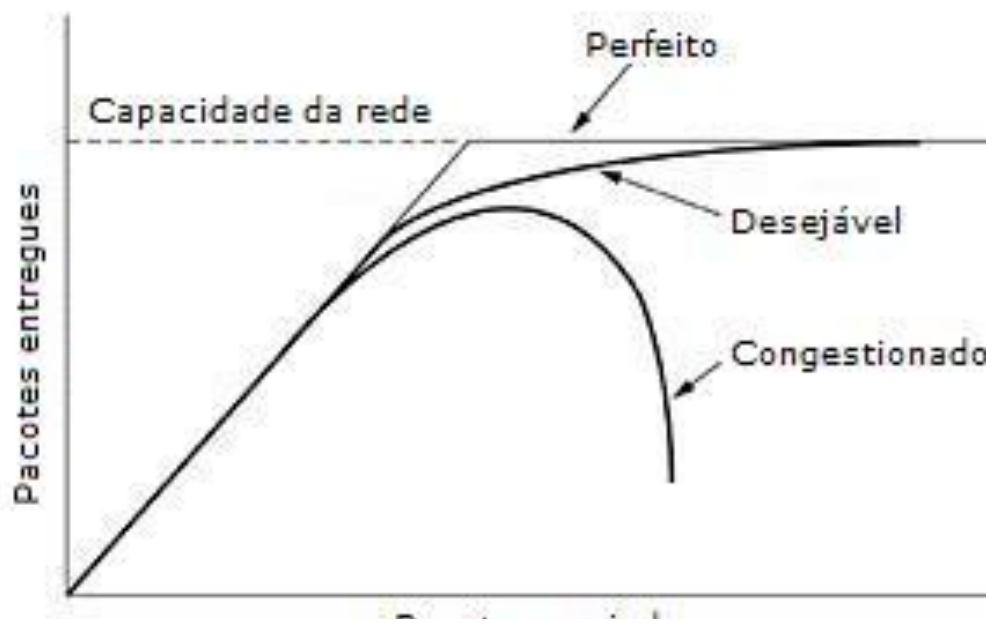

Os possíveis fatores que proporcionam congestionamento em um ambiente de rede são: os roteadores possuem processadores lentos; incompatibilidade entre sistemas; linhas de baixa largura de banda; ou vários transmissores concorrem por roteador/link compartilhado (ABBASOV \& KORUKOGLU, 2009).

Os mecanismos de controle de congestionamento nos roteadores monitoram em tempo o tamanho da fila, sendo capazes de detectar um congestionamento e tomar decisões após esta notificação. Dentre os mecanismos de controle de congestionamento presentes nos roteadores estão os algoritmos de gerenciamento de filas, que procuram conciliar da melhor maneira as métricas de utilização de recurso do equipamento com o processo de descarte.

Torna-se vantajoso fazer o uso de filas, pois as requisições enviadas são armazenadas temporariamente para posteriormente serem processadas, aumentando, assim, a vazão (ou throughput). Para esse fim, os algoritmos de gerenciamento de filas possuem o propósito de complementar os algoritmos de controle de congestionamento a fim de prover níveis de qualidade de serviço (FENG et al., 1999). A funcionalidade desses algoritmos é gerenciar o tamanho das filas ou utilização do link no gateway (nesse caso pode-se considerar a fila dos servidores $(\mathrm{eb})$, sendo realizado o processo de descarte ou de aceitação de pacotes quando apropriado (ARCE et al., 2003).

Uma das formas mais comuns de combate ao congestionamento é fazer o descarte de requisições quando necessário. $\mathrm{O}$ descarte de pacotes deve ser feito de acordo com alguma 
política definida para prevenir ou combater o congestionamento. Tais políticas devem fazer o descarte seletivo de pacotes baseados em alguns requisitos. Em LABRADOR \& BANERJEE (1999) são apresentados alguns critérios para descarte de pacotes na rede.

\subsubsection{Drop Tail}

Partindo dessa necessidade, um método tradicional de gerenciamento de filas é definido pelo algoritmo Drop Tail, pois seu funcionamento consiste em descartar as requisições quando ultrapassar o valor máximo da fila (FIROIU \& BORDEN, 2000). Entretanto, BRADEN et al. (1998) menciona que esse método possui dois pontos negativos em ambientes de rede e, ao final aponta uma solução para tais pontos. O primeiro ponto fraco é permitir que uma simples conexão monopolize o espaço da fila, enquanto outras conexões têm seus pacotes descartados devido à falta de espaço, em segundo, o Drop Tail possibilita que a fila esteja cheia por um longo período, causando uma redução na vazão. A alternativa apresentada por BRADEN et al. (1998) para resolver essas restrições é descartar os pacotes de maneira aleatória. Na figura 10 pode-se observar, graficamente, o comportamento do método Drop Tail.

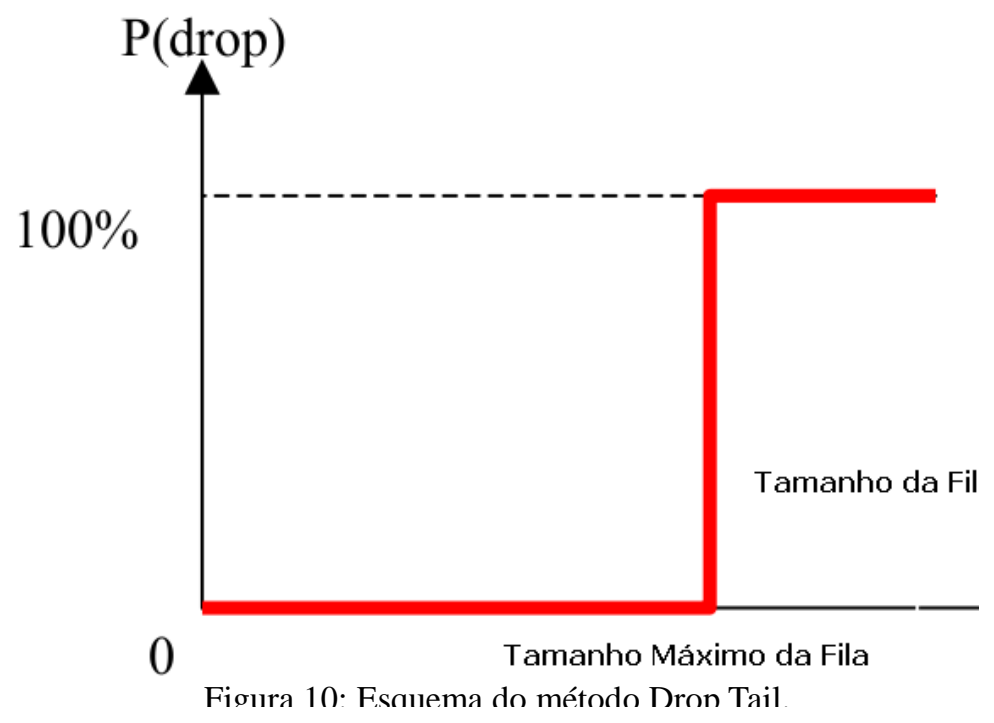


Resumindo, o objetivo de um algoritmo de enfileiramento é que, de forma inteligente, se possam descartar pacotes (ou requisições) antes de ocorrer congestionamentos, ou sobrecargas no elemento gerenciado.

\subsubsection{RED (Random Early Detection)}

Como dito anteriormente, entre os diversos algoritmos de gerenciamento de fila, o RED foi apresentado por FLOYD \& JACOBSON (1993) e tem como finalidade prevenir congestionamentos, ao contrário de corrigi-los. Essencialmente, o algoritmo RED é basicamente formado por duas partes.

Uma dessas partes possui a responsabilidade de realizar o cálculo do tamanho médio da fila, para isso é utilizada a fórmula de média móvel exponencial (weigthed moving average), ou seja, um filtro passa-baixa para filtrar na média uma possível ocorrência de congestionamento. O valor obtido dessa primeira etapa é usado na segunda fase no método RED para tomada de decisão da requisição (STALLINGS, 2002).

O funcionamento do mecanismo consiste em calcular o valor médio da fila e, posteriormente, compará-lo com os limites Mínimo e Máximo (MINth e MAXth, respectivamente). Na figura 11, pode-se observar que os limites demarcam três áreas na fila, sendo que, a primeira área (verde) é composta de valores abaixo do limite mínimo, isto significa que o sistema está em uma área de estabilidade, portanto todas as requisições serão aceitas (nenhuma requisição será descartada). A outra, a área em vermelho, está relacionada com valores maior do que o limite máximo, significando que a máquina está em estado de sobrecarga, por isso toda requisição será rejeitada. A outra possibilidade é se o mesmo estiver entre os limites indicando inicio de congestionamento, pois nesta região a probabilidade de uma requisição ser marcada durante a área de prevenção de congestionamento é proporcional a quantidade de requisições aceitas pelo sistema. A figura 11 apresenta o comportamento do algoritmo RED, através das suas três áreas de atuação definidas a partir dos limiares MINth, MAXth, e da probabilidade Pmax. 


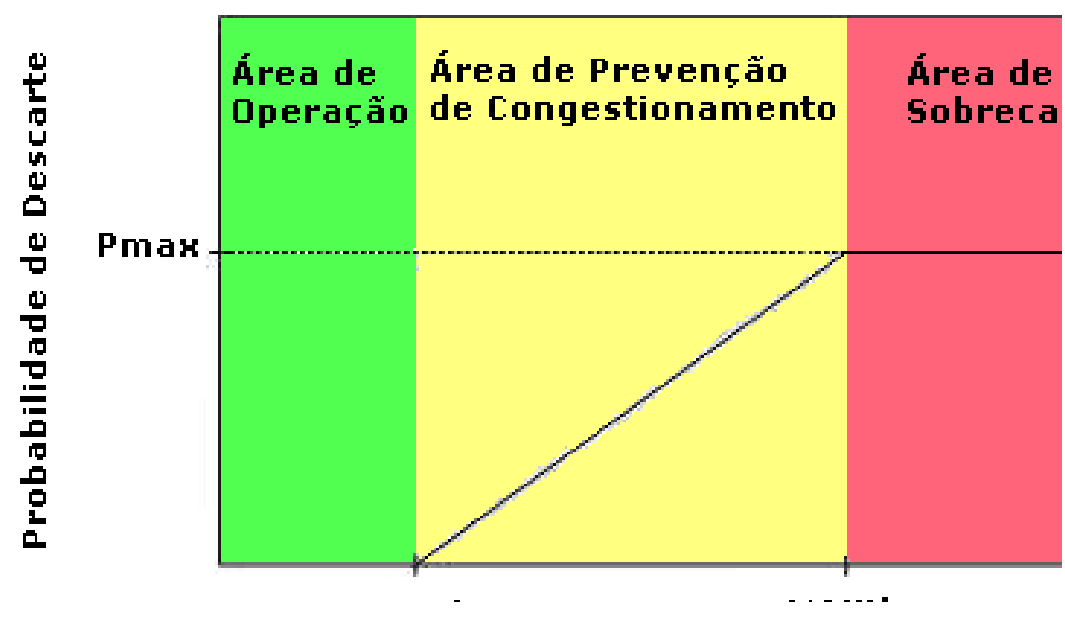

Nas próximas seções serão detalhadas e explicadas as fórmulas aplicadas pelo método RED para cálculo do tamanho médio da fila e probabilidade de descarte.

\subsubsection{Detalhes do mecanismo RED}

Como dito nesta seção, o algoritmo RED utiliza o cálculo do tamanho da fila utilizando um filtro passa baixa, que nada mais é do que a função de média móvel exponencial, conforme mostrado a seguir.

$$
\operatorname{avg}(t)=(1-w q) * \operatorname{avg}(t-1)+w q * q
$$

onde:

avg é o tamanho médio da fila.

wq é o peso.

q é o valor instantâneo do tamanho da fila.

Segundo DANA \& MALELDOO (2010), o parâmetro fixo $w q$ (peso da fila) determina o quão rápido $a v g$ muda em resposta à mudança do tamanho atual da fila $\mathrm{e}, \mathrm{o}$ autor sugere que o valor de wq seja $0 \leq \mathrm{wq} \leq 1$. Caso o valor desse parâmetro seja muito baixo, o cálculo do valor do tamanho médio da fila irá refletir o valor atual da fila (q) com um retardo muito grande. Ou seja, o tamanho médio da fila não refletirá as mudanças repentinas no tamanho atual da fila. 
Na figura 12 é representado o resultado de uma simulação do comportamento de um sistema que faz uso da média móvel exponencial. Essa simulação foi feita utilizando o programa Excel, da Microsoft, no qual é verificada a reação do parâmetro $w q$ de acordo com a variação do valor da quantidade real.

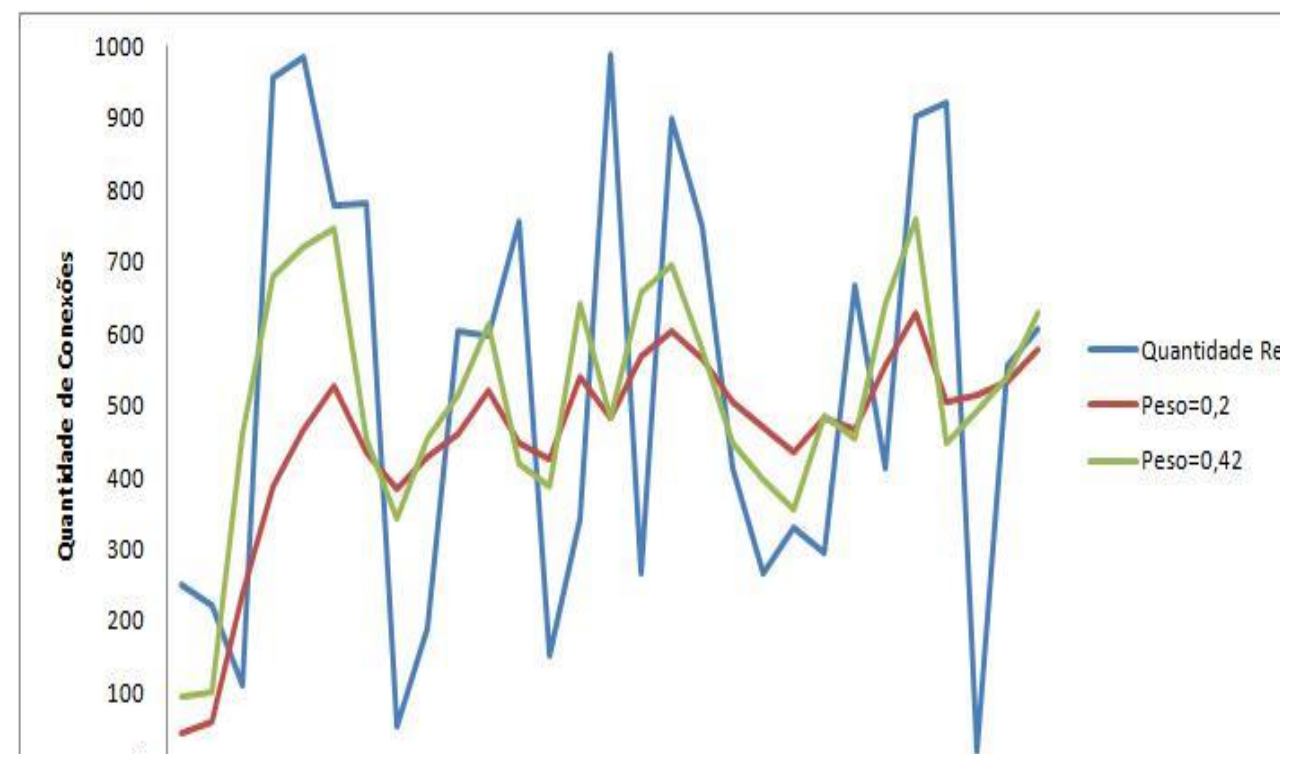

A região crítica é atingida quando o valor de avg estiver entre os dois limiares de mínimo e máximo. No trabalho de BARBOSA (2008) é mencionado que o algoritmo RED assume a probabilidade de descarte para uma requisição de acordo com dois fatores:

- Quanto mais próximo avg estiver de THMAX, maior a probabilidade de descarte;

- Enquanto avg estiver na região crítica, mantém-se uma variável contadora (count) do número de requisições consecutivas que escaparam do descarte; quanto maior o valor de count, maior a probabilidade de descarte.

O cálculo da probabilidade de descarte $(P a)$ de uma requisição está em função dos dois limiares, do tamanho médio da fila e do número de requisições desde a última ocorrência de descarte, sendo que, seu comportamento varia linearmente entre zero e Pmax.

A probabilidade máxima ( $P \max$ ) determina a oscilação da taxa de descarte no sistema, se o valor de Pmax for configurado com um número pequeno, então seu comportamento será 
semelhante ao método Drop Tail. Entretanto, se esse valor for configurado com um valor alto, isso forçará que o sistema oscile severamente e diminua a vazão.

As fórmulas descritas a seguir são empregadas no cálculo da probabilidade de descarte $P a:$

$$
\begin{aligned}
& P a=P b /(1-\text { count } \times P b), \\
& P b=P \max \times(\text { avg }- \text { MINth }) /(\text { MAXth }- \text { MINth })
\end{aligned}
$$

Se o tamanho médio da fila é mantido constante, todos os pacotes que chegam têm a mesma probabilidade de descarte. Um exemplo de implementação do algoritmo RED pode ser visto no código 3.

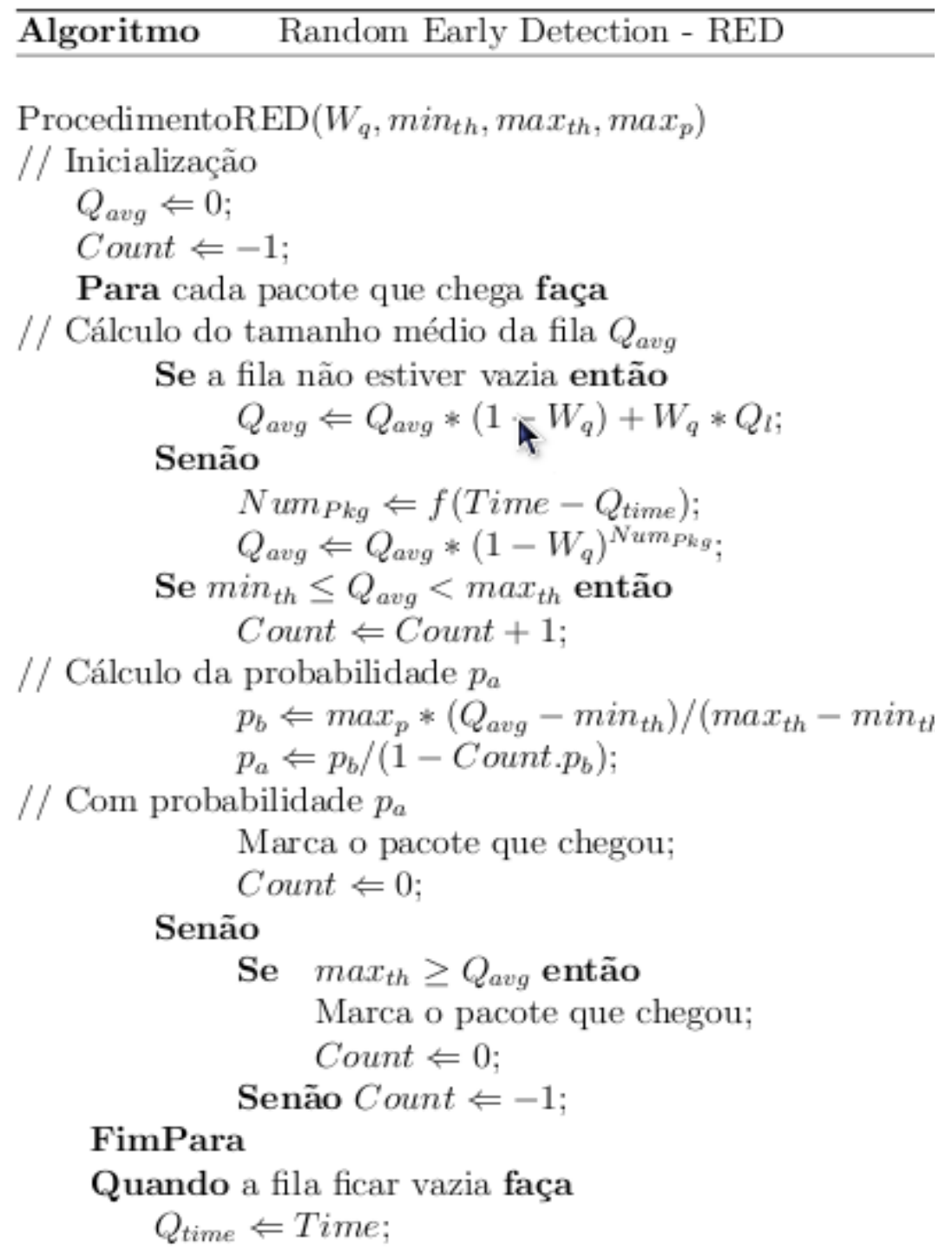


onde:

$P b$ é uma probabilidade temporária usada no cálculo de $P a$.

Pmax é o valor máximo que $P b$ pode atingir.

count é o número de requisições aceitas desde o último descarte.

Como avaliação, alguns trabalhos descrevem os pontos fortes do método, como exemplo pode-se mencionar o trabalho de MAHAJAN et al. (2001), no qual são mostradas as vantagens do método RED, em nível de rede, comparado ao Drop Tail. Tais vantagens podem ser resumidamente descritas como segue:

- Pacotes descartados são usados como um mecanismo para diminuir a taxa de transmissão;

- $\quad$ O buffer não precisa se encher por completo, pois, senão já será muito tarde e terá que eliminar muitos pacotes;

- $\quad$ O RED fornece uma rápida indicação de congestionamento;

- A aleatoriedade do algoritmo reduz o problema de sincronização, que faz as fontes reduzirem a taxa de transmissão simultaneamente.

Entretanto, no trabalho de ABBASOV \& KORUKOGLU (2009) são mencionada algumas dificuldades encontradas com a implantação deste algoritmo, como segue:

- $\quad$ O desempenho do método RED é altamente sensível com seus parâmetros. Pelo menos quatro parâmetros, limite mínimo $(M I N t h)$, limite máximo (MAXth), peso $(w q)$, probabilidade máxima de descarte (Pmax) devem ser configurados apropriadamente;

- $\quad$ É sensível ao número de pacotes/fluxos em competição;

- $\quad$ É sensível ao tamanho do pacote;

- $\quad$ É possível observar a oscilação do buffer em alterações de carga.

Além da dificuldade de configuração dos parâmetros, no trabalho de MAY et al (1999) é concluído através de experimentos que na maioria dos cenários propostos, o método RED não foi capaz de atingir resultados satisfatórios em relação ao Drop Tail. Portanto, na próxima 
seção 4.3 serão vistos alguns trabalhos que propuseram aperfeiçoar, ou solucionar, tais pontos negativos encontrados no algoritmo RED.

\subsection{Trabalhos Relacionados}

Dentre as desvantagens do algoritmo RED observadas na literatura estão a dificuldade em definir valores para os parâmetros a fim de atingir um ponto operacional dentro de um determinado cenário; provocar injustiça no momento de descarte e proporcionar instabilidade no sistema. Com o intuito de solucionar essas questões, diversos trabalhos foram desenvolvidos, criando assim diversas variantes do mecanismo RED. Por exemplo, ALEMU \& JEAN-MARIE (2004) e FLOYD et al. (2001) desenvolveram um mecanismo denominado ARED (Adaptive Random Early Detection) o qual foi simulado e empregado em nível de rede e possui a finalidade de aperfeiçoar a capacidade de previsão de fila do mecanismo, reduzir o atraso de jitter, e de forma automatizada configurar seus parâmetros independentes de demanda. OTT et al., (1999) analisou outra variante denominada SRED (Stabilized Random Early Detection); embora possua grande semelhança com o RED, mas com uma característica adicional, os altos níveis de carga auxiliam na estabilização da fila independente da sua utilização. AWEYA et al., (2001) elaborou o DRED (Dynamic Random Early Detection) no qual é aplicado a teoria de controle na tentativa de reduzir as oscilações do tamanho médio da fila que ocasiona como resultado a instabilidade na rede. VUKADINOVIĆ \& TRAJKOVIĆ (2004) propôs um novo algoritmo de gerenciamento de fila chamado RED-DT (Random Early Detection with Dynamics Thresholds) que, aplicado em redes, adapta os limites dinamicamente de modo conseguir uma distribuição mais justa na capacidade do link.

Outros trabalhos focaram em investigar técnicas que auxiliassem o algoritmo RED, como exemplo, JIANG et al., (2004) baseou-se em análises teóricas e simulações de rede e mostrou que o desempenho do mecanismo RED pode ser melhorado ajustando os parâmetros utilizando DFC (Delayed Feedback Control). ARCE et al. (2003) propôs modificar o cálculo do tamanho médio da fila utilizando um filtro adaptativo de mediana com peso (WM), no qual um vetor com valores de tamanho anteriores é criado e através desse vetor é calculada a fila atual usando a mediana. No trabalho de SUN (2007) foi utilizado um controlador com conceito de lógica fuzzy para ajustar o parâmetro de probabilidade máxima de descarte. 
Durante o desenvolvimento deste trabalho de mestrado, somente dois trabalhos anteriores utilizando o mecanismo RED dentro do contexto de servidores Web foram encontrados (YANG et al. (2009) e BARBOSA (2008)).

YANG et al. (2009) elaborou uma arquitetura de balanceamento de carga por DNS em um cluster de servidores Web no qual essas máquinas servidoras notificavam ao servidor DNS suas informações de carga. O objetivo do trabalho era utilizar o método RED para que fosse mantido os limites de utilização das máquinas entre os limiares mínimo e máximo especificado nos experimentos.

BARBOSA (2008) desenvolveu e analisou o comportamento do algoritmo como controle de admissão na arquitetura SWDS utilizando simulação. Neste trabalho de mestrado, o objetivo é realizar os experimentos com implementação do algoritmo em ambiente real.

\subsection{Considerações Finais}

Neste capítulo foram discutidos os algoritmos Drop Tail e RED. Para o RED foram descritas as fórmulas, o funcionamento e a implementação do mecanismo em pseudocódigo, bem como foram mencionados alguns trabalhos que discutem detalhes a respeito do algoritmo RED. Como pôde ser visto, a maioria dos trabalhos referenciados foram aplicados em ambientes de rede e simulados utilizando algum software, existindo poucos trabalhos que mostram a utilização do RED juntamente com servidores Web.

Com isso, uma das propostas desta dissertação é aplicar o algoritmo RED como controle de admissão de requisições HTTP na arquitetura SWDS, implementando no protótipo estabelecido, observar e analisar seu comportamento mediante diferentes cargas de trabalho. 


\section{Planejamento dos Testes e Resultados Experimentais}

\subsection{Considerações iniciais}

Neste capítulo é descrito o planejamento dos experimentos que foram realizados com o protótipo de servidor Web distribuído, baseado no modelo SWDS, juntamente com a implementação dos mecanismos de controle de congestionamento (RED e Drop Tail) utilizados como algoritmo do controle de admissão.

Neste capítulo são apresentados os resultados obtidos através dos experimentos realizados com o sistema. Primeiro são apresentados os resultados referentes aos algoritmos de controle de admissão, o RED e o Drop Tail.

Os resultados dos experimentos visam a verificar se os algoritmos propostos e implementados no protótipo conseguem fornecer qualidade de serviço, com diferenciação adequada no atendimento entre as classes consideradas, como também observar o comportamento do modelo e dos algoritmos em um ambiente real e com a utilização de geradores de carga para produzir as requisições às páginas Web.

As medições de quantidade de requisições descartadas e a média dos tempos de respostas fim-a-fim foram realizadas em máquinas clientes e utilizadas como métrica para a comparação dos resultados entre os algoritmos.

\subsection{Cenário dos Experimentos}

Após o término da implementação do protótipo da arquitetura SWDS e o desenvolvimento dos algoritmos de controle de admissão, prosseguiu-se até a fase de planejamento e execução dos experimentos. Os experimentos foram executados através de 
medições realizadas nos clientes que, por sua vez, tinham a finalidade de exercitar o protótipo do servidor Web distribuído, construído de acordo com o modelo de arquitetura proposto por Teixeira (2004) e descrito neste trabalho no capítulo 3.

As avaliações a partir de medições em ambientes reais proporcionam algumas vantagens, pois levam em consideração diversas sobrecargas como, por exemplo, a latência da rede, que acabam muitas vezes sendo ignorados em ambientes simulados.

Para avaliar o sistema foram consideradas duas classes de serviço onde a classe 1 possui prioridade maior do que a classe 2. Nos experimentos, para oferecer qualidade de serviços às classes o cluster de máquinas (Backend) foi particionado em dois grupos, de modo a oferecer uma quantidade maior de servidores para a classe de maior prioridade. Para isso, o ambiente de teste foi composto por nove máquinas, sendo duas máquinas como clientes (uma máquina simula clientes de classe 1 e uma máquina simula clientes da classe 2), um computador como Web Switch, quatro máquinas para atender à classe 1 e duas máquinas para atender à classe 2. A figura 13 mostra a arquitetura geral considerada no teste.

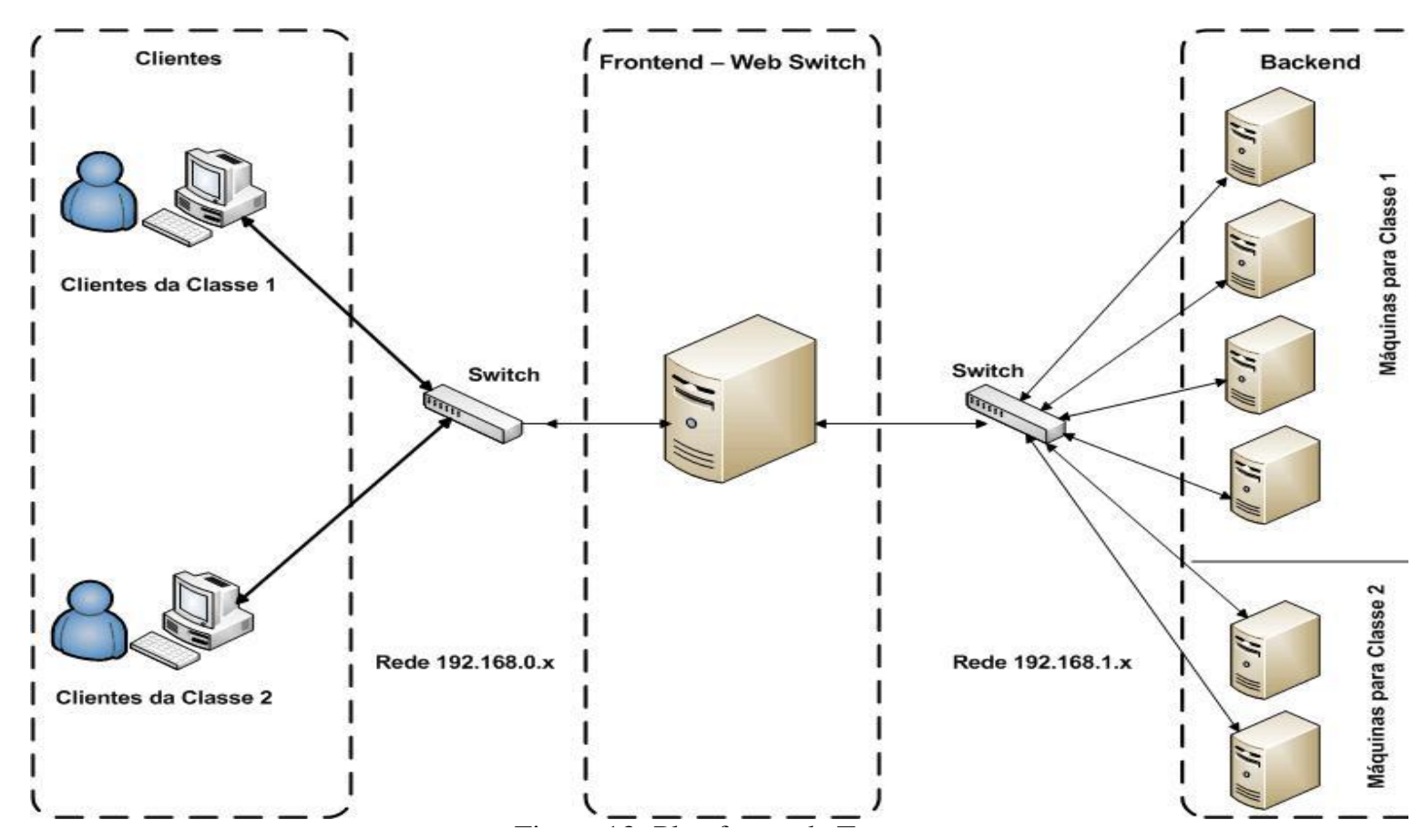

As máquinas utilizadas nesta implementação da arquitetura SWDS são homogêneas, exceto o Web Switch, pois este possui uma configuração mais robusta devido ao fato de ser considerado o "gargalo" do sistema. Pode ser visto na tabela 2 as configurações de hardware e software utilizados nos experimentos. 
Tabela 2: Configuração das máquinas utilizadas nos experimentos.

\begin{tabular}{|c|c|}
\hline Configuração de Hardware & Configuração de Software \\
\hline Clientes - Core 2 Duo 1.73; 2 GB de & Ubuntu Linux kernel 2.6. ; Httperf \\
RAM; & \\
\hline Web Switch - Core 2 Quad 2., 6 GB de & Ubuntu Server 9.04 kernel 2.6; Apache \\
RAM; & HTP Server v. 2.2.2 \\
\hline Backend - Core 2 Quad 2., 2 GB de & Ubuntu Server 9.04 kernel 2.6; Apache \\
RAM; & HTTP Server v. 2.2.1 \\
\hline
\end{tabular}

Para a geração da carga de trabalho dos experimentos, foram analisadas várias possibilidades. Por exemplo, alguns trabalhos como ESTRELLA (2006) e MOURÃO (2006), utilizaram traces de acessos coletados de um servidor Web durante a copa do mundo de 1998 (ARLITT \& JIN, 2000) como base para a geração da carga de trabalho. Esses traces não são adequados para os experimentos considerados nesta dissertação, uma vez que correspondem à uma carga antiga e não representativa para o caso considerado.

Em INTERNET TRAFFIC ARCHIVE (2009) podem ser obtidos traces mais atualizados, disponíveis tanto como $\operatorname{logs}$ de servidores Web, como também como dados de tráfego de pacotes TCP na rede. Uma outra abordagem que pode ser adotada é o uso de distribuições matemáticas para modelar a chegada de requisições no servidor, como por exemplo a distribuição de Paretto, exponencial (Poisson), etc.

Após uma análise geral das possibilidades existentes, decidiu-se utilizar uma carga de trabalho próxima de um ambiente real, provida pelo HTTPERF (MOSBERGER \& JIM, 1998), que constitui um gerador de carga sintética, instalado em cada uma das máquinas clientes. Esta ferramenta de geração de carga possui características adequadas para os experimentos executados neste trabalho, sendo bastante em experimentos com Web cluster, como pode ser visto em SHARIFIAN et al. (2009), SHAN et al. (2005).

Durante os experimentos foi observado que a ferramenta HTTPERF contabiliza de forma única tanto as requisições aceitas no sistema, como as rejeitadas. Isso não é adequado aos propósitos deste trabalho, uma vez que requisições aceitas e requisições rejeitadas têm tempos de resposta distintos (o ciclo de processamento de uma requisição aceita é maior do que uma requisição rejeitada). Assim, visto que a ferramenta contabiliza a média de ambos os tipos de requisições (aceitas e descartadas), foram feitas algumas alterações no código fonte do gerador de carga, com o objetivo de contabilizar somente as requisições aceitas pelo 
controle de admissão.

Após alguns testes preliminares foi observado que páginas com características estáticas não eram suficientes para exercitar o cluster de máquinas servidoras como esperado. Observou-se também que técnicas como cache poderiam agilizar o processo e, como consequência, o comportamento dos algoritmos não poderia ser analisado como esperado. Como consequência, foi desenvolvida uma página especial para o teste, usando a linguagem PHP, com conteúdo dinâmico e com característica $C P U$-bound, impondo a rotina de que, a cada requisição, será necessário o processamento dinâmico dessa página.

\subsection{Planejamento dos Experimentos}

Nesta etapa do processo, foram definidos os valores a serem usados nos parâmetros de configuração dos algoritmos e também foram especificados os cenários onde os algoritmos seriam aplicados.

$\mathrm{Na}$ construção dos cenários de carga foram considerados dois fatores, onde o primeiro fator é a taxa de requisições por segundo submetida ao sistema e o segundo fator é o limite de conexões disponíveis, a ser controlado pelos algoritmos. Nos testes realizados foram aplicados dois valores distintos de carga, tendo-se variado somente os valores da taxa de requisições. O valor total de usuários foi fixado em 50.000 usuários de cada classe, requisitando o conteúdo somente uma vez, e os valores para a taxa de chegada adotada foram de 300 e 600 requisições por segundo. Os resultados apresentados correspondem à média de dez execuções. Os intervalos de confiança apresentados consideram 95\% de confiança, de acordo com a tabela T-Student.

Com o propósito de facilitar a visualização dos resultados nos gráficos, a tabela 3 mostra o planejamento considerando a identificação do experimento, os fatores e os níveis.

Tabela 3: Fatores e Níveis dos Testes realizados.

\begin{tabular}{|c|c|c|}
\hline & Limite & Algoritmos e Parâmetros \\
\hline \multirow{3}{*}{ Teste 1 } & 400 & \\
\cline { 2 - 3 } & & Drop Tail \\
\hline Teste 2 & & Drop Tail com Peso=0,2 \\
\hline
\end{tabular}




\begin{tabular}{|c|c|c|}
\hline Teste 3 & & Drop Tail com Peso=0,42 \\
\hline Teste 4 & & RED; wq=0,2; Limite Mínimo=200 e Limite Máximo=400 \\
\hline Teste 5 & & RED; wq=0,2; Limite Mínimo=300 e Limite Máximo=500 \\
\hline Teste 6 & & RED; wq=0,2; Limite Mínimo=400 e Limite Máximo=600 \\
\hline Teste 7 & & RED; wq=0,42; Limite Mínimo=200 e Limite Máximo=400 \\
\hline Teste 8 & & RED; wq=0,42; Limite Mínimo=300 e Limite Máximo=500 \\
\hline Teste 9 & & RED; wq=0,42; Limite Mínimo=400 e Limite Máximo=600 \\
\hline & 600 & \\
\hline Teste 1 & & Drop Tail \\
\hline Teste 2 & & Drop Tail com Peso=0,2 \\
\hline Teste 3 & & Drop Tail com Peso=0,42 \\
\hline Teste 4 & & RED; wq=0,2; Limite Mínimo=400 e Limite Máximo=600 \\
\hline Teste 5 & & RED; wq=0,2; Limite Mínimo=500 e Limite Máximo=700 \\
\hline Teste 6 & & RED; wq=0,2; Limite Mínimo=600 e Limite Máximo=800 \\
\hline Teste 7 & & RED; wq=0,42; Limite Mínimo=400 e Limite Máximo=600 \\
\hline Teste 8 & & RED; wq=0,42; Limite Mínimo=500 e Limite Máximo=700 \\
\hline Teste 9 & & RED; wq=0,42; Limite Mínimo=600 e Limite Máximo=800 \\
\hline
\end{tabular}

Nos experimentos realizados com o método RED, o valor de Pmax igual a 0,2 foi considerado como parâmetro fixo. Durante a realização dos testes foi observado que não era correto comparar os algoritmos Drop Tail e RED devido à grande diferença no cálculo das conexões ocupadas e, devido a isso, foi desenvolvido um método variante do algoritmo Drop Tail, que se enquadra como uma alternativa intermediária, denominado Drop Tail com Peso. Suas características básicas, como descarte de requisições, assemelha-se ao método original tendo somente como distinção a análise da quantidade de conexões ocupadas instantaneamente. Nessa nova versão o cálculo de conexões é feito utilizando-se uma média móvel exponencial, semelhante à utilizada no algoritmo RED.

Os valores propostos na configuração de peso do algoritmo RED foram extraídos dos 
trabalhos de ZHENG \& ATIQUZZAMAN (2008), sendo que esses valores foram multiplicados por 100, por exemplo, o valor utilizado no trabalho anterior foi de 0,0042 e neste será igual a 0,42. Essa alteração foi realizada devido ao valor original $(0,0042)$ ser extremamente pequeno, provocando uma reação extremamente lenta na variação da quantidade de conexões, resultando em, praticamente, atendimento total das requisições.

Para cada um dos testes têm-se a média e o intervalo de confiança para o tempo de resposta e a porcentagem de requisições descartadas. $O$ intervalo de confiança não foi apresentado nos gráficos de requisições descartadas devido ao fato desses valores serem desprezíveis.

Os dados foram coletados considerando-se duas classes de serviços (A - maior prioridade e B - menor prioridade). Em todos os gráficos, as colunas de mesma cor representam um teste, sendo que a primeira coluna apresenta os resultados para a classe A e a segunda coluna identifica os resultados da classe B.

\subsection{Resultados Experimentais}

Os resultados apresentados nesta seção foram obtidos através da submissão de duas taxas de requisições (300 e 600) ao sistema, como explicado anteriormente, e uma carga de trabalho composta majoritariamente por requisições dinâmicas e $C P U$-bound, ou seja, que se assemelham à carga de trabalho padrão existente na Web. Os seguintes tópicos serão uma combinação entre os fatores carga de trabalho e limite para a análise em diferentes situações.

\subsubsection{Configuração com limite igual a 400}

Nesta subseção serão apresentados os algoritmos configurados para limite igual a 400, como pode ser visto na tabela v. Esse valor é considerado baixo em relação à configuração de cada servidor (Backend), onde são disponibilizados 1000 conexões.

\subsubsection{Carga com 300 requisições por segundo}

Neste experimento foi utilizada uma carga considerada baixa para o sistema, visto que este valor não expõe o cluster SWDS a um estado de sobrecarga. Os resultados mostram que 
o valor da carga imposta é menor ou igual ao throughput do sistema.

Pode-se analisar na figura 14 que o método Drop Tail (Teste 1) e Drop Tail com Peso (Teste 2 e 3) possuíram um tempo inferior quando comparado com os testes realizados pelo algoritmo RED. Contudo, é possível observar também que, o fator $w q$ não obteve relevãncia mediante a aplicação de carga onde significa que a carga foi baixo para esboçar uma reação no mecanismo. Por exemplo, comparando os testes 4 e 7, 5 e 8 e 6 e 9 onde a distinção entre os testes foi o valor do fator $w q$, os valores de tempo de resposta são praticamente equivalentes.

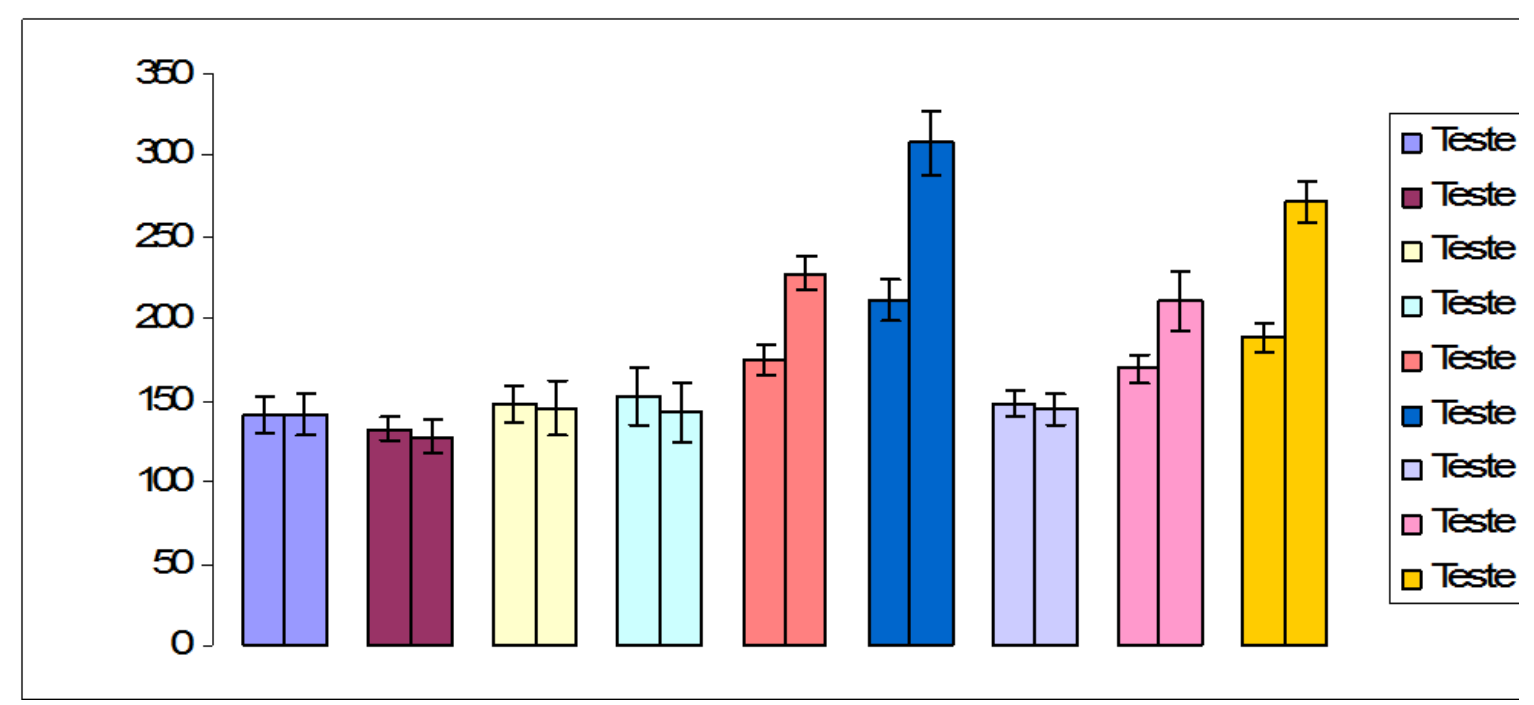

Uma justificativa importante para os baixos valores de tempo de resposta observados é a quantidade de requisições descartadas durante os testes. Foi observado no decorrer dos experimentos que existe uma relação inversamente proporcional entre as métricas tempo de resposta e quantidade de requisições descartadas. Essa relação pode ser comprovada através da análise da figura 15, sendo que os testes que obtiveram uma porcentagem maior de descarte são exatamente os testes que conseguiram alcançar baixos de tempo de resposta. 


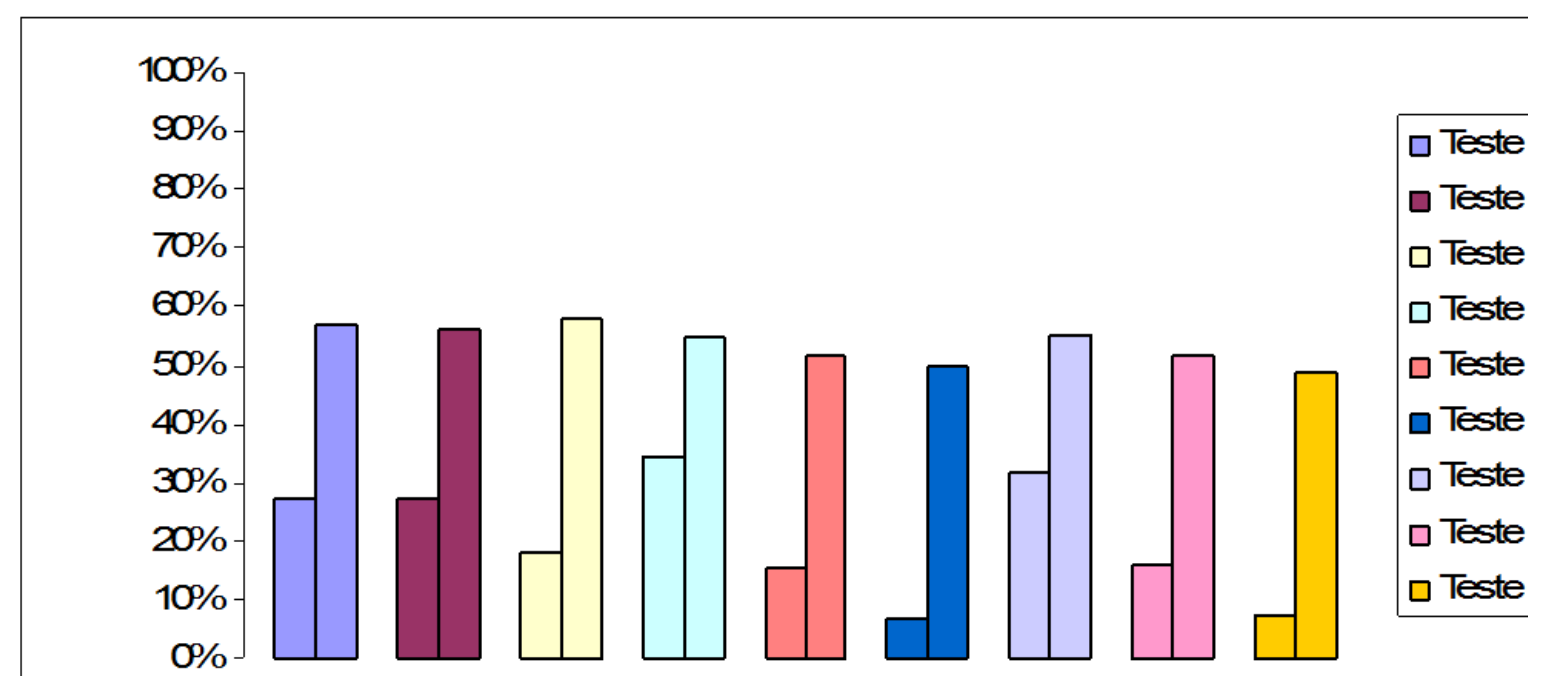

Baseando-se nos resultados obtidos, conclui-se que o método RED possuiu o pior desempenho neste cenário, sendo que em alguns experimentos obteve o maior tempo de resposta e alcançou a maior porcentagem de descartes.

\subsubsection{Carga com 600 requisições por segundo}

Pelo fato da carga submetida ao sistema ser relativamente mais alta em relação ao cenário anterior, alguns comportamentos característicos de cada algoritmo podem ser melhor observados. Na figura 16 podem-se observar que os valores de tempo de resposta e os valores de intervalo de confiança, aumentaram. Além disso, o valor do throughput médio, que no cenário anterior acompanhava a taxa de requisições do sistema (sistema não sobrecarregado), neste caso é igual a $432 \mathrm{req} / \mathrm{s}$, para uma carga de $600 \mathrm{req} / \mathrm{s}$. Esses resultados permitem observar que o sistema está em estado de sobrecarga. 


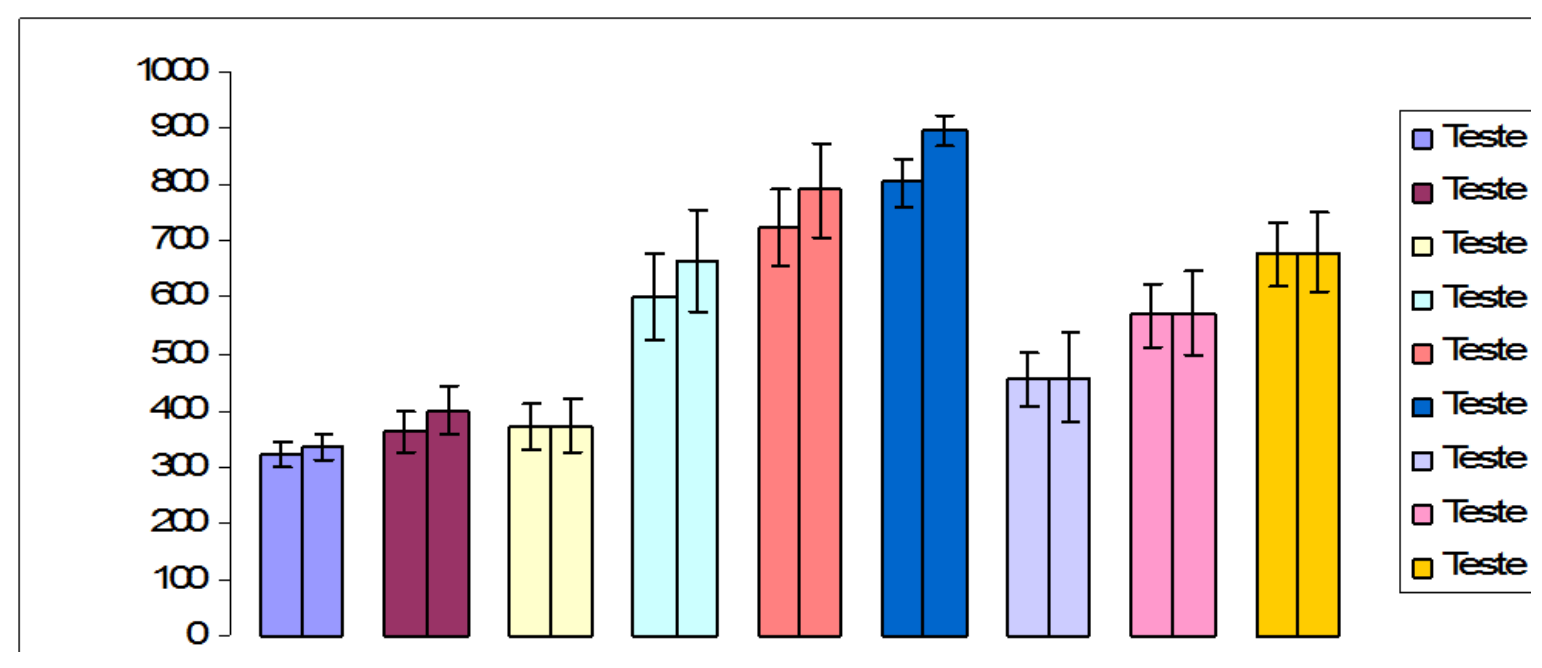

Na figura 16, além de mostrar que o algoritmo Drop Tail continua tendo o menor tempo de resposta em comparação aos demais métodos analisados, este ambiente possibilitou analisar um ponto importante no método RED, envolvendo o ajuste de parâmetro e desempenho. Foi possível observar que, os testes 4, 5 e 6 resultaram em tempos de resposta maiores em comparação aos testes 7,8 e 9. Isto ocorre devido ao parâmetro peso $(w q)$ configurado nestes testes. O parâmetro peso $(w q)$ dos testes 4,5 e 6 possuem um valor menor do que os testes 7,8 e 9, com isso a resposta à variação do número de conexões é lenta e, como resultado, os servidores atenderam mais requisições para que fosse atingido os limites (mínimo e máximo) pré-configurados.

A figura 17 mostra os valores da porcentagem de descartes de requisições nesse ambiente e, como podem ser visto, esses valores são maiores. Isto se deve ao fato da taxa de requisições ser maior neste cenário, mas, embora isso, neste ambiente houve diferenças pequenas entre os testes analisados que, estatisticamente, permanecessem equivalentes.

Analisando os valores de porcentagem do algoritmo RED, é possível observar que este mecanismo proporcionou um número maior de aceitação das requisições, cerca de 4,78\% de requisições em média, comparado com o algoritmo Drop Tail. Esta observação pode ser vista comparando os valores dos testes 1, 2, 3 e 4, relacionados ao Drop Tail, que são maiores do que testes 5, 6, 7, 8 e 9, que dizem repeito ao algoritmo RED. 


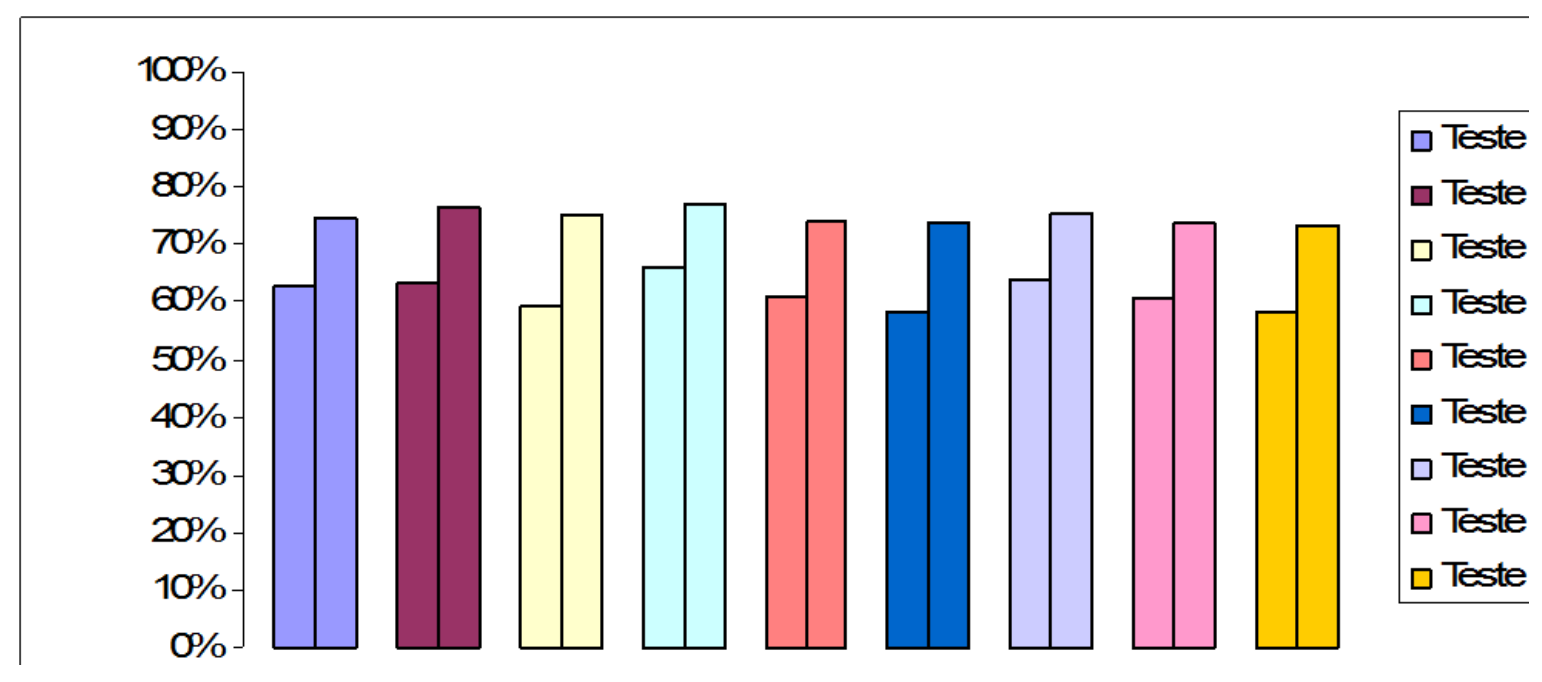

\subsubsection{Configuração com limite igual a 600}

Nesta subseção serão apresentados os algoritmos configurados para um limite igual a 600 , como pode ser visto na tabela 3. Com este valor, os servidores passarão a aceitar mais requisições e, consequentemente, entrar em um estado de sobrecarga. Deve ser lembrado que estão disponíveis para cada servidor 1000 conexões.

\subsubsection{Carga com 300 requisições por segundo}

Visto que neste cenário o limiar de conexões disponíveis possui um valor próximo do limite máximo, então, foi aplicada uma carga considerada baixa, que não é capaz de sobrecarregar o cluster de servidores. Com isso foi analisado o comportamento dos algoritmos nesse ambiente. O comportamento previsto anteriormente aos testes pode ser constatado conforme os resultados apresentados na figura 18. Ao comparar os dois cenários com carga igual a 300 requisições por segundo é possível avaliar que não há diferença estatisticamente significante nos tempos de respostas, tendo apenas um aumento de 4,22\%. 


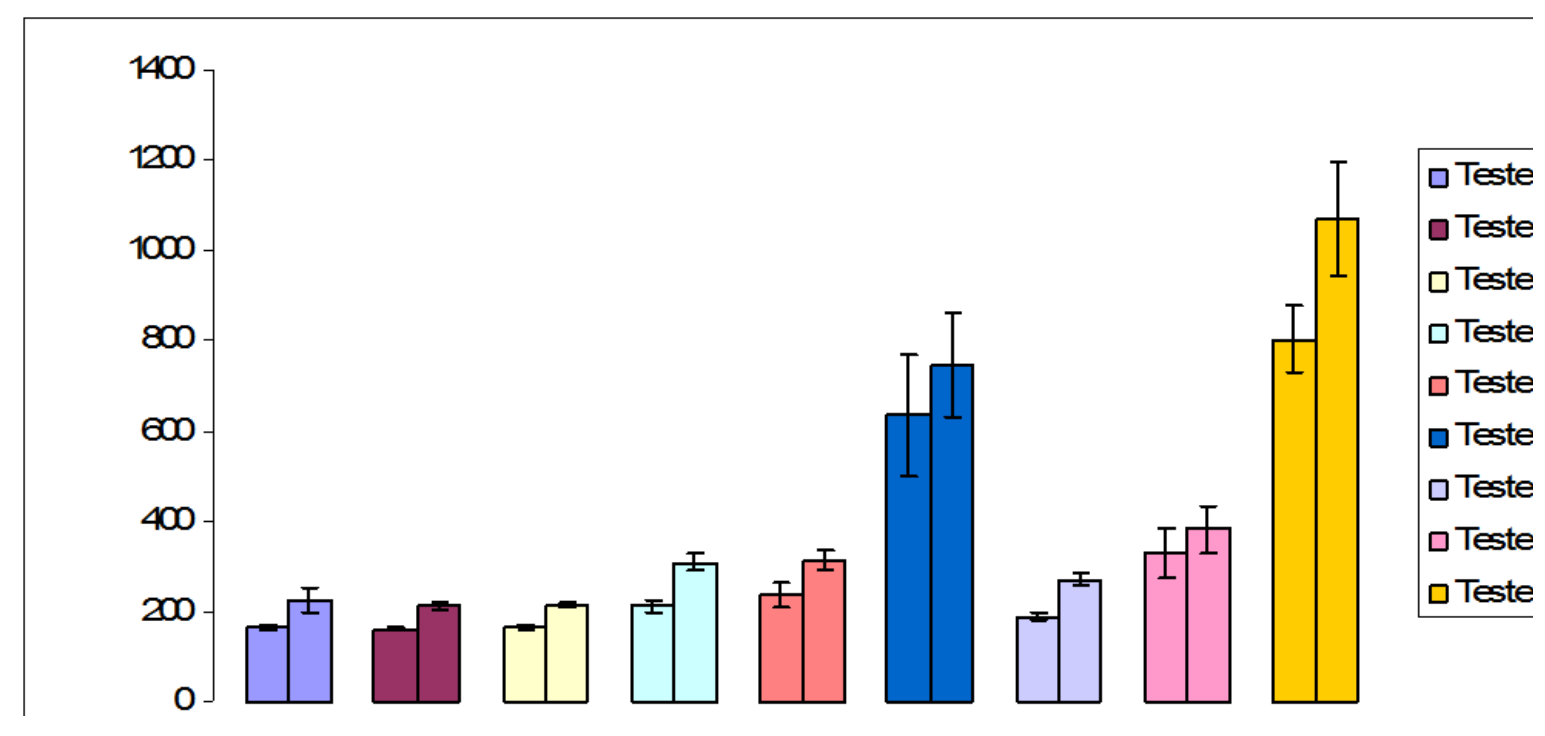

Outro ponto a ser comentado com base na figura 18 esta relacionado aos intervalos de confiança, visto que a maioria dos testes obtiveram valores pequenos, exceto para os testes $6 \mathrm{e}$ 9, onde esses valores foram maiores. Analisando o ambiente acredita-se que este fato tenha ocorrido com o teste 6 e 9 devido a configuração e a carga aplicada, fazendo com que a estabilidade do sistema fosse comprometida.

A figura 19 mostra uma baixa porcentagem de requisições descartadas, em comparação com o cenário de limite igual a 400 conexões. Esta característica se deve ao fato do aumento do limiar adotado, sendo que este novo limiar possibilitou que um número maior de requisições fosse atendido pelo sistema.

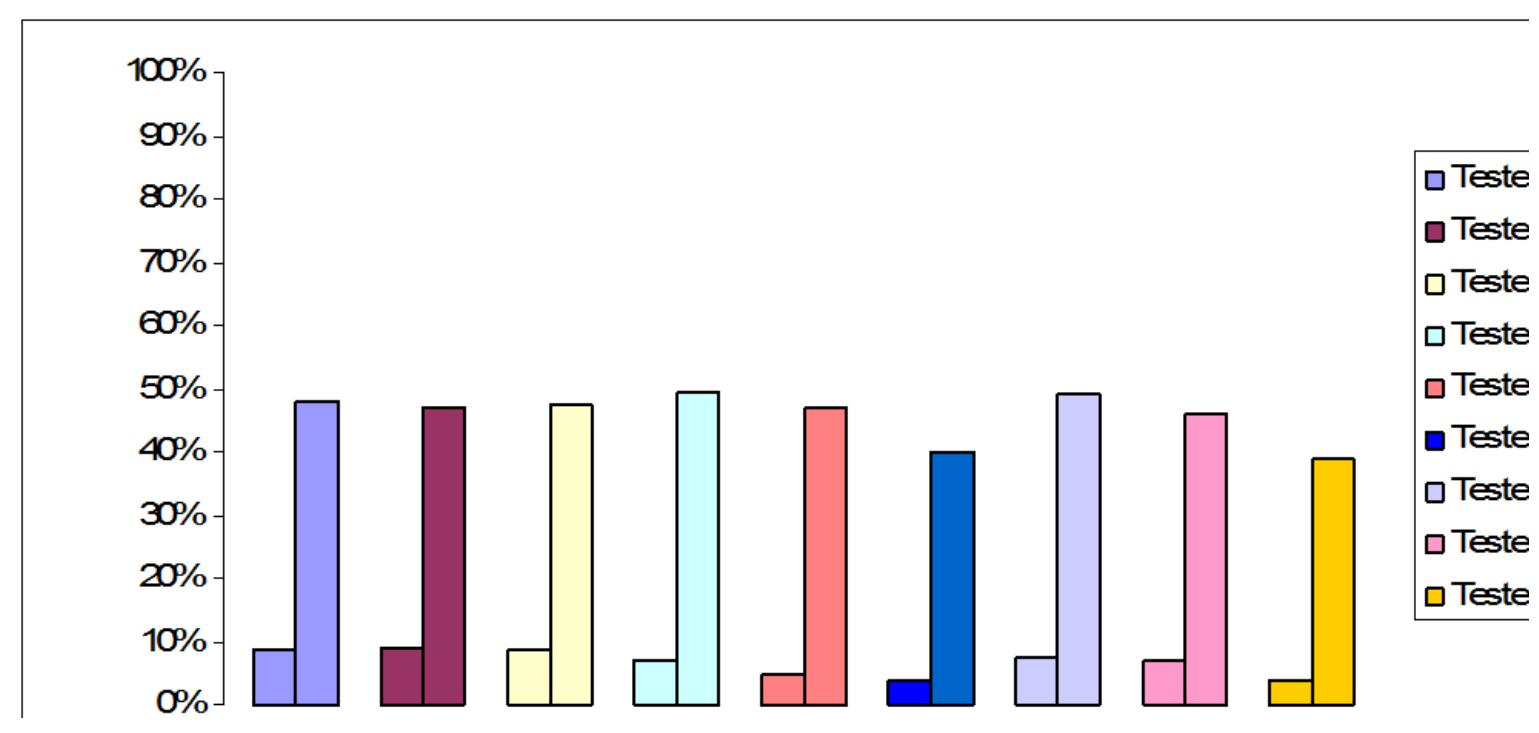




\subsubsection{Carga com 600 requisições por segundo}

No último teste o ambiente é composto por uma alta taxa de requisições, colocando-se o sistema em estado de saturação. $\mathrm{Na}$ análise do throughput médio neste cenário foi obtido o valor de $457.2 \mathrm{req} / \mathrm{s}$, comprovando que o sistema não consegue atender à demanda (600 req/s). Outro ponto no qual pode-se observar esta característica de saturação é através do intervalo de confiança mostrado na figura 20 , onde os valores são maiores comparando-se com os outros cenários.

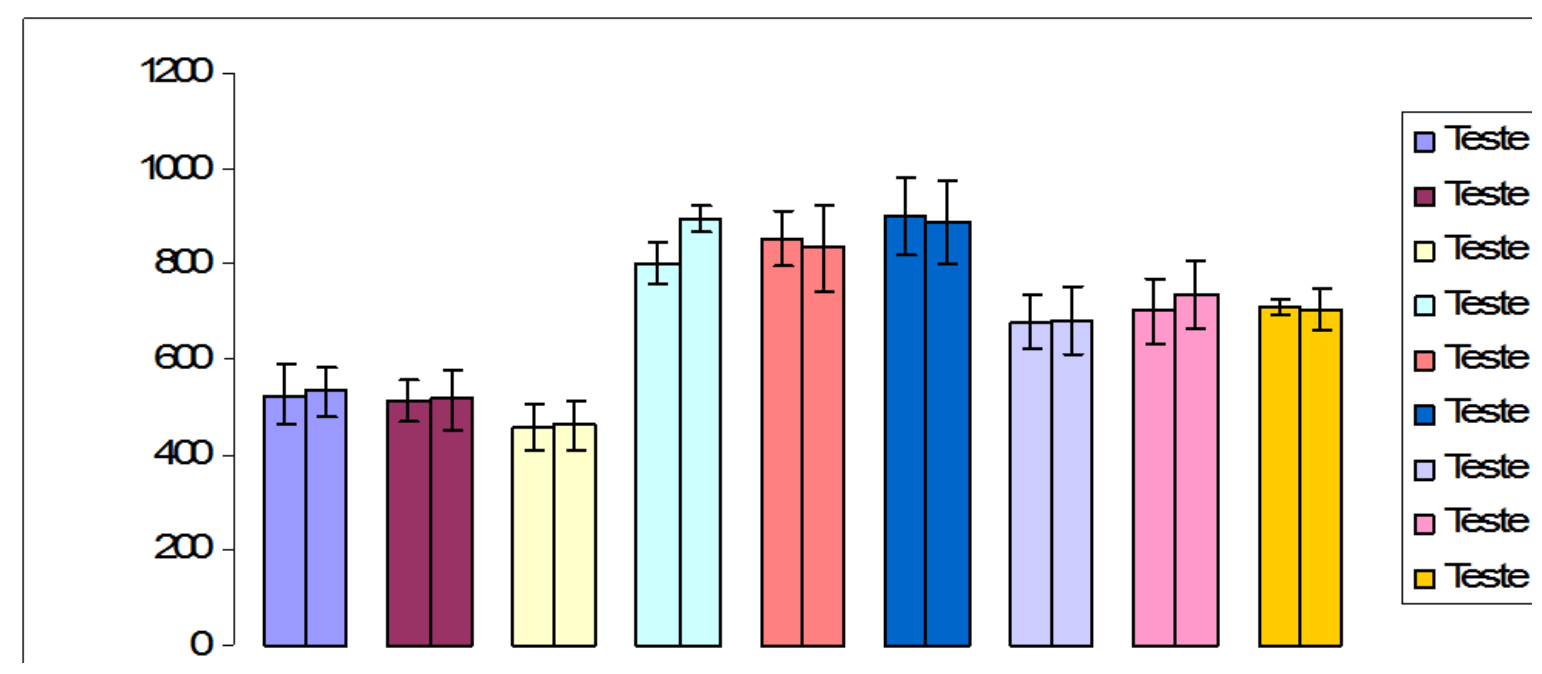

Os métodos Drop Tail e Drop Tail com peso continuaram apresentando melhores tempos de resposta do que o método RED nesta configuração de experimento, porém o método RED possuiu uma sucinta vantagem no quesito descarte das requisições, onde aceitou aproximadamente $3,1 \%$ de requisições comparado aos demais métodos. Este fato pode ser observado na figura 21 . 


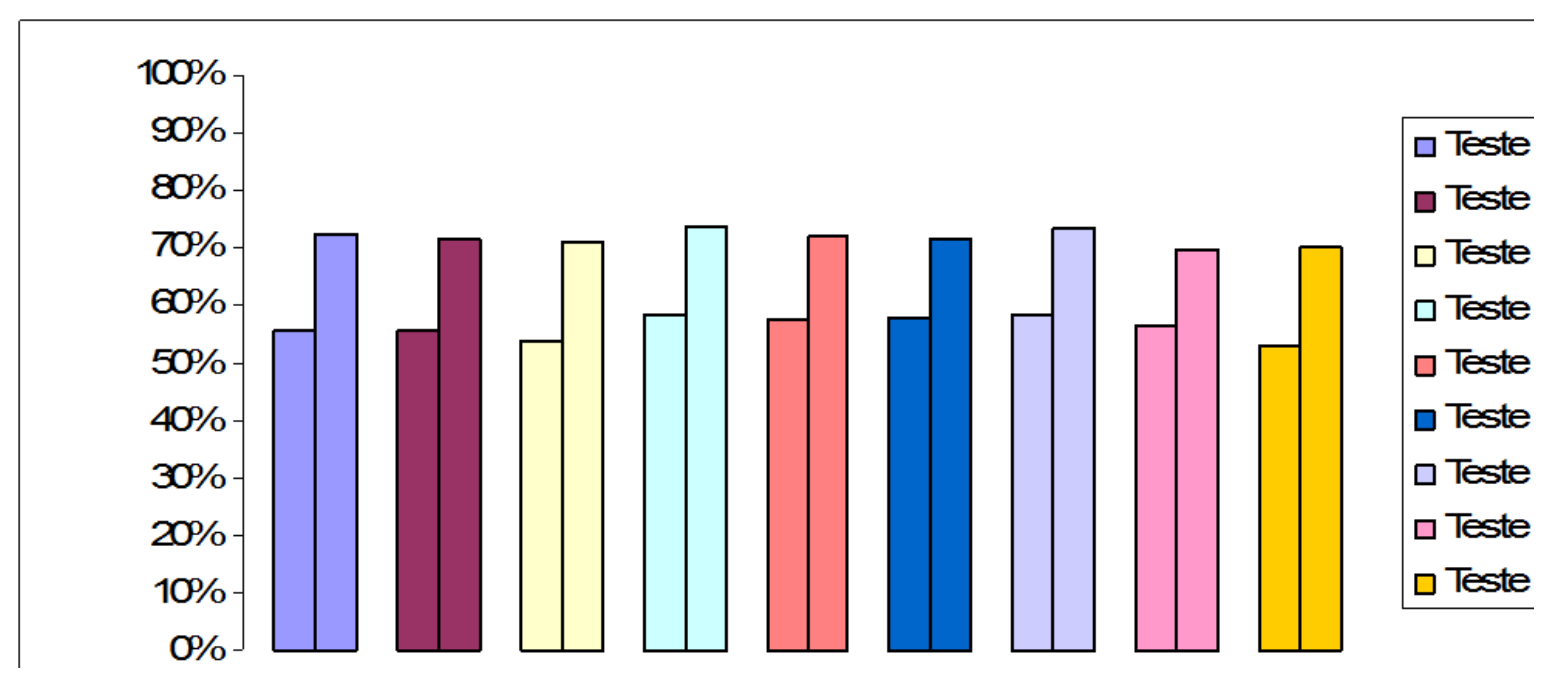

\subsubsection{Análise de Influência}

A partir dos testes realizados na seção anterior, foi possível extrair outras informações como, por exemplo, a porcentagem de influência de cada fator e o impacto causado por esses fatores juntamente com os valores atribuídos aos respectivos níveis. Nesta seção serão apresentados os gráficos de influência de cada fator e suas possíveis combinações, aplicandose aos métodos e classes utilizadas.

\subsubsection{Drop Tail}

Neste algoritmo foi possível realizar a combinação de dois fatores, o parâmetro limite e carga, sendo que para cada um destes fatores foram atribuídos dois níveis. Os níveis atribuídos para o fator limite são 400 e 600 conexões disponíveis e os níveis para o fator carga de trabalho são iguais a 300 e 600 requisições por segundo.

Pode-se observar que na figura 22, o fator carga de trabalho possuiu o valor de $83,02 \%$ em tempo de resposta e 90,59\% em descarte de requisições da classe 1 e este comportamento pode ser observado em ambas as classes de serviço (classe 1 e classe 2). A soma dos outros fatores (Limites e Limites+Carga) totalizou apenas 16,98\% e 9,41\% para a classe 1 e 24,35\% e 7,17\% para classe 2, sendo que estes valores não foram capazes de interferir no desempenho total do algoritmo no sistema. 


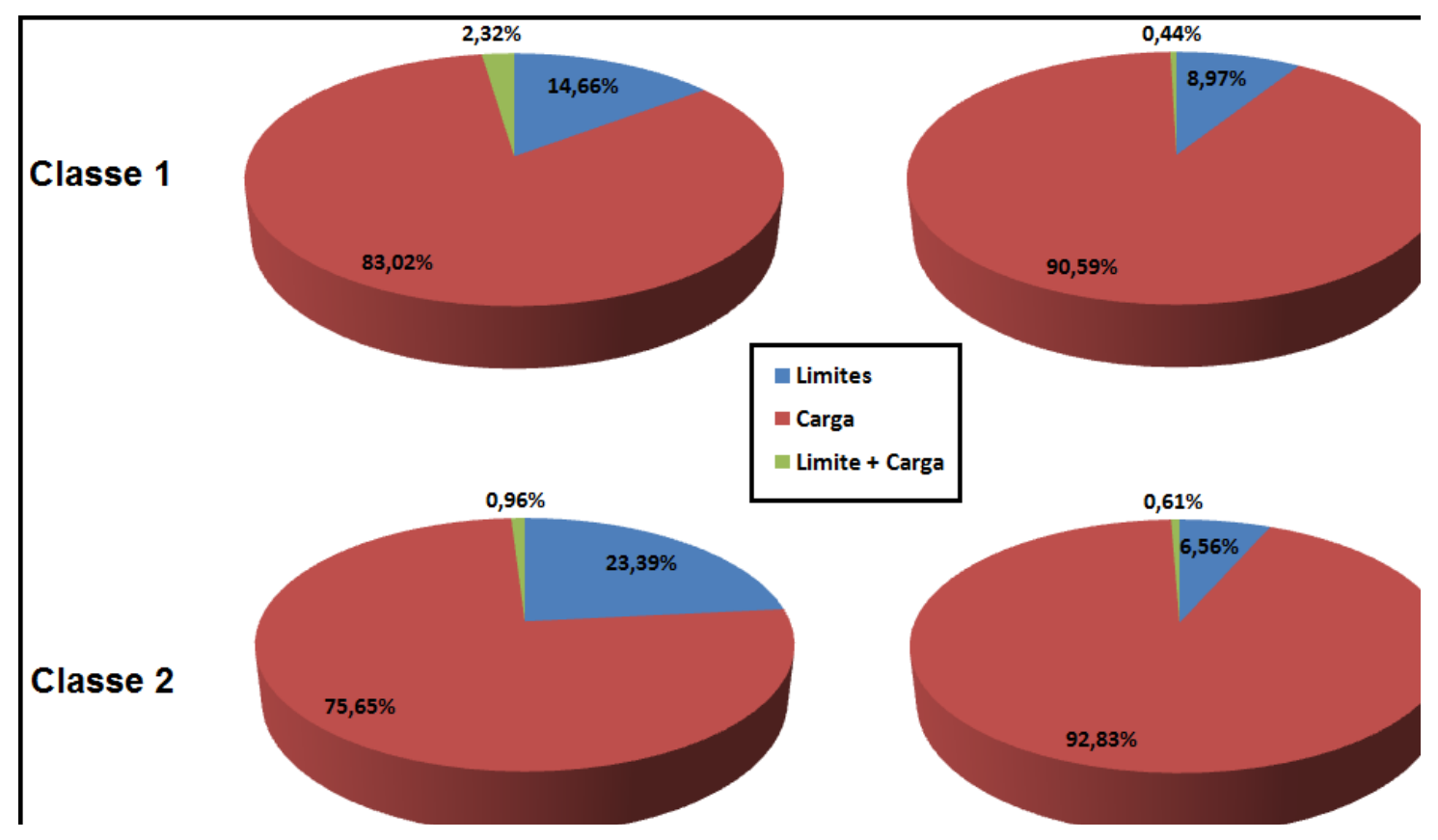

\subsubsection{Drop Tail com Peso}

Durante a análise deste método foi possível observar a influência de mais um parâmetro pertinente ao algoritmo, o parâmetro peso, além de outros fatores como limite, carga e a combinação deles. Na avaliação, o novo atributo foi avaliado utilizando-se 2 níveis, 0,2 e 0,42 .

A figura 23 mostra que, semelhantemente à análise do algoritmo anterior, o fator carga de trabalho permaneceu como o fator que obteve o maior impacto nos valores de desempenho nas métricas utilizadas, obtendo $90,18 \%$ e $92,70 \%$ para o tempo de resposta e descarte de requisições respectivamente para a classe 1 . Na mesma figura pode ser visto que para a classe 2 foram alcançados os valores de 88,30\% e 87,95\% em tempo de resposta e descarte de requisições respectivamente.

O novo parâmetro analisado possui pouca influência nas métricas para ambas as classes de serviço, como pode ser visto na avaliação da classe 2 , onde o fator peso passa a ter valores significativos somente a partir da $3^{\mathrm{a}}$. casa após a vírgula, dada como uma influência desprezível. 


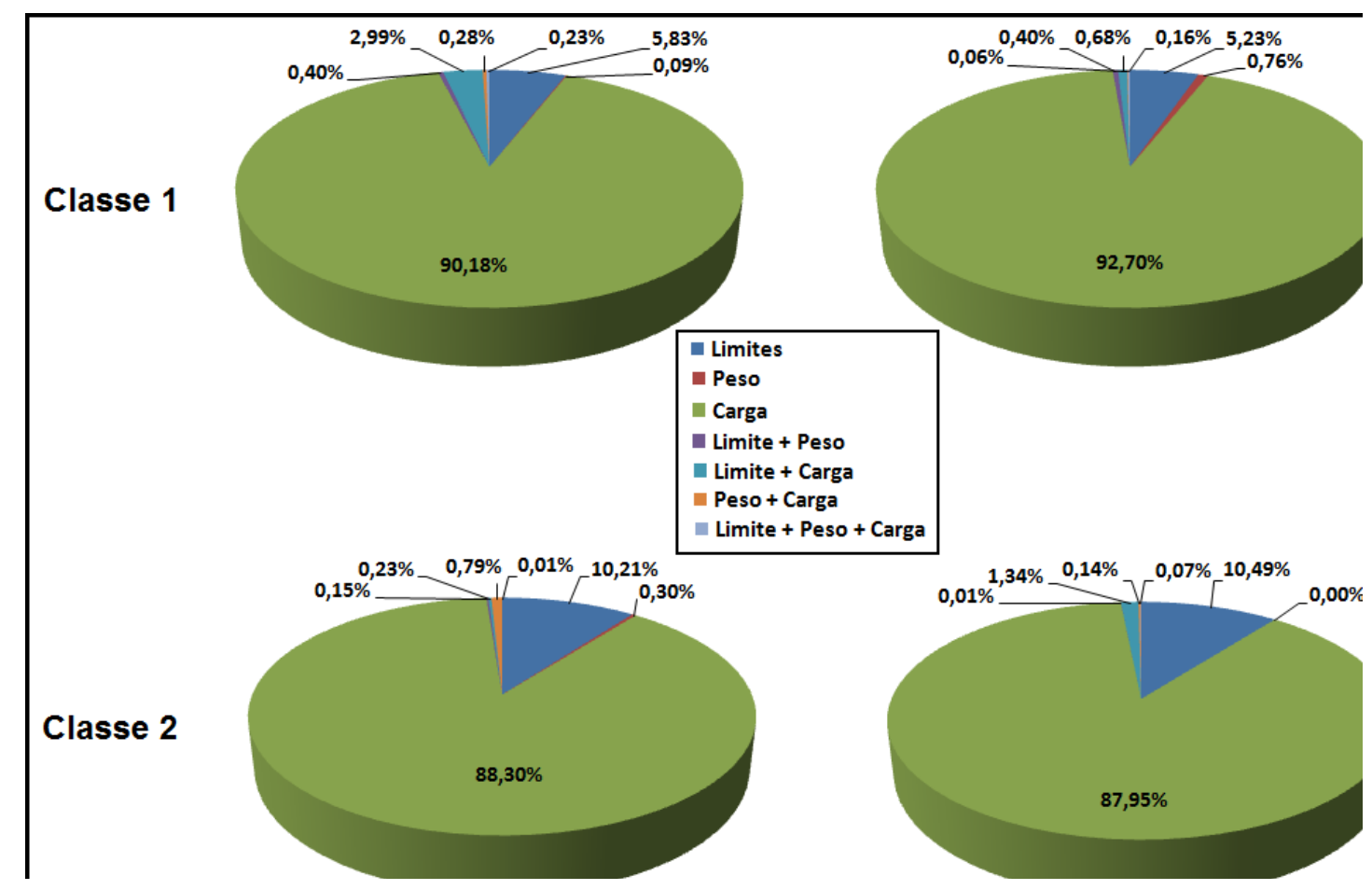

\subsubsection{RED}

Com o algoritmo RED, também foi possível avaliar a influência dos fatores, no qual foi considerado quatro cenários onde os valores obtidos foram confrontados.

Os ambientes avaliados consideram o cenário com limite igual a 400, neste caso foram usados os 200-400 e 400-600 para limiares mínimos e máximos, respectivamente, e o cenário com limite igual a 600, onde os limiares confrontados foram 400-600 e 600-800.

Pode ser observado na figura 24 que a carga de trabalho continuou sendo o fator que mais influenciou no desempenho do mecanismo RED para a classe 1 , tendo desta vez uma leve diferença comparado as figuras anteriores, cerca de 4,87\% de diferença entre fator Carga e fator Limite. Outro ponto nesta figura é o resultado de tempo de resposta para a classe 2 sendo que pela primeira vez nestes testes de influência outro fator, além de carga de trabalho, possuiu uma grande relevância. O Limite obteve um valor de $22,49 \%$ a mais que o fator Carga de trabalho.

A figura 24 também mostra que, no momento em que o cluster de servidores se encontra em estado de sobrecarga, todos os fatores começam a causar uma influência maior no desempenho, resultando em instabilidade e grandes tempos de resposta. 


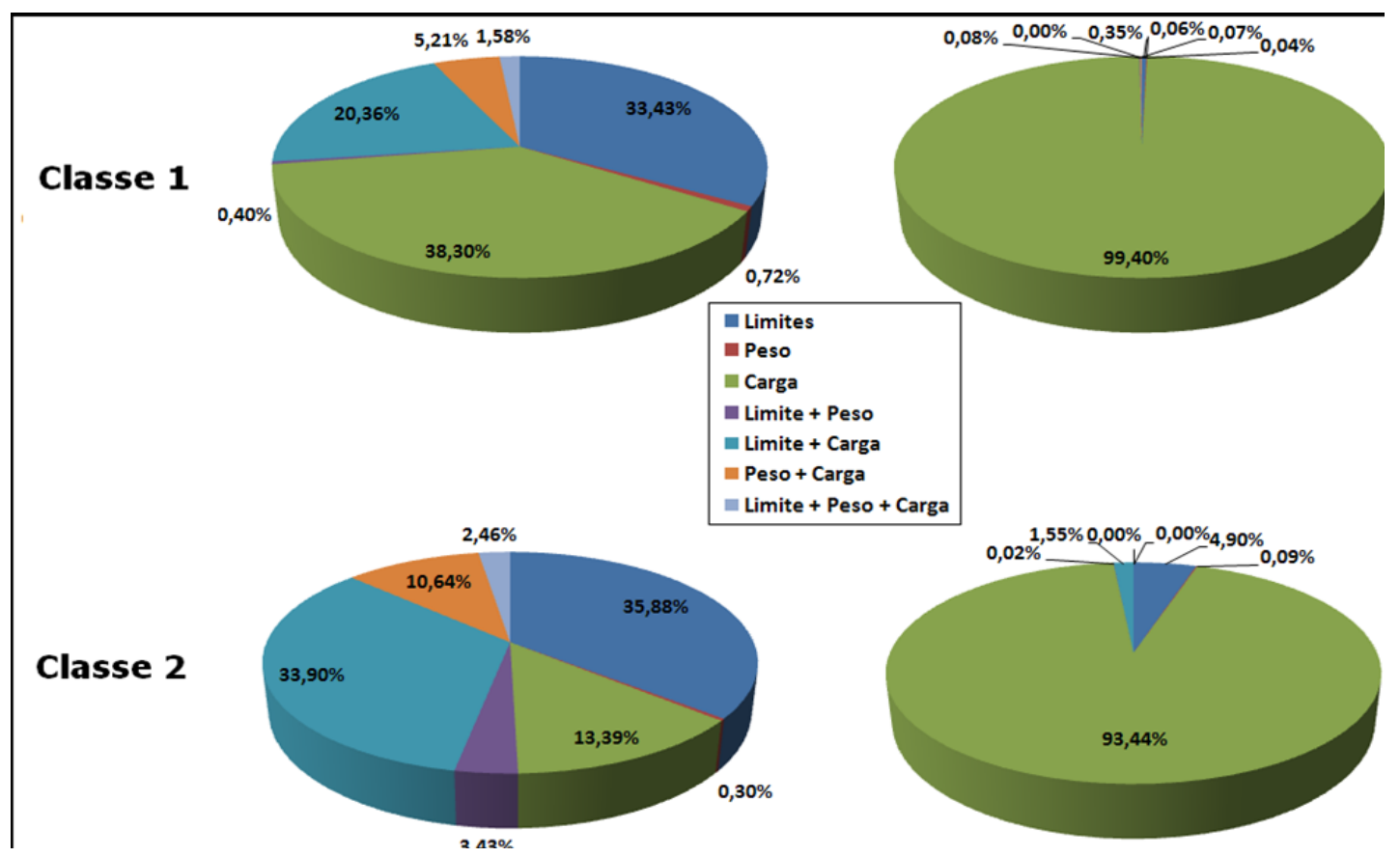

Como conclusão dos testes de influência foi possível observar que a carga de trabalho foi o fator que proporcionou uma grande influencia nos resultados obtidos por todos os algoritmos avaliados. Com isso, a carga utilizada nestes experimentos é considerada alta, em relação aos outros fatores que, por fim, não influenciaram no desempenho analisado. Através da conclusão obtida nesta seção foi elaborado um novo experimento, cuja finalidade é observar a principal característica do controle de admissão, isto é, o gerenciamento da quantidade de conexões disponíveis no sistema.

\subsubsection{Comportamento do Algoritmo}

Devido ao fator carga de trabalho ter proporcionado uma grande influência nos testes realizados na seção anterior, nesta seção serão apresentados os resultados obtidos analisandose o comportamento do controle de admissão, por meio da verificação da quantidade de conexões e se o limiar está sendo respeitado, em situações de carga alta de requisições.

Os experimentos realizados foram executados uma única vez sendo que durante a execução do teste foram feitas capturas das informações de carga de cada servidor Web, em intervalos de 1 segundo, com os valores salvos em um arquivo texto. Para isso, mais uma vez foi utilizada a ferramenta HTTPERF como instrumento de submissão de requisições ao 
sistema. Os valores usados na taxa de requisições para estes testes são de 450 e 800 requisições por segundo, tendo sido também configurado o valor do limite para 500 nos algoritmos Drop Tail, Drop Tail com Peso e para o algoritmo RED foram fixados os valores de 400 e 600 conexões como limite mínimo e máximo, utilizando-se o parâmetro peso em 0,2 e 0,42 .

A carga aplicada ao sistema é maior que o limite suportado pelos algoritmos, e isto foi proposital, com a intenção de se observar os descartes realizados e a quantidade máxima de conexões utilizadas. Vale ressaltar que para estes testes foi utilizado um número menor de máquinas, somente quatro, e não foram exigidos nenhum parâmetro de qualidade de serviço, já que a finalidade é observar o nível de utilização das conexões nos servidores Web.

\subsubsection{Drop Tail}

Com a carga menor que o limite estabelecido, pode-se observar que o algoritmo iniciou o processo de descarte de requisições assim que a quantidade de conexões utilizadas ultrapassou o valor 500 em cada servidor. A figura 25 mostra que no final do experimento pode ser observada a existência de um pequeno crescimento, o que leva a se acreditar que seria o momento em que iniciaria o processo de aceitação de requisições, caso o experimento não tivesse terminado.

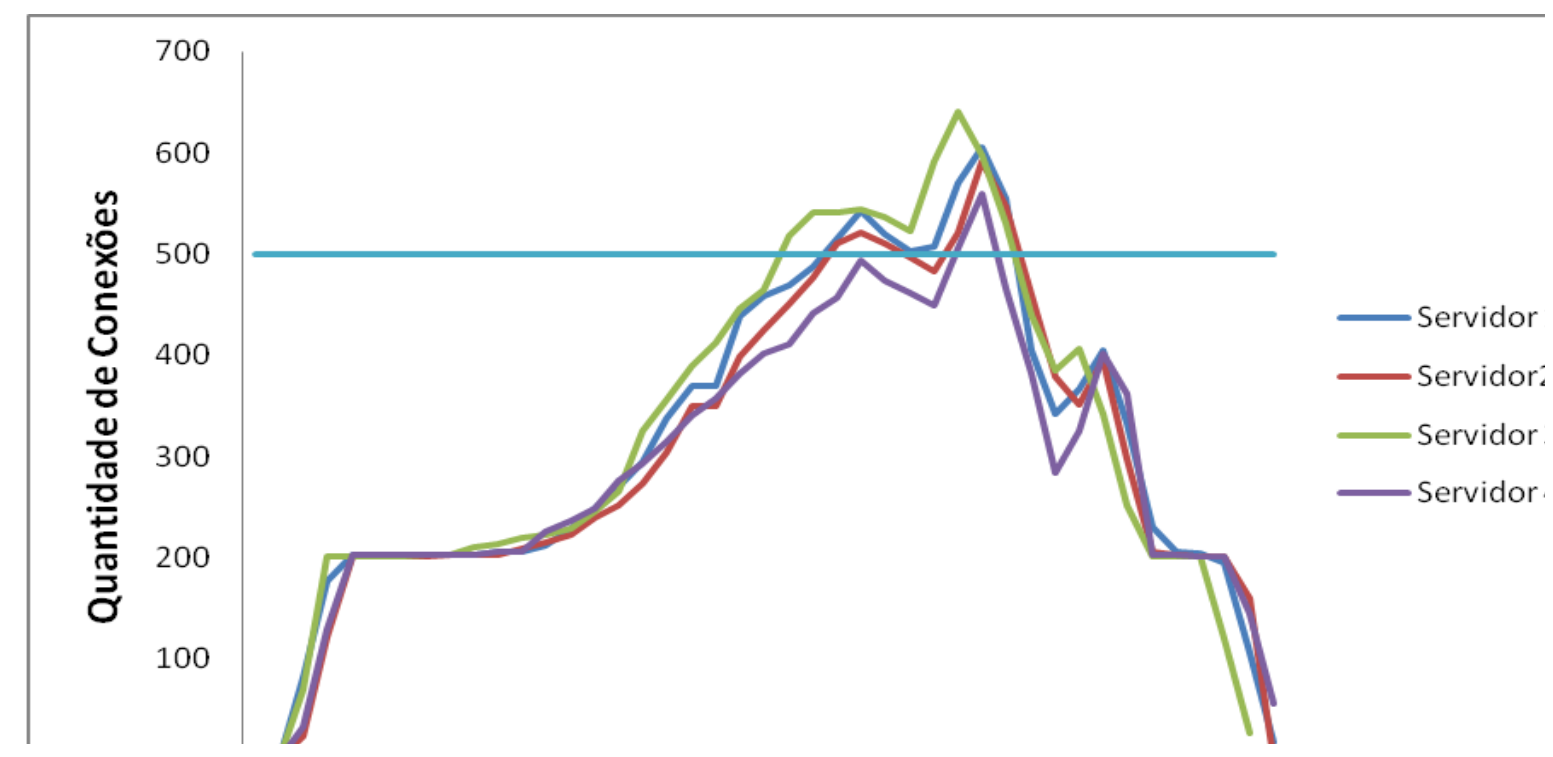


A figura 26 mostra o comportamento dos servidores em um cenário onde a quantidade de requisições submetida ao sistema é maior que o limiar suportado pela máquina. Pode-se perceber que durante a execução houve cinco picos de aproximadamente 250 conexões a mais do que limite pré estabelecido pelo algoritmo (500 conexões).

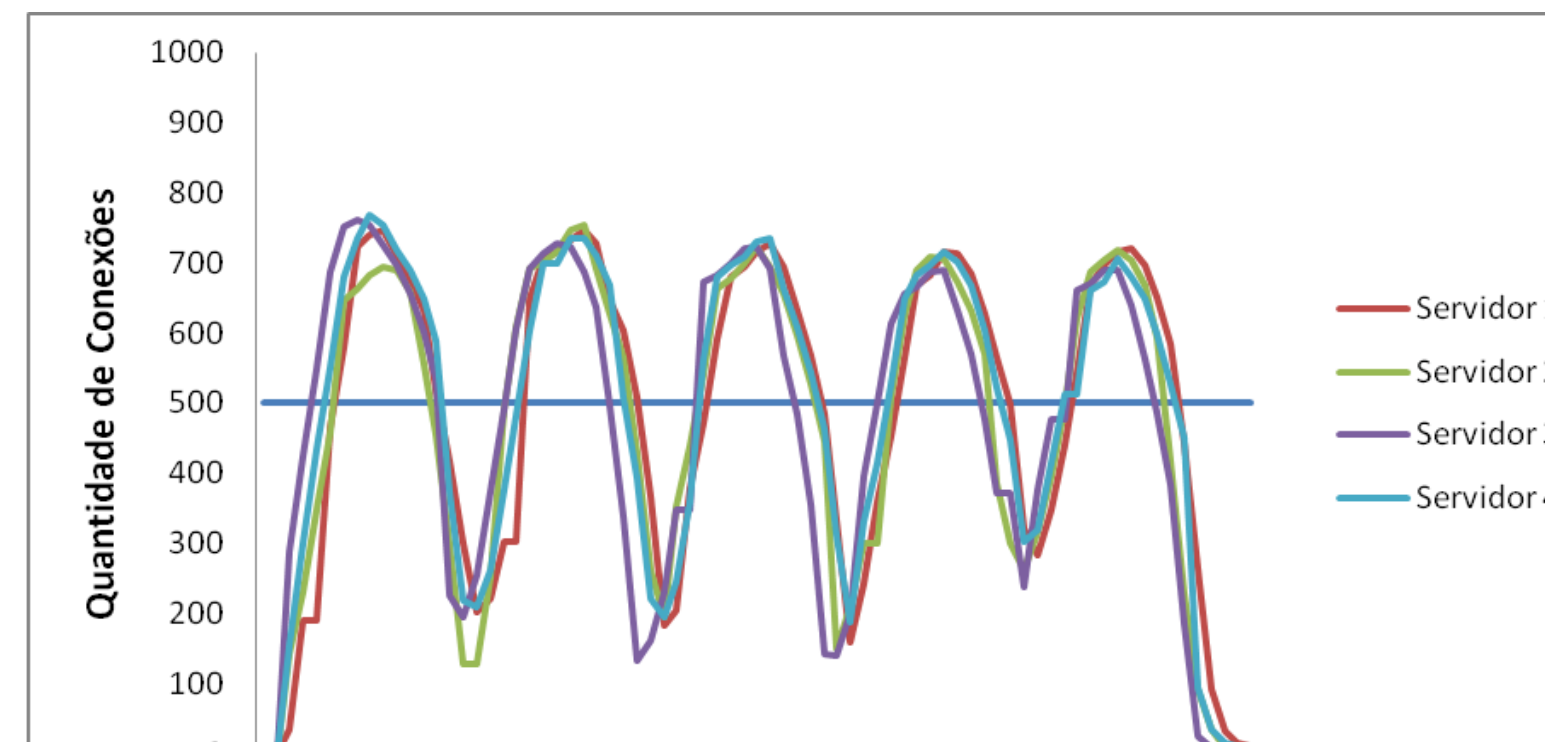

Uma outra característica interessante na visualização da figura 26 é que os servidores comportam-se da mesma forma durante todo o experimento, mostrando que o controle de admissão passa a vigorar para todos os servidores, simultaneamente.

\subsubsection{Drop Tail com Peso 0,2}

Fazendo-se uma comparação entre a figura 25 e 27, percebe-se que as máquinas não ultrapassaram, em grandes quantidades, o limite configurado, ao contrário do que ocorreu no algoritmo anterior, atingindo um número de aproximadamente 100 conexões a menos entre ambos os métodos.

Acredita-se que o uso do cálculo da média móvel exponencial para a análise da quantidade de conexões utilizadas, auxiliou para que o algoritmo tivesse uma reação mais próxima do esperado. Neste cálculo foi atribuído um valor para o peso no qual foi considerado uma relevância maior aos valores anteriores das médias de conexões. 


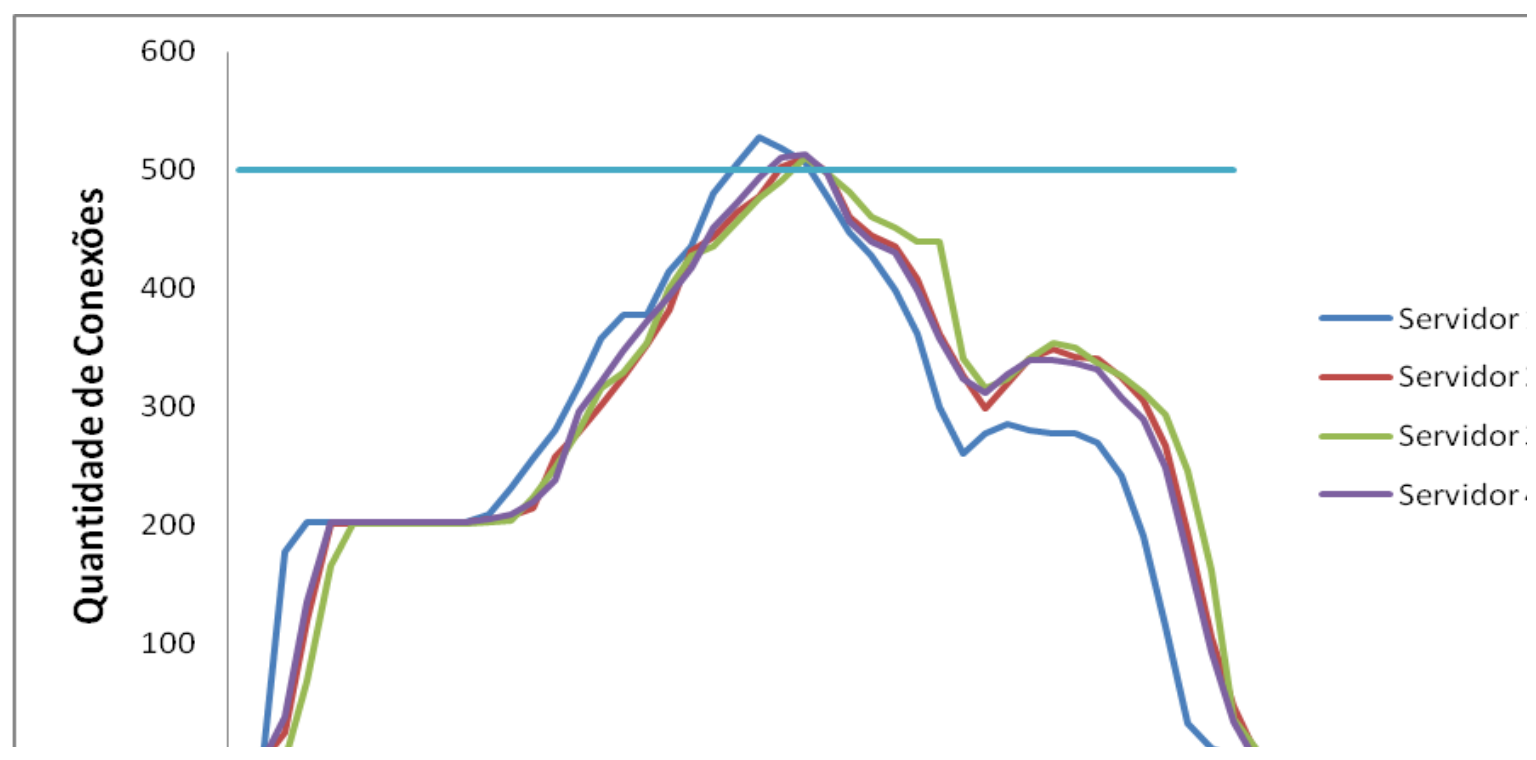

Realizando outra comparação entre o método atual e o anterior neste ambiente de baixa demanda, é visto na figura 27 que houve uma redução no número de conexões utilizadas para o processamento, sendo que este número é aproximadamente de 100 requisições.

Outro ponto a ser comentado é quando se realiza uma comparação entre as figuras 26 e 28, onde observa-se que à medida que aumenta a carga submetida ao sistema, o método possui um atraso para o início do processo de descarte. Uma possível causa para a ocorrência desse atraso das informações de carga seria a concorrência de acesso à rede entre o grande número de requisições escalonadas para os servidores e as informações enviadas pelos monitores. 
Figura 28: Comportamento do mecanismo Drop Tail com Peso com carga de 800 rea/s.

\subsubsection{Drop Tail com Peso 0,42}

Nos testes desta seção, o método Drop Tail com peso possui um peso maior, fazendo com que haja um atraso menor na variação de conexões utilizadas. Através da comparação entre as figuras 27 e 29 onde a variação foi apenas do parâmetro $w q$, pode-se concluir que não houve um comportamento diferenciado através da variação deste parâmetro. 


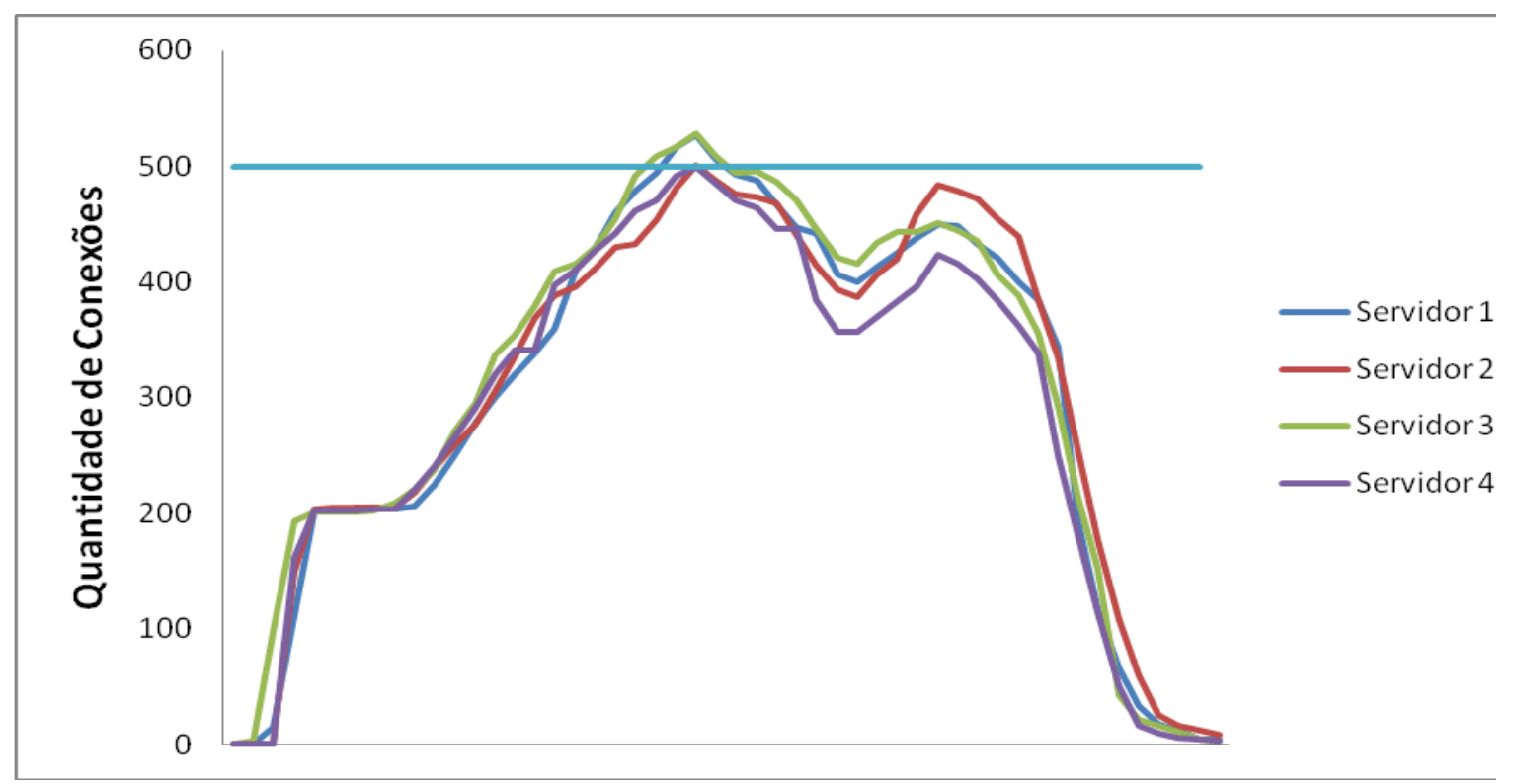

Figura 29: Comportamento do mecanismo Drop Tail com Peso com carga de 450 rea/s.

A figura 30 mostra a ocorrência das mesmas características quando o sistema é submetido a uma carga maior. Entretanto, houve uma reação distinta exatamente no meio do experimento, onde uma quantidade maior de requisições foram aceitas, fazendo com que os servidores alcançassem aproximadamente 900 conexões.

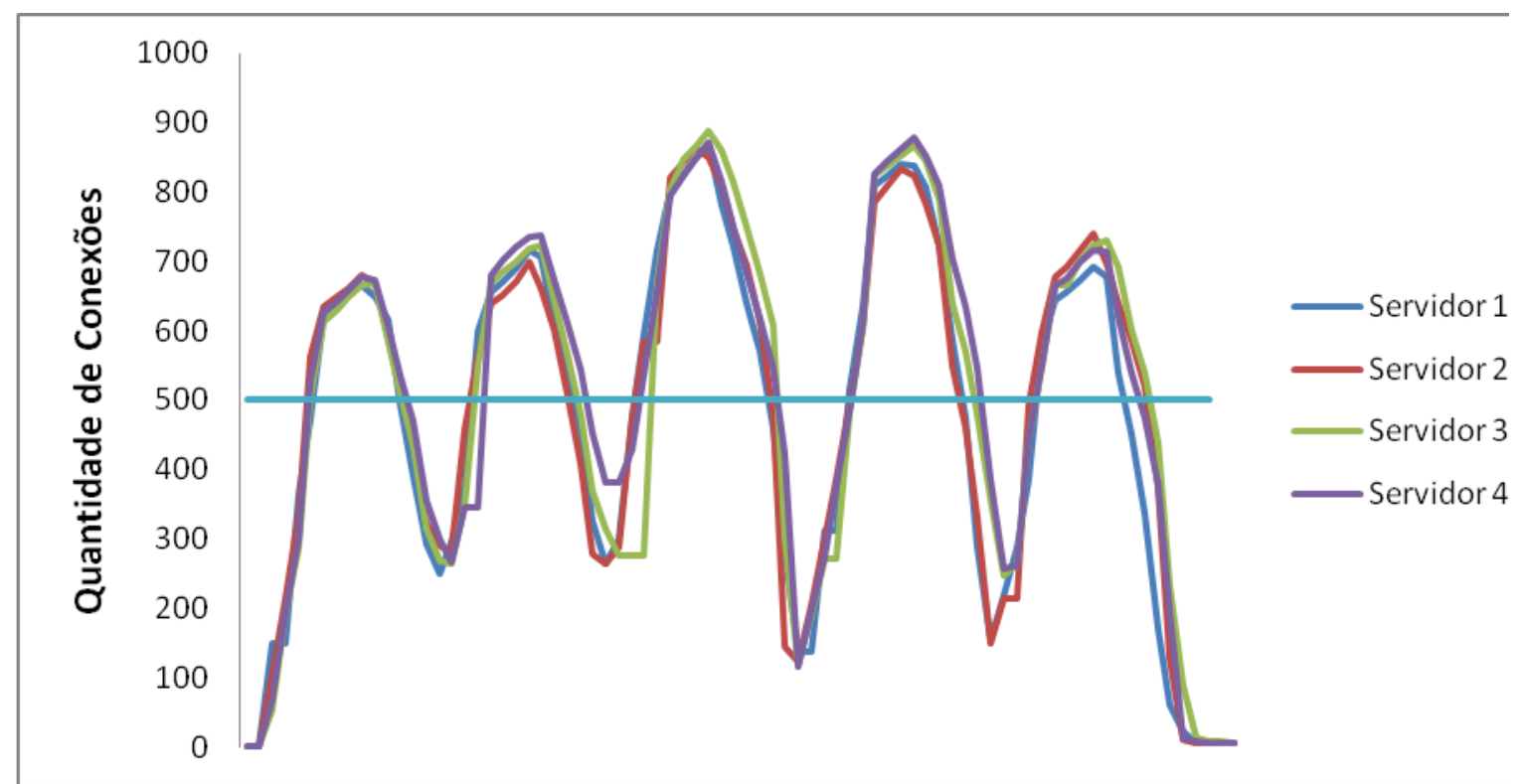

Figura 30: Comportamento do mecanismo Drop Tail com Peso com carga de 800 req/s.

Ainda assim, os atrasos dos monitores com o cálculo de informações defasadas provocaram picos e quedas distante do limite configurado, como pode ser visto no gráfico 30. 


\subsubsection{RED com Peso 0,2}

Utilizando-se o método RED configurado com peso igual a 0,2 foi possível observar na figura 31 que, devido às características de limite mínimo e máximo o método permitiu que fosse atendido um número maior de requisições, fazendo com que os servidores chegassem até 700 conexões (apenas um servidor ultrapassou o limite).

Dos resultados obtidos com os experimentos observa-se que a taxa de requisições pode influenciar no desempenho do método, pois, comparando-se as figuras 25 e 31 percebe-se que o RED consegue reagir com maior rapidez quando a intensidade de carga é menor. À medida que a taxa aumenta, o processo de descarte influencia negativamente o desempenho.

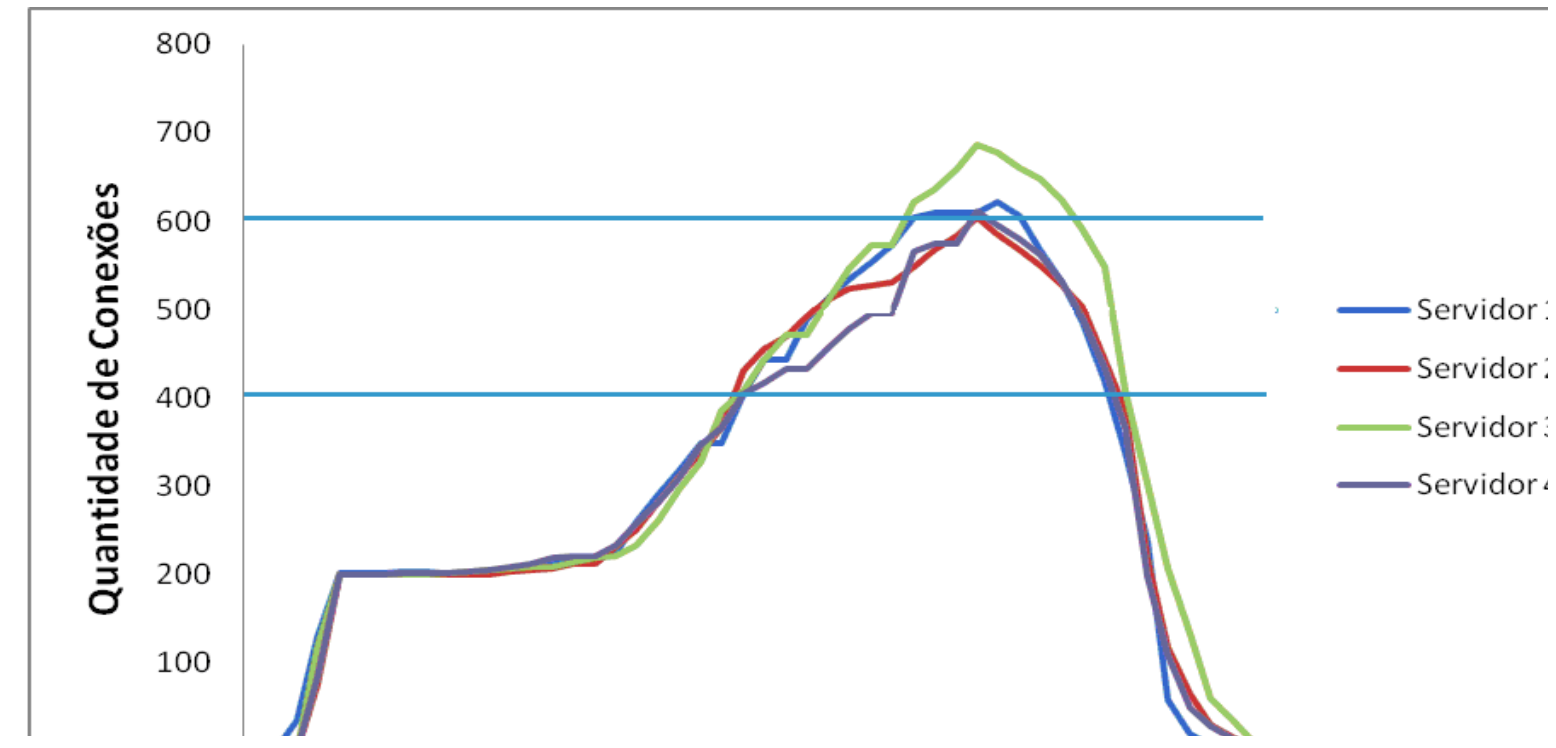

A figura 31 mostra um comportamento diferente dos mecanismos anteriores, onde o algoritmo RED possibilitou que um grande número de requisições fossem aceitas nesse ambiente, com aproximadamente 500 requisições a mais em comparação aos métodos Drop Tail e Drop Tail com peso. A explicação para este fato deve-se ao uso da região crítica adotada pelo mecanismo RED, fazendo com que possibilite a entrada de mais requisições ao sistema.

$\mathrm{Na}$ seção anterior foi explicado como foram realizados os experimentos de análise da quantidade de conexões usadas no sistema, sendo que as informações mostradas nos gráficos foram resultados de uma execução. Nesta configuração do mecanismo foi notado um comportamento anormal do algoritmo e, por consequência desta anomalia, outras execuções foram realizadas para fins de observação. Na figura 32 observa-se que, no inicio do 
experimento, a aceitação de requisições é alta, mas que ao decorrer da avaliação, a média dos picos reduz gradualmente até manter-se no último valor de pico (aproximadamente 800 requisições).

Acredita-se que este comportamento ocorre devido ao ajuste da média na fórmula durante o experimento. $\mathrm{O}$ atraso dos monitores explica a permanência do valor no último pico do gráfico.

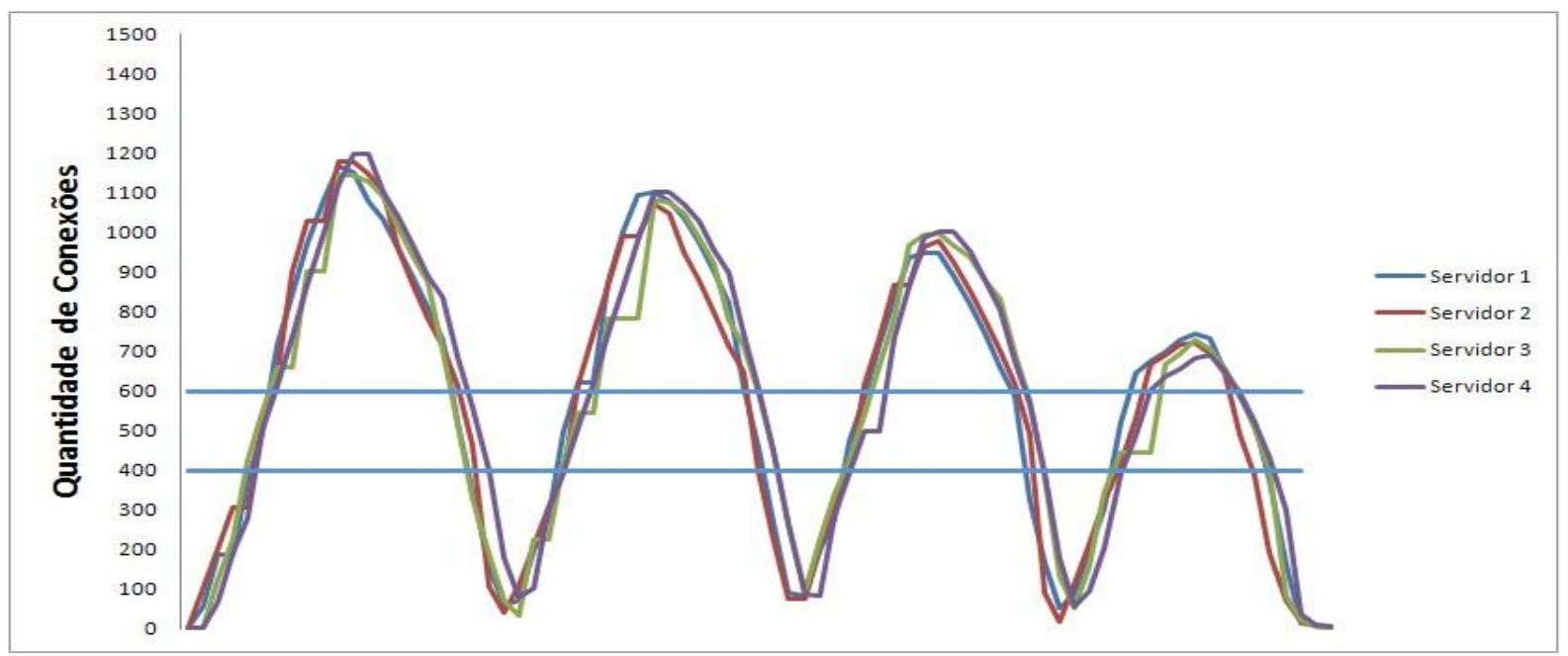

Figura 32: Comportamento do mecanismo RED com carga de 800 req/s.

\subsubsection{RED com Peso 0,42}

Neste experimento, cujos resultados estão apresentados na figura 33, não houve uma 
diferença significativa quando comparado ao gráfico da figura 31. Observam-se neste gráfico que apenas duas máquinas ultrapassaram o limite máximo, enquanto no gráfico da figura 31 apenas uma máquina.

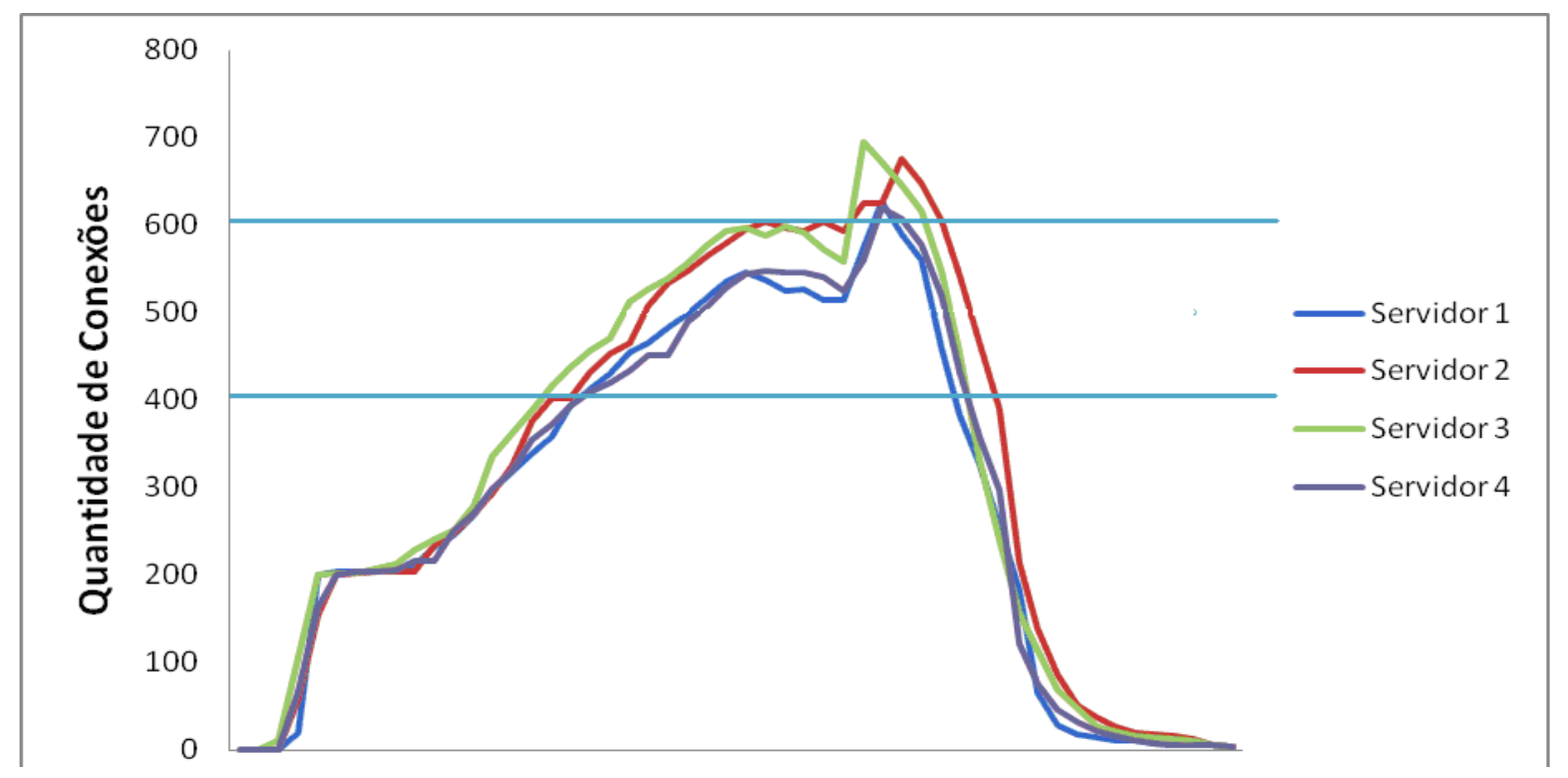

Entretanto, o comportamento anormal visto na figura 32 é também visto, ainda que mais suavemente, na figura 34, observando-se que os três primeiros picos estão em ordem decrescente, sendo que o último pico equivale ao valor do primeiro.

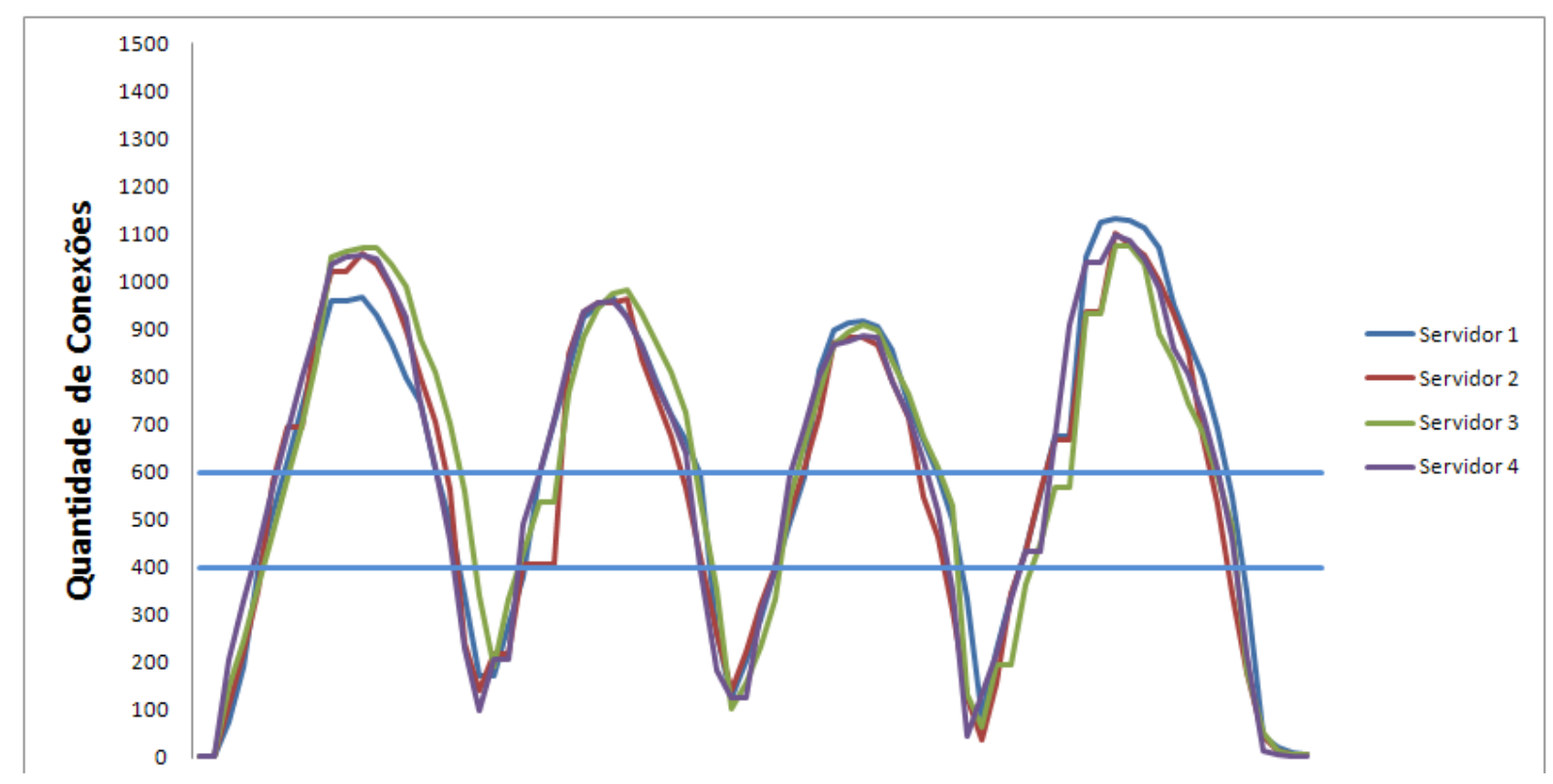




\subsection{Considerações Finais}

Neste capítulo foram apresentados os resultados obtidos nos experimentos realizados com os algoritmos de controle de admissão Drop Tail, RED e Drop Tail com peso, aplicados no protótipo de servidor Web distribuído, implementado com base no modelo SWDS apresentado no capítulo 3.

Foi visto que o algoritmo Drop Tail mostrou-se como a melhor opção, pois possuiu a melhor média em tempo de resposta e cumpriu adequadamente com a finalidade de evitar sobrecarga nos servidores, devido à sua característica de possuir o limite de controle mais rígido. O método RED obteve um desempenho inferior em relação aos demais algoritmos porque seus limiares (mínimo e máximo) permitiram que houvesse mais requisições aceitas pelo sistema.

Outro ponto que vale ser lembrado é com relação aos atrasos proporcionados pelo sistema atual de monitoramento do protótipo. Devido à grande concorrência por acesso ao canal de comunicação, os programas monitores acabam não realizando a tarefa de transmitir as informações da máquina e, assim, os métodos acabam fazendo cálculos com valores desatualizados. A consequência deste fato é visto no atraso do processo de descarte do algoritmo, sendo que nos piores casos chega a ser atendida, em média, 250 a 350 requisições a mais do que o limite especificado.

É importante salientar ainda que, neste capítulo, foi apresentada uma contribuição relevante para a compreensão do comportamento das técnicas e dos mecanismos utilizados para incluir qualidade de serviço em sistemas reais de servidores Web distribuídos. Particularmente, os experimentos desenvolvidos e apresentados neste capítulo, consideram servidores Web distribuídos que fazem uso de componentes que realizam funções relacionadas à classificação, admissão de requisições e controle de estado de sobrecarga, para garantia de qualidade de serviço.

Na próxima seção serão apresentadas as conclusões finais deste trabalho. 


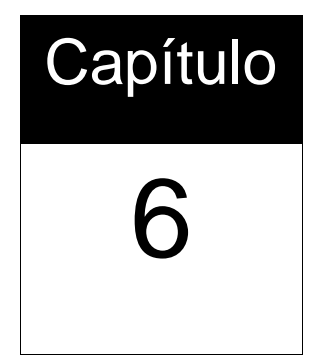

Conclusões

\subsection{Visão Geral}

O objetivo central deste trabalho considerou duas metas importantes: a primeira consistiu em construir um protótipo de servidor Web distribuído, com capacidade de realizar diferenciação de serviço, tendo como base o modelo SWDS proposto por TEIXEIRA (2004); considerando que o modelo SWDS é composto por diversos componentes básicos (classificador, controle de admissão, etc), a segunda meta deste trabalho consistiu na implementação de algoritmos de controle de admissão, a fim de avaliar o comportamento e desempenho da plataforma de teste quando submetida à operação dos algoritmos considerados. Essas duas metas constituem, por si, importantes contribuições gerais deste trabalho, uma vez que se estabeleceu uma plataforma de teste real e esta pode ser exercitada sob diversos enfoques, constituindo diferentes cenários de operação.

A motivação geral deste trabalho está ligada ao crescimento expressivo da Web ao longo da ultima década, o que levou à incorporação de diversos novos tipos de serviços, além das aplicações tradicionais, aumentando a complexidade envolvida, e impondo novos requisitos que incluem a introdução de QoS nas aplicações executadas atualmente. A maioria dos servidores Web atuais ainda processam as requisições utilizando a política FCFS, tal como no início da concepção da Web. Entretanto, para ambientes com aplicações mais complexas, este tipo de política não é bom e tende a desapontar as expectativas gerais dos usuários.

A literatura mostrou diversos trabalhos que buscam oferecer qualidade de serviço nos servidores Web, complementando os esforços desenvolvidos no que se refere à infra-estrutura das redes. Nesse sentido, o capítulo 4 desta dissertação abordou a arquitetura SWDS que estabeleceu a base geral para o desenvolvimento do trabalho, provendo QoS por meio de diferenciação de serviço, utilizando apenas mecanismos em nível de aplicação. No processo de implementação do modelo SWDS foi empregada a técnica Web Switch Layer 7 two-way, 
utilizando o software APACHE configurado como proxy reverso através do módulo mod_proxy. Dessa forma, foi possível implementar o modelo SWDS, incorporando todos os componentes propostos originalmente na máquina chamada denominada por Web Switch.

\subsection{Principais Resultados e Contribuições}

Dentro dos objetivos alcançados neste trabalho e das atividades desenvolvidas durante seu desenvolvimento, podem-se ressaltar alguns pontos importantes que constituem contribuições relevantes, como segue:

- Revisão Bibliográfica - Durante o desenvolvimento desta dissertação foi realizada uma revisão bibliográfica abrangente e detalhada, com o intuito de contextualizar adequadamente o trabalho, bem como estabelecer uma boa plataforma de estudo dos conceitos envolvidos. A revisão abrange qualidade de serviço aplicada a ambientes com servidores Web e métodos de controle de congestionamento. Além disso, revisou-se o modelo de Servidor Web com Diferenciação de Serviço (SWDS) que serviu de base para este trabalho, além de alternativas gerais para a organização de cluster de servidores Web. Com isso, a revisão realizada contribui no sentido de auxiliar os próximos trabalhos envolvidos com esta área.

- Implementação de um Protótipo do Modelo SWDS - Uma das finalidades deste trabalho foi o desenvolvimento e implementação de um protótipo baseado no modelo SWDS, visando ao estabelecimento de uma plataforma de testes para estudos envolvendo servidores e serviços Web em geral. A implementação desse protótipo foi feita com hardware e software dedicados, tendo sido possível incorporar no protótipo todas as funcionalidades especificadas no modelo original. Esse protótipo constitui uma importante contribuição desta dissertação, ficando à disposição para servir de base para diversos outros trabalhos do GSDPC.

- Mecanismos de Controle de Admissão - A segunda meta estabelecida para este trabalho consistiu na implementação de mecanismos de controle de admissão, visando a explorar os requisitos de QoS por meio do controle de congestionamento no servidor Web. 
Especificamente, dois algoritmos de controle de congestionamento foram implementados e exercitados exaustivamente neste trabalho, o Drop Tail e o RED. Um novo algoritmo foi desenvolvido, constituindo o que foi denominado por Drop Tail com Peso, incorporando ao mecanismo básico do Drop Tail o uso de média móvel exponencial, característica do RED. Dessa forma, a implementação dos algoritmos Drop Tail e RED no protótipo, por si já trazem diversas contribuições para a área, uma vez que os testes foram desenvolvidos de forma planejada e os resultados foram analisados cuidadosamente com base em técnicas estatísticas. A inclusão de um novo algoritmo, o Drop Tail com Peso, amplia a contribuição estabelecida neste trabalho.

- Testes dos Algoritmos em um Ambiente Real - Para finalizar, umas das contribuições fundamentais alcançadas neste trabalho foi o estabelecimento de um estudo geral de avaliação do modelo SWDS e dos algoritmos propostos em um ambiente real, levando-se em consideração várias perturbações reais, normalmente inexistentes nos estudas baseados exclusivamente em simulação, tornando os resultados muito próximos da realidade. Adicionalmente, acredita-se que o trabalho experimental, bastante árduo, desenvolvido nesta dissertação, sirva de base para o planejamento, avaliação e análise de outros estudos que utilizem o protótipo estabelecido como plataforma de testes.

\subsection{Trabalhos Futuros}

Durante as etapas de implementação e teste do protótipo, bem como o desenvolvimento e a avaliação dos algoritmos de controle de admissão, novas perspectivas foram vislumbradas para a continuidade deste projeto.

Este trabalho proporcionou uma avaliação do modelo e dos algoritmos de controle de admissão segundo uma nova ótica para o GSDPC, uma vez que os estudos anteriores se basearam mais intensamente em simulação. A seguir são elencadas algumas possibilidades visando à continuidade deste projeto:

- Utilização de carga de trabalho focada em transações de compra e venda na Web (ecommerce), considerando-se que este tipo de carga é composto por sessões seguras, operações 
em banco de dados, entre outros. Como sugestão para o desenvolvimento desse tipo de aplicação, foi pesquisada uma carga de trabalho denominada RUBIS onde são implementadas diversas operações comerciais; CECCHET et al., (2003) e AMZA et al., (2002) implementaram seus trabalhos utilizando RUBIS como carga de trabalho;

- $\quad$ Remover o problema destacado no capítulo 6 relacionado ao atraso das informações de cargas enviadas pelos monitores, que permitem que os números de conexões ultrapassem o limite estabelecido. Observando-se que a rede interna do sistema pode estar em congestionamento devido ao grande numero de requisições, uma possível solução seria a instalação de outra interface de rede exclusiva para o envio de informações ou aperfeiçoar o sistema implementado. Uma alternativa, nesse caso, seria aperfeiçoar o sistema de monitoramento utilizado neste trabalho ou adotar um sistema específico tal como o Ganglia (SACERDORTI et al., 2003);

- Tomando como base os resultados discutidos capítulo 6 deste trabalho, pôde-se observar um desempenho não satisfatório do algoritmo RED. Existem algumas dificuldades na investigação desse algoritmo, tal como a configuração de cada parâmetro do método para um determinado cenário, assim como observado no trabalho de MAY et al (1999), onde é mostrado que os resultados usando o método RED não possui grande diferença quando comparado ao Drop Tail. Assim, uma sugestão é implementar algumas variantes do algoritmo RED no protótipo SWDS e avaliar o comportamento em cenários distintos.

Espera-se que esta dissertação de mestrado possa servir de diretriz para o estabelecimento de novas propostas para trabalhos futuros, que busquem atender as novas expectativas que possam surgir na área de qualidade de serviço e de algoritmos de controle de admissão aplicados ao contexto de servidores Web. 


\section{Referências Bibliográficas}

ABBASOV, B.; KORUKOGLU, S.; Effective RED: An algorithm to improve RED's performance by reducing packet loss rate, J. Netw. Comput. Appl., n 32, vol. 3, pp. 703-709, May, 2009.

ALEMU, T.; JEAN-MARIE, A.; Dynamic configuration of RED parameters [random early detection], Global Telecommunications Conference, 2004. GLOBECOM '04. IEEE , vol.3, no., pp. 1600- 1604 Vol.3, 29 Nov.-3 Dec. 2004.

ARCE, G. R.; BARNER, K. E.; LIANGPING, M; RED gateway congestion control using median queue size estimates, Signal Processing, IEEE Transactions on, vol.51, no.8, pp. 2149-2164, Aug. 2003, doi: 10.1109/TSP.2003.814462.

AMZA, C.; CHANDA, A.; COX, A.L.; ELNIKETY, S.; GIL, R.; RAJAMANI, K.; ZWAENEPOEL, W.; CECCHET, E.; MARGUERITE, J.; Specification and implementation of dynamic Web site benchmarks, Workload Characterization, 2002. WWC-5. 2002 IEEE International Workshop on , vol., no., pp. 3- 13, 25 Nov. 2002.

ANDREOLINI, M.; CASALICCHIO , E.; COLAJANNI , M.; MAMBELLI , M. A clusterbased web system providing differentiated and guaranteed services. Cluster Computing, v. 7, n. 1, p. 7-19, 2004.

APACHE SOFTWARE FOUNDATION; (acessado em 06/2009). Disponível em: http://www.apache.org.

ARLITT, M.; JIN, T.; A workload characterization study of the 1998 World Cup Web site, Network, IEEE, vol.14, no.3, pp.30-37, May/Jun 2000.

ARON, M., DRUSCHEL, P.; ZWAENEPOEL, W.; Cluster reserves: a mechanism for resource management in cluster-based network servers. In Proceedings of the 2000 ACM SIGMETRICS international conference on Measurement and modeling of computer systems (SIGMETRICS '00). ACM, New York, NY, USA, 90-101, 2000. 
AURRECOECHEA, C., CAMPBELL, A. T., e HAUW, L. (1998). A survey of qos architectures. Multimedia Systems, Vol. 6, No. 3, pp. 138-151.

AWDUCHE, D. O.; JABBARI, B.; Internet traffic engineering using multi-protocol label switching (MPLS). Comput. Netw, vo. 40, pp. 111-129, September, 2002.

AWEYA, J.; OUELLETTE, M.; MONTUNO, D. Y.; A control theoretic approach to active queue management. Comput. Netw. 36, 2-3, pp. 203-235, July, 2001.

BARBOSA, A. F. A.; Mecanismo de Controle de Admissão para um Servidor Web com Diferenciação de Serviços: algoritmo Random Early Detection [trabalho de conclusão de curso]. São Luís: Universidade Federal de Maranhão, Curso de Ciência da Computação, Departamento de Informática; 2007.

BARROS, V.H.; OLIVEIRA, A.C.M.; TEIXEIRA, M.M.; A Fuzzy Admission Controller in a QoS-Aware Web Server Architecture, Hybrid Intelligent Systems, 2008. HIS '08. Eighth International Conference on, vol., no., pp.453-458, 10-12, Sept. 2008 doi: 10.1109/HIS.2008.73.

BHATTI, N.; FRIEDRICH, R.; Web server support for tiered services, Network, IEEE, vol.13, no.5, pp.64-71, Sep/Oct 1999, doi: 10.1109/65.793694.

BHOJ, P.; RAMANATHAN, S.; SINGHAL, S.; Web2K: Bringing QoS to Web servers. Technical Report HPL-2000-61, HP Labs, May 2000.

BLAKE, S.; BLACK, D.; CARLSON, M.; DAVIES, E.; WANG, Z.; WEISS, W.; An Architecture for Differentiated Service, RFC 2475, Dec 1998.

BRADEN, R.; CLARK, D.; SHENKER, S.; Integrated Services in the Internet Architecture: an overview, RFC 1633, Jun 1994.

BRADEN, R.; ZHANG, L.; BERSON, S.; HERZOG, S.; JAMIN, S. Resource Reservation Protocol (RSVP) — Version 1 Functional Specification. RFC 2205, IETF., 1997. 
BRADEN, B.; CLARK, D.; CROWCROFT, J.; DAVIE, B.; DEERING, S.; ESTRIN, D.; FLOYD, S.; JACOBSON V.; MINSHALL, G.; PARTRIDGE, C.; PETERSON, L.; RAMAKRISHNAN K.; SHENKER, S.; WROCLAWSKI， J.; ZHANG， L.; Recommendations on queue management and congestion avoidance in the Internet, RFC 2309, Apr 1998.

CARDELLINI, V.; COLAJANNI, M.; YU, P.S.; Dynamic load balancing on Web-server systems, Internet Computing, IEEE, vol.3, no.3, pp.28-39, May/Jun 1999, doi: $10.1109 / 4236.769420$

CARDELLINI, V.; CASALICCHIO, E.; COLAJANNI, M.; YU, P. S.; The state of the art in locally distributed Web-server systems. ACM Computing Survey, vol 34, pp. 263-311. 2002, DOI=10.1145/508352.508355 http://doi.acm.org/10.1145/508352.508355

CARPENTER, B.E.; NICHOLS, K.; Differentiated services in the Internet, Proceedings of the IEEE, vol.90, no.9, pp. 1479-1494, Sep 2002.

CASTRO, M.F.; M'HAMED, A.; GAITI, D.; OLIVEIRA, M.; , Simulated Internet traffic behavior under different QoS management scenarios, Computers and Communication, 2003. (ISCC 2003). Proceedings. Eighth IEEE International Symposium on, vol., no., pp. 320-326, vol.1, 30 June-3 July, 2003, doi: 10.1109/ISCC.2003.1214140.

CECCHET, E.; CHANDA, A.; ELNIKETY, S.; MARGUERITE, J.; ZWAENEPOEL, W.; Performance comparison of middleware architectures for generating dynamic web content. In Proceedings of the ACM/IFIP/USENIX 2003 international Conference on Middleware (Rio de Janeiro, Brazil, June 16 - 20, 2003). M. Endler, Ed. Middleware Conference. Springer-Verlag New York, New York, NY, 242-261.

CHRISTIN, N.; LIEBEHERR, J.; ABDELZAHER, T. F.; A Quantitative Assured Forwarding service, INFOCOM 2002. Twenty-First Annual Joint Conference of the IEEE Computer and Communications Societies. Proceedings. IEEE, vol.2, no., pp. 864- 873 vol.2, 2002.

CLARK, D.D.; FANG, W.; Explicit allocation of best-effort packet delivery service, Networking, IEEE/ACM Transactions on, vol.6, no.4, pp.362-373, Aug 1998 
doi: $10.1109 / 90.720870$.

DANA, A.; MAleldoO, A.; Perfomance Comparision between Active and Passive Queue Management, IJCSI International Journal of Computer Science Issues, Vol. 7, Issue 3, No 5, May 2010.

DOVROLIS, C.; RAMANATHAN, P.; A case for relative differentiated services and the proportional differentiation model, Network, IEEE, vol.13, no.5, pp.26-34, Sep/Oct 1999 doi: $10.1109 / 65.793688$.

ELLOUMI, O.; AFIFI, H.; RED algorithm in ATM networks, IEEE ATM Workshop 1997. Proceedings, vol., no., pp.312-319, 25-28 May 1997 doi: 10.1109/ATM.1997.624699.

ENGESCHALL, P.; Load balancing your web site, web techniques, 1998.

ESTRELlA, J. C.; Mecanismos de negociação no módulo de controle de admissão da arquitetura de servidor web com diferenciação de serviços (SWDS). 2006. 75. Tese (Mestrado) - ICMC-USP, São Carlos-SP.

FENG, W. C.; KANDLUR, D. D.; SAHA, D.; SHIN, K.G.; A self-configuring RED gateway, INFOCOM '99. Eighteenth Annual Joint Conference of the IEEE Computer and Communications Societies. Proceedings. IEEE, vol.3, no., pp.1320-1328 vol.3, 21-25 Mar 1999.

FIROIU, V.; BORDEN, M.; A study of active queue management for congestion control, INFOCOM 2000. Nineteenth Annual Joint Conference of the IEEE Computer and Communications Societies. Proceedings. IEEE, vol.3, no., pp.1435-1444 vol.3, 26-30 Mar 2000, doi: 10.1109/INFCOM.2000.832541.

FLOYD, S.; JACOBSON, V.; Random early detection gateways for congestion avoidance, Networking, IEEE/ACM Transactions on, vol.1, no.4, pp.397-413, Aug 1993 doi: 10.1109/90.251892.

FLOYD, S.; PAXSON, V.; Difficulties in simulating the Internet, Networking, IEEE/ACM Transactions on, vol.9, no.4, pp.392-403, Aug 2001, doi: 10.1109/90.944338. 
FLOYD S.; GUMMADI R.; SHENKER S; Adaptive RED: an algorithm for incresing the robustness of RED's Active Queue Management, 2001, http://www.icir.org/ floyd.

FLUCKIGER, F. Understanding networked multimedia: applications and technology. Prentice Hall International (UK) Ltd.Hertfordshire, UK, 1995.

GOZDECKI, J.; JAJSZCZYK, A.; STANKIEWICZ, R.; Quality of service terminology in IP networks, Communications Magazine, IEEE, vol.41, no.3, pp. 153- 159, Mar 2003.

GUO, C.; XIONG, Z.; YAN, P.; A dynamic load scheduling algorithm for web servers. In: . [S.1.]: IEEE Computer Society, p. 259-264, 2004.

HARJU, J.; KIVIMAKI, P.; Co-operation and comparison of DiffServ and IntServ: performance measurements, Local Computer Networks, 2000. LCN 2000. Proceedings. 25th Annual IEEE Conference on, vol., no., pp.177-186, 2000.

HEINANEN, J.; BAKER, F.; WEISS, W.; WROCLAWSKI, J.; Assured Forwarding PHB Group, RFC 2597, Jun 1999.

HOLTON, D.R.W.; AWAN, I.U.; YOUNAS, M.; Priority Scheduling of Requests to Web Portals, Advanced Information Networking and Applications, 2009. AINA '09. International Conference on, vol., no., pp.786-791, 26-29 May 2009.

INTERNET TRAFFIC ARCHIVE. Traces available in the Internet Traffic Archive. Atualizada em 09 de Abril de 2008. Acesso em 05/04/2009. Disponível em: http://ita.ee.lbl.gov/html/traces.html

JIANG, K.; WANG, X. F.; XI, Y.; A robust RED algorithm based on time-delayed feedback control, Control Conference, 2004. 5th Asian, vol.2, no., pp. 708- 713 Vol.2, 20-23 July 2004.

KAJANCKAS, A.; ANSKAITIS, A.; GURŜNYS, D.; Individual Quality of Service concept in Next Generations Telecommunications networks. Elektronika ir elektrotechnika. ISSN $1392-1215.4(60)$ p. 11-16, 2005. 
KILKKI, K.; Differentiated Services for the Internet, Macmillan Technical Publishing, Indianapolis, IN, USA, June 1999.

KUO, G.; KO, P.; Dynamic RSVP protocol, Communications Magazine, IEEE, vol.41, no.5, pp. 130- 135, May 2003.

KUROSE, J.; ROSS, K.; Computer Networking: A Top-Down Approach Featuring the Internet. 3. ediçã̃o. ed. [S.1.]: Person, p. 712, 2005.

LABRADOR, M. A.; BANERJEE, S.; Packet dropping policies for ATM and IP networks, Communications Surveys \& Tutorials, IEEE, vol.2, no.3, pp.2-14, Third Quarter 1999, doi: 10.1109/COMST.1999.5340708.

LI, D.; YONG-LE, G.; A queue buffer management algorithm based on traffic prediction in DiffServ architecture, Logistics Systems and Intelligent Management, 2010 International Conference on, vol.2, no., pp.1176-1180, 9-10 Jan. 2010.

MAGALHÃES, M. F.; CARDOZO, E. Qualidade de serviço na Internet. Relatório técnico, UNICAMP/FEEC/DCA, Campinas, SP, 1999.

MAHAJAN, R.; FLOYD, S.; WETHERALL, D.; Controlling high-bandwidth flows at the congested router, Network Protocols, 2001. Ninth International Conference on, vol., no., pp. 192- 201, 11-14, Nov. 2001 doi: 10.1109/ICNP.2001.992899.

MAN, H.; XU, L.; LI, Z.; ZHANG, L.; End-to-end QoS implement by DiffServ and MPLS, Electrical and Computer Engineering, 2004. Canadian Conference on , vol.2, no., pp. 641- 644 Vol.2, 2-5 May 2004.

MAY, M.; BOLOT, J.; DIOT, C.; LYLES, B.; Reasons not to deploy RED, Quality of Service, 1999. IWQoS '99. 1999 Seventh International Workshop on, vol., no., pp.260-262, 1999. MESSIAS, V. R.; Servidor Web distribuído com diferenciação de serviços - implementação e avaliação de um protótipo. 2007. 100. Tese (Mestrado) - ICMC-USP, São Carlos-SP. 
MOSBERGER, D.; JIM, T.; httperf - a tool for measuring web server performance. ACM - First Workshop on Internet Server Performance, Vol. pp. 56-67, 1998.

MOURAO, H. C. B. Reconhecimento de sessões HTTP em um modelo para servidor Web com diferenciação de serviços (SWDS). 2006. 75. Tese (Mestrado) - ICMC-USP, São Carlos-SP.

ODLYZKO, A. M.; Internet traffic growth: Sources and implications, in Optical Transmission Systems and Equipment for WDM Networking II, B. B. Dingel, W. Weiershausen, A. K. Dutta, and K.-I. Sato, eds., Proc. SPIE, vol. 5247, pp. 1-15., 2003.

OTT, T. J.; LAKSHMAN, T. V.; WONG, L. H.; SRED: stabilized RED, INFOCOM '99. Eighteenth Annual Joint Conference of the IEEE Computer and Communications Societies. Proceedings. IEEE, vol.3, no., pp.1346-1355 vol.3, 21-25 Mar 1999.

PADILLA, J.J.; PARADELLS, J.; RODRIGUEZ, A.; Supporting QoS over IPv6 wireless networks with IntServ6, Personal, Indoor and Mobile Radio Communications, 2006 IEEE 17th International Symposium on, vol., no., pp.1-6, 11-14 Sept. 2006.

ROSEN, E.; VISWANATHAN, A.; CALLON, R.; Multiprotocol Label Switching Architecture, RFC 3031, Jan 2001.

SACERDOTI, F. D.; KATZ, M. J.; MASSIE, M. L.; CULLER, D. E.; Wide area cluster monitoring with Ganglia, Cluster Computing, 2003. Proceedings. 2003 IEEE International Conference on, vol., no., pp. 289- 298, 1-4 Dec. 2003.

SCHLEMBACH , J.; SKOE , A.; YUAN , P.; KNIGHTLY, E. W. Design and implementation of scalable admission control. In: QoS-IP '01: Proceedings of the International Workshop on Quality of Service in Multiservice IP Networks, London, UK: Springer-Verlag, 2001, p. 1-16.

SEMPREBOM T.; OLIVEIRA, R.; MOMTEZ, C.; Classes de serviço em servidores web apache através de escalonamento adaptativo e controle de admissão. Proc. In: XII Simpósio Brasileiro de Sistemas Multimídia e Web, 2006 - Webmedia 2006, pp. 273-282, Natal, RN. 
SERRA, A.; GAITI, D.; BARROSO, G.; BOUDY, J.; Assuring QoS differentiation and load balancing on web servers clusters, Control Applications, 2005. CCA 2005. Proceedings of 2005 IEEE Conference on, vol., no., pp.885-890, 28-31 Aug. 2005.

SHAN, Z.; LIN, C.; WEI, Y.; Prototype implementation and performance evaluation of a QoS-based Web server, Service-Oriented System Engineering, 2005. SOSE 2005. IEEE International Workshop, vol., no., pp. 191-196, 20-21 Oct. 2005 doi: 10.1109/SOSE.2005.29.

SHARIFIAN, S.; MOTAMEDI, S. A.; AKBARI, M. K.; An approximation-based loadbalancing algorithm with admission control for cluster web servers with dynamic workloads. J. Supercomput. 53, 3 (September 2010), 440-463. DOI=10.1007/s11227-009-0303-8 http://dx.doi.org/10.1007/s11227-009-0303-8.

SHENKER, S.; PARTRIDGE, C.; GUERIN, R.; Specification of Guaranteed Quality of Service. RFC 2212, IETF, 1997.

SHIODA, S.; MASE, K.; Performance comparison between IntServ-based and DiffServbased networks, Global Telecommunications Conference, 2005. GLOBECOM '05. IEEE, vol.1, no., pp.6 pp.-534, 2-2 Dec. 2005.

STALLINGS, W. High-Speed Networks and Internets. 2 ed. São Paulo: Editora Prentice Hall, 2002.

STANKOVIC, J.A.; TIAN H.; ABDELZAHER, T.; MARLEY, M.; GANG, T; SANG S.; Chenyang Lu; Feedback control scheduling in distributed real-time systems, Real-Time Systems Symposium, 2001. (RTSS 2001). Proceedings. 22nd IEEE, vol., no., pp. 59- 70, 3-6 Dec. 2001.

STARDUST; The need for qos. Disponível em: http://citeseerx.ist.psu.edu/viewdoc/summary?doi=10.1.1.41.3374. 
STRNADL, C.; At your service: QoS for the internet [Book Review], Multimedia, IEEE, vol.9, no.1, pp.93-95, Jan-Mar 2002.

SUN, J.; ZUKERMAN, M.; PALANISWAMI, M.; Stabilizing RED using a Fuzzy Controller, Communications, 2007. ICC '07. IEEE International Conference on , vol., no., pp.266271, 24-28 June 2007. doi: 10.1109/ICC.2007.52.

TEIXEIRA, M. A. M.; SANTANA, M. J.; SANTANA, R. H. C.; Analysis of task scheduling algorithms in distributed web-server systems. Proceedings of the International Sysmposium on Performance Evaluation of Computer and Telecommunication Systems (SPECTS 2003)., p. 655-663. SPECTS 2003.

TEIXEIRA, M. A. M.; Suporte a serviços diferenciados em servidores web: modelos e algoritmos. 2004. 131p. Tese (Doutorado) - ICMC-USP, São Carlos-SP.

TRALDI, O. A., BARBATO, A. K., SANTANA, R. H.; Service differentiating algorithms for QoS-enabled web servers. In Proceedings of the 12th Brazilian Symposium on Multimedia and the Web (Natal, Rio Grande do Norte, Brazil, November 19 - 22, 2006). WebMedia '06, vol. 192. ACM, New York, NY, 263-272.

VASILIOU , N.; Overview of internet qos and web server qos. 2000.

VUKADINOVIĆ, V.; TRAJKOVIĆ, L. RED with Dynamic Thresholds for improved fairness. In Proceedings of the 2004 ACM Symposium on Applied Computing (Nicosia, Cyprus, March 14 - 17, 2004). SAC '04. ACM, New York, NY, 371-372.

WEN, J.; LU, X.; The design of QoS guarantee network subsystem. ACM SIGOPS Operating Systems Review, 2002.

WROCLAWSKI, J.; Specification of the Controlled-Load Network Element Service, RFC 2211, September 1997.

XIAO, X.; NI, L.M.; Internet QoS: a big picture, Network, IEEE, vol.13, no.2, pp.8-18, Mar/Apr 1999. 
XIONG, Z.; YAN, P.; WANG, J.; A Self-Adjusting Size-Based Load Balance Policy for Web Server Cluster, Computer and Information Technology, 2005. CIT 2005. The Fifth International Conference on, vol., no., pp.368-374, 21-23 Sept. 2005.

YANG, W.; LI, S.; CHENG D.; The Research of a New Web Server Cluster Architecture Supporting QoS, Network and Parallel Computing Workshops, 2007. NPC Workshops. IFIP International Conference on, vol., no., pp.618-623, 18-21 Sept. 2007.

YANG, C.; CHEN, C.; CHEN, J.; Random Early Detection Web Servers for Dynamic Load Balancing, Pervasive Systems, Algorithms, and Networks (ISPAN), 2009 10th International Symposium on , vol., no., pp.364-368, pag.14-16 Dec. 2009.

ZHAO, W.; OLSHEFSKI, D.; SCHULZRINNE, H.; Internet quality of service: an overview. Relatório Técnico CUCS-003-00, Columbia University, 2000.

ZHANG, J.; HAMALAINEN, T.; JOUTSENSALO, J.; A new mechanism for supporting differentiated services in cluster-based network servers,Modeling, Analysis and Simulation of Computer and Telecommunications Systems, 2002. MASCOTS 2002. Proceedings. 10th IEEE International Symposium on, vol., no., pp. 427- 432, 2002.

ZHANG, Y.; ZHAO, Y.; The revenues driven resource allocation algorithm for clusterbased web server, Proceedings of the 6th World Congress on Intelligent Control and Automation, June 21 - 23, 2006.

ZHENG, B.; ATIQUZZAMAN, M.; A framework to determine the optimal weight parameter of RED in next-generation Internet routers, International Journal of Communication Systems, vol. 21, no. 9, pp. 987-1008, 2008. 